Captura da interação para autoria e compartilhamento multimídia em dispositivos móveis

Bruna Carolina Rodrigues da Cunha 

SERVIÇO DE PÓS-GRADUAÇÃO DO ICMC-USP

Data de Depósito:

Assinatura:

\title{
Captura da interação para autoria e compartilhamento multimídia em dispositivos móveis
}

\author{
Bruna Carolina Rodrigues da Cunha
}

Orientadora: Profa. Dra. Maria da Graça Campos Pimentel

Dissertação apresentada ao Instituto de Ciências Matemáticas e de Computação - ICMC-USP, como parte dos requisitos para obtenção do título de Mestre em Ciências - Ciências de Computação e Matemática Computacional. VERSÃO REVISADA. 
Ficha catalográfica elaborada pela Biblioteca Prof. Achille Bassi e Seção Técnica de Informática, ICMC/USP, com os dados fornecidos pelo(a) autor(a)

Cunha, Bruna C. R.

C972C Captura da interação para autoria e compartilhamento multimídia em dispositivos móveis / Bruna C. R. Cunha; orientadora Maria da Graça C. Pimentel. -- São Carlos, 2014. $95 \mathrm{p}$.

Dissertação (Mestrado - Programa de Pós-Graduação em Ciências de Computação e Matemática Computacional) -- Instituto de Ciências Matemáticas e de Computação, Universidade de São Paulo, 2014.

1. Anotações em Vídeo. 2. Dispositivos Móveis. 3. Interação Usuário-Computador. 4. Multimídia. I. Pimentel, Maria da Graça C., orient. II. Título. 


\section{Agradecimentos}

À minha orientadora, Profa. Dra. Graça Pimentel, por todo o apoio, técnico e emocional, durante todo o meu mestrado e pelo incalculável conhecimento que obtive por meio de sua orientação.

Aos professores e funcionários ICMC e a todos os colegas do Intermídia que ajudaram direta ou indiretamente em meu trabalho.

Ao meu supervisor do estágio no exterior, Dr. Pablo Cesar, e a todos do CWI que me auxiliaram nessa etapa de grande aprendizado.

À minha família pelo apoio incondicional. Em especial a minha mãe, Lucélia, ao meu pai, Luzmar, ao meu namorado, Hideki, e aos meus avôs, Benedito e Ademar. Agradeço também às minhas avós, Dulce e Luzia, que não estão mais comigo, mas sei que me apoiariam em todos os momentos.

A todos os que colaboraram participando das avaliações e experimentos relacionados a este trabalho.

À Fundação de Amparo à Pesquisa do Estado de São Paulo (FAPESP) pelo apoio financeiro concedido as meus projetos, processo $\mathrm{n}^{\circ} 11 / 17040-0$ e processo $\mathrm{n}^{\circ} 13 / 01809-8$, sem o qual este trabalho não seria possível. 


\section{Resumo}

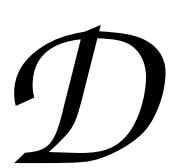

ispositivos móveis do tipo smartphones e tablets possibilitam uma interação rica e intuitiva, abrindo novas possibilidades para usuários e desenvolvedores. Entre as características que os tornam populares estão a alta capacidade de processamento, a melhoria constante das alternativas de interação com usuários e a possibilidade de captura de imagens e vídeos, além da comodidade de acessar serviços e informações em dispositivos tão portáteis. Além disso, ao longo dos últimos anos tem-se observado uma cultura de geração de conteúdo por parte de usuários, ao mesmo tempo que dispositivos móveis se tornam populares reprodutores de mídias e adquirem um papel importante na produção de conteúdo multimídia. Da mesma forma que novas mídias podem ser capturadas é também possivel enriquece-las com anotações. Anotações são comuns em documentos textuais e recentemente tornaram-se populares em imagens, sendo possivel encontrar diversos aplicativos para anotação em dispositivos móveis. No entanto, aplicativos para anotação em vídeo em dispositivos móveis ainda são raros. Explorando esta oportunidade, o principal objetivo deste trabalho foi investigar alternativas de interação entre usuários e seus dispositivos móveis considerando o cenário de anotação em vídeos. Para investigar os problemas relacionados foi desenvolvido um aplicativo executável em tablets e smartphones com soluções singulares para o contexto proposto. Com foco na interação humano-computador foram realizadas três avaliações, sendo uma avaliação de usabilidade com usuários, uma avaliação heurística com especialistas e uma avaliação colaborativa com uma usuária da área de terapia ocupacional. Resultados de avaliações auxiliaram na definição de novos requisitos e na identificação de problemas que se aplicam não apenas ao contexto de anotações em vídeo, mas em aplicações para dispositivos móveis, de forma geral. Assim, as principais contribuições deste trabalho consistem em soluções relacionadas à autoria multimídia, à captura de interações para sistemas de anotação em vídeo em dispositivos móveis e à usabilidade para aplicativos. 


\section{Abstract}

obile devices like smartphones and tablets enable rich and intuitive
interactions, which brings new possibilities for users and developers.
The high processing power, the constant improvement of user interaction, the ability to capture pictures and videos and the convenient way of accessing information and services are among the features that make them so popular. Over the past years we have been observing a growing in user generated content. In this context, modern mobile devices not only became popular media players, but also play an important role on multimedia content production. Furthermore, it is possible both to create new media and to enrich them with annotations. Annotations are usual in textual documents and recently became popular in pictures. Although applications for annotations are widely available for mobile devices, applications for mobile video annotation are still rare. The main objective of this research was to investigate interaction alternatives between users and their mobile devices considering the video annotation scenario. To investigate related problems, we have developed an application for tablets and smartphones with unique solutions for the proposed topic. With focus on human-computer interaction we conducted three evaluations: a usability evaluation with users, a heuristic evaluation with computer specialists and a collaborative assessment with a specialist in occupational therapy in the role of a user. Evaluation results helped to define new requirements and to identify issues that are not only applied in the video annotation context, but also in mobile applications in general. Thus, the main contributions of this study are solutions related to multimedia authoring, capture of interactions for video annotation on mobile devices and usability of applications. 


\section{Sumário}

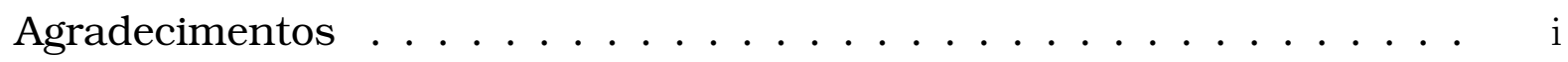

Resumo ...................... iii

Abstract ........................

Sumário . . . . . . . . . . . . . . . . . viii

Lista de Abreviaturas . . . . . . . . . . . . . . . . ix

Lista de Figuras . . . . . . . . . . . . . . . . . . xi

Lista de Tabelas ...................... . . xiii

Lista de Listagens . . . . . . . . . . . . . . . . . . $x$

1 Introdução $\quad 1$

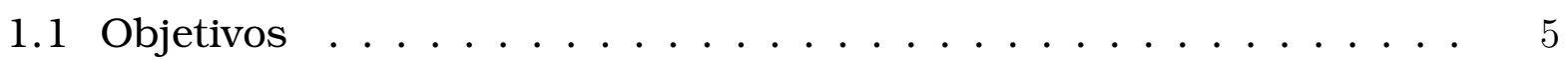

1.2 Metodologia e Problemas Investigados . . . . . . . . . . 6

1.3 Contribuições e Resultados . . . . . . . . . . . . . . . . . . 7

1.4 Estrutura do Documento . . . . . . . . . . . . . 8

2 Conceitos Relacionados $\quad 9$

2.1 Computação Ubíqua . . . . . . . . . . . . . . . . . . . . 9

2.2 Captura e Acesso . . . . . . . . . . . . . . . . . . 11

2.3 Sistemas Colaborativos . . . . . . . . . . . . . . 13

2.4 Sistema Operacional Android . . . . . . . . . . . . 14

2.5 Métodos Estatísticos . . . . . . . . . . . . . . . . 15

2.6 Experiência do Usuário . . . . . . . . . . . . . . . . . . 16

2.7 Considerações Finais . . . . . . . . . . . . . . . . . 17

3 Trabalhos Relacionados $\quad 19$

3.1 Mapeamento Sistemático: Anotações Colaborativas em Vídeo . . . . 19

3.1.1 Planejamento e Execução . . . . . . . . . . . . . . . . . . 19

3.1.2 Discussão ........................ 22

3.2 Interactors+WaC-Editor . . . . . . . . . . . . . . 27 
3.2.1 A História da Ferramenta I+WaC-Editor

3.2.2 Colaboração em um Experimento com a Ferramenta I+WaCEditor ..................... 29

3.3 Considerações Finais . . . . . . . . . . . . . . 33

4 MoViA: Uma Ferramenta de Anotação em Video em Dispositivos Móveis

4.1 Processo de Desenvolvimento . . . . . . . . . . . . . . . . 35

4.2 Arquitetura . . . . . . . . . . . . . . . . . . 38

4.3 Anotações e Captura . . . . . . . . . . . . . . . . . . 41

4.4 Informações de Contexto . . . . . . . . . . . . . . . . 50

4.5 Navegação . . . . . . . . . . . . . . . . . . . 51

4.6 Compartilhamento e Exportação . . . . . . . . . . . . . . . . 52

4.7 Síntese dos Resultados das Avaliações . . . . . . . . . . . . . . . 55

4.7.1 Avaliação de Usabilidade . . . . . . . . . . . . . 56

4.7 .2 Avaliação Heurística . . . . . . . . . . . . . . . . . . 58

4.7.3 Avaliação com Especialista na Área de Terapia Ocupacional 60

4.7.4 Dispositivos Testados . . . . . . . . . . . . 62

4.8 Considerações Finais . . . . . . . . . . . . . . . . . 63

5 Conclusões $\quad 65$

5.1 Sumário e Discussão . . . . . . . . . . . . . . 65

5.2 Limitações . . . . . . . . . . . . . . . . . . . 67

5.3 Trabalhos Futuros . . . . . . . . . . . . . . . 69

5.4 Publicações Resultantes . . . . . . . . . . . . . 70

$\begin{array}{ll}\text { Referências } & \mathbf{7 1}\end{array}$

A Estágio de Pesquisa no Exterior: Avaliação das Experiências do Usuá$\begin{array}{ll}\text { rio Compartilhadas } & 83\end{array}$

A. 1 Conceitos Relacionados . . . . . . . . . . . . . . . . . . 84

A. 1.1 Medidas Fisiológicas . . . . . . . . . . . . . . . . 84

A. 1.2 Qualidade de Experiência . . . . . . . . . . . . . . 85

A.2 Interpretação de Dados Fisiológicos em um Contexto Educacional . 85

A.2.1 Desenvolvimento . . . . . . . . . . . . . 86

A.2.2 Discussão . . . . . . . . . . . . . . . 89

A.3 Qualidade de Experiência em Videoconferências em Grupo . . . . . 90

A.3.1 Desenvolvimento . . . . . . . . . . . . . . . . 91

A.3.2 Discussão . . . . . . . . . . . . . . . . 95

A.4 Considerações Finais . . . . . . . . . . . . . . . . . . . 95 


\section{Lista de Abreviaturas}

ANOVA Analysis of Variance

API Application Programming Interface

CWI Centrum Wiskunde \& Informatica

DTV Digital Television

GSR Galvanic Skin Response

HTML HyperText Markup Language

JPEG Joint Photographic Experts Group

JSON JavaScript Object Notation

MDS Multidimensional Scaling

MPEG-7 Multimedia Content Description Interface

NCL Nested Context Language

OWL Web Ontology Language

QoE Quality of Experience

QoS Quality of Service

RDF Resource Description Framework

SDK Software Development Kit

SMIL Synchronized Multimedia Integration Language

XML Extensible Markup Language 


\section{Lista de Figuras}

1.1 Crescimento do número de dispositivos conectados à Internet . . . 2

2.1 O processo evolutivo de produção multimídia . . . . . . . . . . . . 12

3.1 Exemplo da interface da ferramenta I+WaC-Editor em funcionamento 29

3.2 Gráfico para medidas de menor esforço, facilidade e performance para anotações ....................... 33

4.1 Telas de anotação e navegação do primeiro estágio da ferramenta . 36

4.2 Tela de anotação do segundo estágio da ferramenta . . . . . . . . . 37

4.3 Arquitetura da ferramenta de anotação em vídeo desenvolvida . . . 39

4.4 Telas de seleção de vídeo e autores adicionais . . . . . . . . . . . . . 44

4.5 Tela de reprodução e anotações visualizada em um tablet . . . . . . 45

4.6 Tela de reprodução e anotações visualizada em um smartphone . . 46

4.7 Tela de reprodução visualizada na posição horizontal . . . . . . . . 47

4.8 Tela de captura com botões para marcar o vídeo e parar a captura 49

4.9 Informações de contexto na aplicação . . . . . . . . . . . . . . 51

4.10Tela de navegação por anotações . . . . . . . . . . . . . 53

4.11 Ilustração do conceito de transparência em textos . . . . . . . . . 55

A. 1 O conceito de Qualidade de Experiência . . . . . . . . . . . 85

A.2 Gráfico MDS para dados coletados de sensores . . . . . . . . . . . 88

A.3 Tela do testbed de videoconferências como vista pelos usuários . 91 


\section{Lista de Tabelas}

2.1 Distribuições das versões do Android coletadas em Julho de 2014 . 14

3.1 Número de trabalhos em cada estágio da revisão sistemática . . . . 21

3.2 Classificação dos trabalhos: plataforma . . . . . . . . . . . . 22

3.3 Classificação dos trabalhos: tipo de anotação e formato . . . . . . . 23

3.4 Classificação dos trabalhos: colaboração e navegação . . . . . . . . 23

3.5 Classificação dos trabalhos: avaliação . . . . . . . . . . . . . . 24

4.1 Resultados do questionário para avaliação das funcionalidades . . 58

4.2 Dispositivos em que a aplicação foi testada . . . . . . . . . . . 63

5.1 Tabela Comparativa de Ferramentas: plataforma e tipo de anotação 67

5.2 Tabela Comparativa de Ferramentas: formato, colaboração e nave-

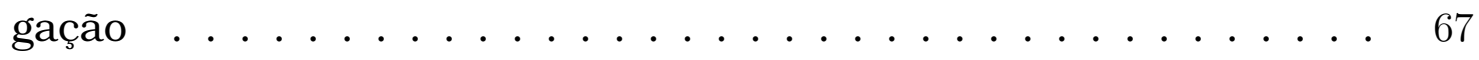

5.3 Tabela Comparativa de Ferramentas: avaliação . . . . . . . . . . 68

A.1 Questões de pesquisa, hipóteses e conceitos para o experimento de videoconferência planejado . . . . . . . . . . . . 93 


\section{Lista de Listagens}

4.1 Trecho XML para anotação em texto . . . . . . . . . . . . . . 41

4.2 Trecho XML para anotação em tinta eletrônica . . . . . . . . . . . . 42

4.3 Trecho XML para informações de contexto . . . . . . . . . . . . . . . 42 
xvi LISTA DE LISTAGENS 


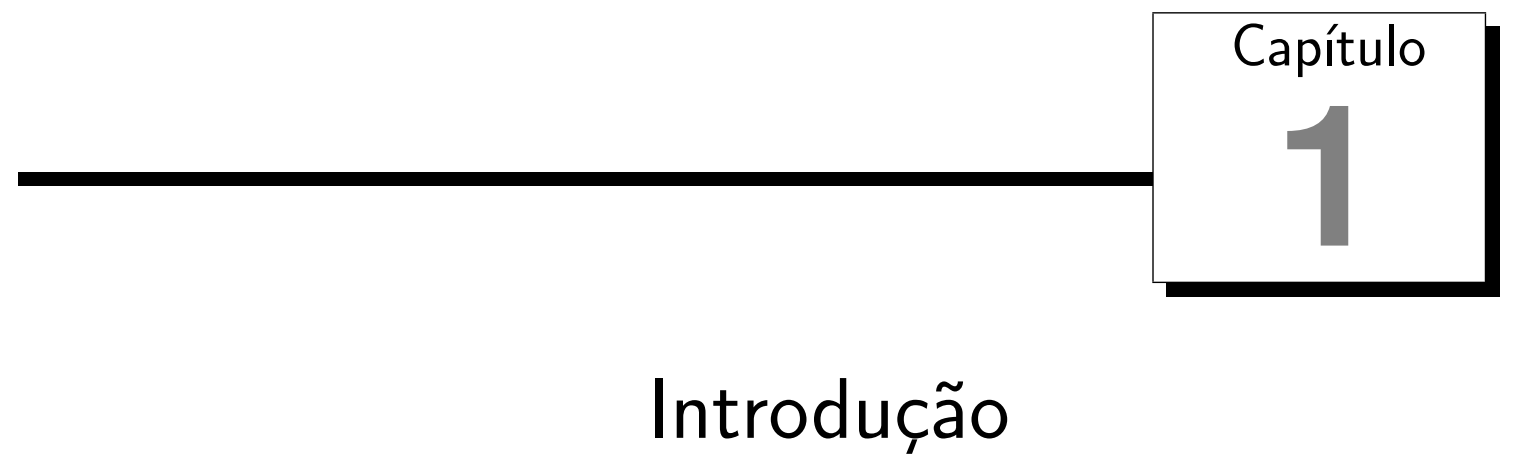

$\mathcal{A}$

Internet tem claramente evoluído de uma rede restrita a um pequeno grupo a uma rede que conecta bilhões de dispositivos e de um cenário de produtores de conteúdo que dominam ferramentas e linguagens de programação a um cenário em que usuários comuns, sem treinamentos específicos, geram conteúdo a partir das ferramentas desenvolvidas ao longo dos anos. A criação de blogs, wikis, redes sociais e websites de compartilhamento de mídias permitiu que usuários sem conhecimento em programação criassem suas próprias páginas na Internet, distribuíssem suas fotos e vídeos e contribuíssem com a geração de informação colaborativamente. A mais famosa enciclopédia livre de edição colaborativa, a Wikipédia, e o maior website de compartilhamento de vídeos, o YouTube, são exemplos de como a criação de conteúdo e colaboração entre usuários finais pode resultar em um acervo rico em informações e mídias. Esses aplicativos buscam facilitar o processo de produção e distribuição de conteúdo, gerando documentos e código automaticamente, utilizando apenas dados advindos de interações transparentes e de alto nível.

A notável evolução e o aumento da popularidade de smartphones e tablets fez com que o número de dispositivos conectados à Internet ultrapassasse a população mundial, como ilustra a Figura 1.1 [Evans, 2011]. A evolução da computação possibilitou um grande poder de processamento e armazenamento em um tamanho extremamente reduzido, impulsionando a criação de dispositivos portáteis com alto desempenho a preços acessiveis. Ao mesmo tempo, a melhoria constante da interação com estes dispositivos estimulou o interesse dos usuários [IDC, 2013]. Telas de alta qualidade e sensíveis ao toque, múltiplas 


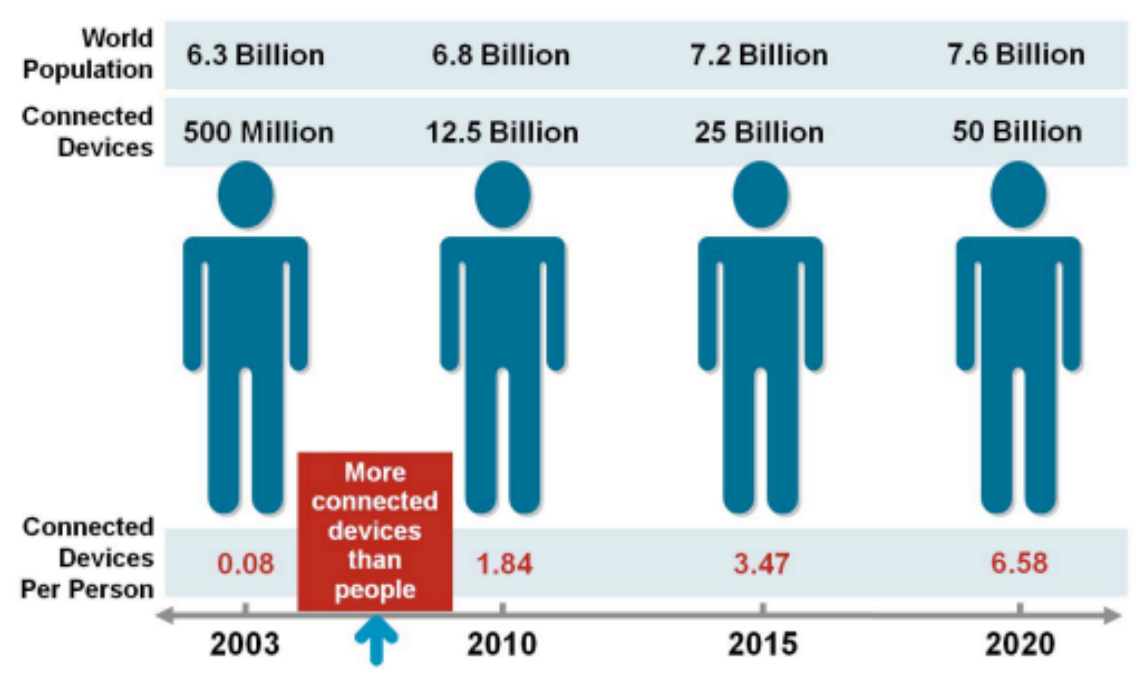

Figura 1.1: Crescimento do número de dispositivos conectados à Internet [Evans, 2011].

alternativas de conexão e câmeras e microfones integrados aprimoram a interação dos usuários com seus dispositivos e facilitam o acesso a informações e serviços, enquanto a mobilidade permite que as pessoas utilizem o tempo ocioso que possuem enquanto viajam, fazem o trajeto de casa ao trabalho ou aguardam em salas de espera, por exemplo.

A ampla quantidade de recursos integrados em smartphones e tablets permite que usuários utilizem seus dispositivos não apenas para acessar informações mas também para captura de mídias. Com seus dispositivos, usuários podem gerar textos, imagens e gravações em áudio e vídeo com grande facilidade. Além de capturar novas mídias, existe a possibilidade de enriquecer seu conteúdo por meio da adição de anotações. Realizar anotações em texto é uma prática extremamente comum e natural em papel, por este motivo visualizadores de texto buscam simular esta experiência em ambientes computacionais. Um exemplo comum são visualizadores de arquivos em formato PDF que trazem funções de anotação integradas. A atual facilidade de tirar fotos por meio das câmeras acopladas em dispositivos móveis tem aumentado a popularidade de anotações em imagens. Uma busca em lojas de aplicativos para os sistemas Android e iOS revela diversos aplicativos que permitem anotar e compartilhar fotos com áudio, como o aplicativo lenshare ${ }^{1}$, ou com rabiscos, como a ferramenta Skitch ${ }^{2}$. No entanto, apesar da captura, exibição e compartilhamento de vídeos em dispositivos móveis terem se tornado parte do cotidiano de usuários [O'Hara et al., 2007], aplicativos para anotações em vídeo em dispositivos móveis ainda são poucos.

Pesquisas em anotações em vídeo possuem um longo histórico. Isto pode ser

\footnotetext{
${ }^{1}$ http://www.lenshare.com/

${ }^{2}$ https://evernote.com/skitch/
} 
observado em trabalhos como o de Davis [1993], que propõe uma linguagem de anotação icônica para vídeos, e o de Weher e Poon [1994] que, propõe uma ferramenta para anotações em tempo real em gravações de vídeos não digitais. Mais recentemente, com o excepcional crescimento da quantidade de conteúdo audiovisual na Internet, aumentou-se a preocupação com a indexação, busca, filtragem e organização deste conteúdo. Neste contexto, o padrão MPEG-7 [ISO, 2002] foi desenvolvido pelo grupo MPEG (Moving Picture Experts Group) com foco na descrição textual de conteúdo multimídia. Estas descrições de conteúdo permitem que tanto usuários quanto aplicativos identifiquem, recuperem e filtrem o conteúdo de vídeos. Após a proposta do padrão MPEG-7 surgiram ferramentas que facilitavam o seu uso. Em especial, a ferramenta VideoAnnEx, mais conhecida como IBM MPEG-7 Annotation Tool [Lin et al., 2003], permite o uso transparente do MPEG-7, de modo que usuários finais, sem conhecimentos sobre o padrão, podem descrever o conteúdo de vídeos.

Comentários são uma forma de interação muito comum em vídeos e podem ser considerados como um tipo de anotação. Em sistemas de exibição de vídeo online realizar comentários é uma atividade praticada com naturalidade pelos usuários. Porém, é preciso destacar que anotações nestes sistemas geralmente são limitadas. No YouTube Annotations ${ }^{3}$, por exemplo, apenas o responsável pelo vídeo pode realizar anotações temporais e síncronas. Usuários finais realizam comentários, que apesar de permitirem a indicação de momentos específicos do vídeo, não são síncronos e seu compartilhamento é limitado. Entre os cenários em que anotações temporais têm um papel significativo, é importante destacar vídeos educacionais [Hürst et al., 2007], tutorias, entrevistas e observações. Em tais atividades, a autoria por parte do usuário pode não só enriquecer o conteúdo com comentários, mas também através de marcações de pontos de interesse, que podem auxiliar a revisão e navegação em vídeos. Explorando o problema de anotações temporais, ferramentas como a VideoANT [Hosack, 2010] e o Ambulant Captioner [Guimarães et al., 2012] foram desenvolvidas para permitir a adição de anotações textuais que são exibidas de forma síncrona com o vídeo.

Anotações em vídeo feitas por meio de dispositivos móveis é um tema de pesquisa recente na área da computação. Apesar de dispositivos móveis do tipo smartphones e tablets terem sido lançados recentemente (o primeiro iPhone, por exemplo, foi lançado em 2007), pesquisas na área surgiram antes, fazendo uso de dispositivos bastante limitados em termos de mobilidade e interatividade.

Uma das principais inovações dos primeiros tablet PCs foi a possibilidade de interagir com a tela do computador usando uma caneta digital. Este novo meio

\footnotetext{
${ }^{3}$ https://www.youtube.com/yt/playbook/annotations.html
} 
de interação incentivou trabalhos sobre anotações em tinta eletrônica em vídeos [Bulterman, 2004]. A integração de microfones a estes computadores também motivou a investigação de anotações em áudio, de forma que as ferramentas desenvolvidas começaram a permitir anotações multimodais. A ferramenta M4Note [Goularte et al., 2004], por exemplo, utiliza tablet PCs e interações baseadas em caneta e voz para capturar as anotações. Anotações em áudio são convertidas em texto. Já anotações capturadas por caneta, ou seja, em formato de tinta eletrônica, são convertidas em texto ou símbolos definidos pelo usuário. A ferramenta permite que as anotações sejam adicionadas durante a captura ou reprodução do vídeo. Também executáveis em tablet PCs, as ferramentas Watch-andComment (WaCTool) [Cattelan et al., 2008] e Creation-Tool [Cabral et al., 2011] permitem realizar anotações em texto, áudio e tinta eletrônica em um vídeo gravado, explorando a multimodalidade de uma forma mais ampla. Zhang et al. [2013] apresentam outro trabalho que utiliza tablet PCs. A ferramenta trabalha apenas com tinta eletrônica, porém o seu diferencial é a possibilidade de realizar anotações colaborativas e síncronas.

Já a ferramenta MobiCon [Lahti et al., 2005] tem como plataforma celulares equipados com câmera e permite anotações em forma de metadados em vídeos gravados. Devido às limitações do dispositivo, em termos de interação e inserção de texto, o aplicativo prevê a conexão com um servidor que sugere possíveis anotações. O aplicativo Mesh [Concejero et al., 2008] também é executado em celulares e permite associar palavras-chave e anotações textuais ao vídeo. Apesar das diversas limitações, o aplicativo permite que as anotações sejam associadas a momentos específicos do vídeo.

Trabalhos recentes reportam aplicações desenvolvidas para dispositivos móveis atuais. Como no caso de Bakopoulos et al. [2011], que apresentam uma ferramenta para anotação em vídeos de emergência fazendo uso de elementos gráficos e rótulos pré-definidos específicos para este cenário. Lux e Riegler [2013] apresentam um aplicativo para o sistema Android para anotações em vídeos de endoscopia. O aplicativo foi idealizado para tablets e é possível adicionar anotações em áudio, texto e tinta eletrônica. Também é possível fazer marcações de pontos de interesse chacoalhando o dispositivo. Já Huang e Fox [2012] reportam um aplicativo Android para contextos genéricos que permite anotações em texto e tinta eletrônica em uma transmissão de vídeo. O diferencial do trabalho é a possibilidade de realizar anotações colaborativas de forma síncrona.

Contudo, apesar da maturidade dos dispositivos atuais, observa-se que ainda são raros os trabalhos de anotação em vídeo que consideram esses dispositivos e investigam suas peculiaridades em termos de captura e interação.

Processos de autoria e de produção de conteúdo multimídia são tópicos que 
continuam a evoluir. A demanda por pesquisas atuais que envolvam este tema é reconhecida, inclusive, por organizadores de uma das principais conferências internacionais [ACM Multimedia, 2014; Boll e Bulterman, 2011]. Naaman e Zancanaro [2011] observam que a área de multimídia demanda contribuições que envolvam metodologias de design centradas em usuários e técnicas que permitam interação multimodal, além de avaliações que envolvam estudos com usuários. Já Gatica-Perez e Hua [2011] observam que, cada vez mais, dispositivos móveis se tornam dispositivos multimídia naturais por serem capazes de adquirir, acessar, gerenciar e transmitir múltiplos tipos de mídia.

Esse cenário motiva a realização de pesquisas que tragam inovações aos processos de produção e compartilhamento de conteúdo multimídia [Pimentel et al., 2012] que considerem o uso de dispositivos móveis [Timmerer et al., 2012] e multimodais [Jaimes e Sebe, 2007] considerando metodologias de design centrado no usuário. Mais especificamente, dadas as deficiências e oportunidades identificadas, se faz oportuna a investigação da captura de anotações em vídeo via dispositivos móveis.

\subsection{Objetivos}

Este trabalho teve por objetivo investigar alternativas de captura e compartilhamento de anotações em vídeos realizadas por usuários por meio de dispositivos móveis. A perspectiva adotada envolveu explorar a interação de usuários visando a produção automática de documentos de anotações. Os dispositivos móveis considerados possuem como principal característica a interação baseada em toque dos dedos na tela. Tal investigação demandou a construção de um aplicativo de anotação em vídeo para dispositivos do tipo smartphones e tablets. Com foco na interação usuário-computador, testes de usabilidade foram realizados durante o desenvolvimento do aplicativo. Foram definidos os seguintes objetivos específicos do trabalho:

1. Construção de uma ferramenta de anotação em vídeo para dispositivos móveis. Diferentes alternativas de captura são consideradas: texto, áudio e tinta eletrônica.

2. Construção de algoritmos que permitam a captura e a representação de informações de contexto.

3. Construção de algoritmos e definição de mecanismos para autoria de documentos multimídia interativos com base na especificação do conteúdo para permitir a navegação não linear pela mídia.

4. Construção de algoritmos e definição de mecanismos para compartilhamento das anotações capturadas via dispositivos móveis de modo a permitir a colaboração assíncrona. 
5. Criação de um conversor para integração com a ferramenta I+WaC-Editor [Martins, 2014]. A integração deve permitir que anotações realizadas no ferramental móvel sejam reproduzidas e estendidas em um reprodutor web multiplataforma com funcionalidades de navegação.

6. Avaliações contínuas com usuários.

\subsection{Metodologia e Problemas Investigados}

A condução da investigação proposta demandou o desenvolvimento de uma ferramenta de anotação em vídeo para dispositivos móveis. Foi premissa do trabalho que o ferramental desenvolvido tivesse como foco usuários não especialistas em sistemas de autoria ou edição de vídeo e fosse de uso genérico, podendo ser utilizada em diferentes aplicações. Com ênfase na interação humanocomputador e considerando metodologias de design centrado no usuário, durante o desenvolvimento foram realizadas avaliações de usabilidade envolvendo usuários e especialistas. Cada etapa de avaliação identificou novos problemas a serem trabalhados além de avaliarem a ferramenta.

A motivação, os objetivos e os problemas iniciais foram definidos por uma revisão do estado da arte. No entanto, para identificar problemas específicos foi executado um mapeamento sistemático sobre o tema de anotações colaborativas em vídeo. Os resultados do mapeamento sistemático permitiram identificar tendências e problemas nos trabalhos selecionados. A partir disto foram selecionados problemas específicos a serem investigados.

Considerando dispositivos móveis com telas sensíveis ao toque, mais especificamente tablets e smartphones com sistema Android, e a interação de usuários com estes dispositivos, os principais problemas investigados em ordem de importância foram:

- Múltiplas alternativas de entrada de dados para anotações: texto, tinta eletrônica e áudio.

- Anotações síncronas em vídeo durante a reprodução.

- Navegação em vídeo com base nas anotações geradas.

- Compartilhamento assíncrono de anotações em dispositivos móveis.

- Tratamento de várias anotações exibidas simultaneamente de forma síncrona com o vídeo, considerando anotações feitas por diferentes usuários ocorrendo em um mesmo momento de execução do vídeo.

- Anotações durante a captura do vídeo.

- Conversão de documentos de anotações gerados para o formato especificado por um reprodutor web, neste caso, a ferramenta I+WaC-Editor [Martins, 2014].

- Captura de informações de contexto relativas às anotações geradas. 


\subsection{Contribuições e Resultados}

As principais contribuições desta dissertação, em termos de interação de usuários com dispositivos móveis, são:

- A proposta de uma interface e de um conjunto de interações para captura de anotações multimodais e geração de documentos explorando os recursos de dispositivos móveis de (1) tela sensível ao toque para adição de anotações em forma de desenhos sobre os vídeos, (2) gravação de áudio para adição de anotações em áudio e de (3) gravação de vídeo para criar vídeos e marcar pontos temporais de interesse durante o processo de captura.

- A proposta de uma interface e de um conjunto de interações para anotação e navegação em vídeo em dispositivos móveis com tamanho de telas variados, sendo possível realizar as ações em dispositivos (1) sem teclado físico, (2) com interação baseada em toque dos dedos e (3) com telas de tamanho reduzido.

- A proposta de um método para colaboração assíncrona no contexto de anotações temporais, permitindo que os usuários compartilhem as anotações e as recebam de outros usuários. A solução proposta permite a visualização síncrona e simultânea de múltiplas anotações textuais, originadas por diferentes usuários, em uma interface adequada para dispositivos com tamanho de tela reduzido. Anotações em tinta e áudio podem ser visualizadas através de um sistema de troca de usuário principal, o que pode ser realizado em tempo de execução, sem a necessidade de pausa durante a interação.

Para investigar os objetivos definidos foi desenvolvida uma ferramenta de anotação em vídeo para Android que apresenta as contribuições descritas. Destaca-se também a criação de um conversor de anotações textuais explorando a compatibilidade com a ferramenta I+WaC-Editor [Martins, 2014], permitindo assim a integração com um reprodutor web multiplataforma com capacidades de anotação e navegação.

Resultados de um teste de usabilidade com usuários e uma avaliação heurística com especialistas na área de computação contribuíram para identificar problemas na interface e novos requisitos para a aplicação. Os problemas encontrados não se aplicam apenas ao cenário de anotação em vídeo. Deste modo, soluções propostas para problemas de usabilidade podem ser aplicadas em sistemas que utilizam dispositivos móveis de forma geral.

Uma avaliação colaborativa realizada com uma usuária especialista na área de terapia ocupacional identificou que, apesar da ferramenta ser de grande uti- 
lidade em seu trabalho e auxiliar no tratamento de seus pacientes, novos requisitos surgem para seu contexto específico. Por exemplo, além de permitir gravar e anotar vídeos de exercícios para facilitar a repetição por pacientes, é interessante a possibilidade de acompanhamento do paciente por parte da profissional após a consulta, identificando se ele realizou os exercícios programados. Assim é interessante a extensão da ferramenta para cenários específicos de uso.

Comparações com outros sistemas de anotação em vídeo mostram que o aplicativo desenvolvido neste trabalho é único e apresenta soluções específicas e originais para dispositivos móveis do tipo tablets e smartphones no contexto de anotações em vídeo.

\subsection{Estrutura do Documento}

O restante deste trabalho está organizado da seguinte forma. O Capítulo 2 introduz fundamentos importantes para facilitar o entendimento do trabalho, considerando tanto a proposta principal quanto os trabalhos relacionados. Primeiramente, são apresentados conceitos de computação ubíqua, captura e acesso, sistemas colaborativos e uma descrição sobre o sistema Android. Em seguida é discutido o conceito de experiência do usuário. Ao final são explicadas brevemente técnicas de análise estatística.

O Capítulo 3 apresenta trabalhos relacionados. É descrito um mapeamento sistemático sobre o tema de anotações colaborativas organizado em uma breve explicação sobre seu planejamento e execução e uma discussão sobre os resultados que afetam diretamente este trabalho. Também é apresentada a ferramenta I+WaC-Editor para compreensão da integração que este trabalho propõe e um experimento sobre anotações em vídeos educativos realizado em colaboração com outros pesquisadores.

Capítulo 4 discute o desenvolvimento do trabalho e a ferramenta desenvolvida, detalhando os desafios enfrentados, as soluções adotadas e as avaliações realizadas no decorrer da execução do trabalho.

O último capítulo apresenta a síntese dos resultados do trabalho com um comparativo de ferramentas para anotação em vídeo, uma discussão das limitações, trabalhos futuros e publicações resultantes.

O Apêndice A traz uma breve descrição dos trabalhos executados em um estágio de pesquisa no exterior realizado pela aluna no Centrum Wiskunde \& Informatica (CWI), em Amsterdã. 


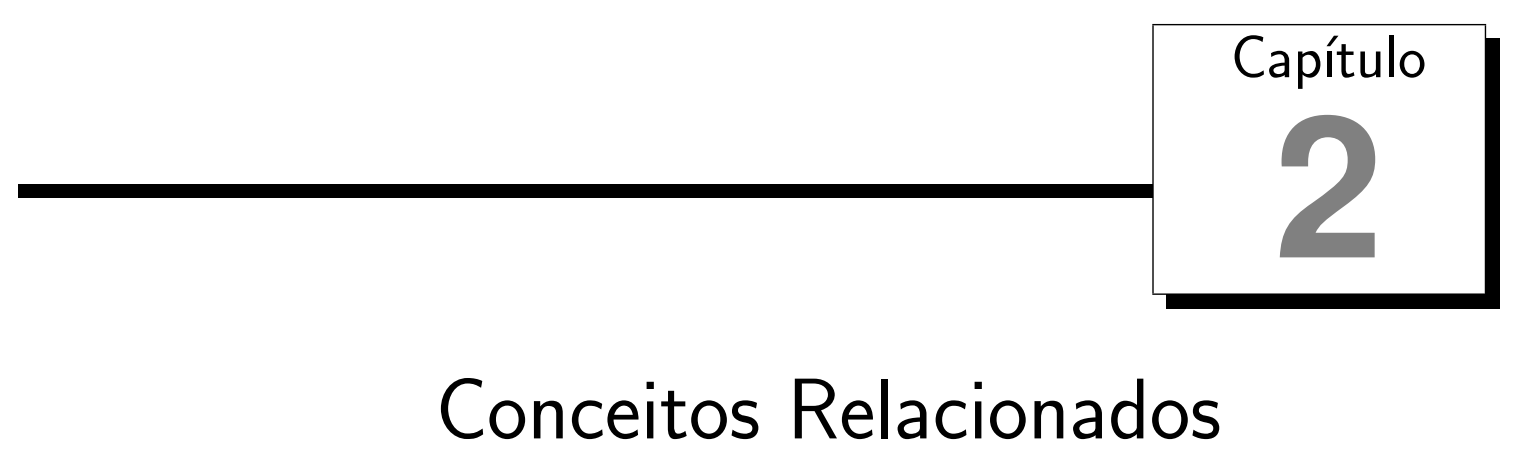

Este capítulo introduz conceitos importantes que são referenciados no restante do trabalho: computação ubíqua (Seção 2.1), captura e acesso (Seção 2.2), sistemas colaborativos (Seção 2.3), sistema operacional Android (Seção 2.4), experiência do usuário (Seção 2.6) e métodos estatísticos (Seção 2.5).

\subsection{Computação Ubiqua}

Computação ubíqua é um conceito concebido por Weiser [1991] para denominar o acesso à computação em qualquer ambiente e a qualquer momento. A computação ubíqua é definida, de forma aproximada, como sendo o oposto da realidade virtual. Interfaces de realidade virtual têm como proposta levar o indivíduo a um mundo gerado por computador, enquanto a computação ubíqua impõe ao sistema computacional que se adapte ao mundo humano. Assim, o design de aplicações de computação ubíqua é uma difícil tarefa de integração de fatores humanos, engenharia, ciências computacionais e sociais [Cho, 2011].

Segundo a proposta original de Weiser [1991, 1993], o objetivo da computação ubíqua é melhorar o uso da computação e aumentar seu apoio aos usuários, possibilitando que diversos serviços e aplicações sejam acessíveis através do ambiente físico, porém fazendo que os sistemas computacionais envolvidos sejam efetivamente invisiveis ao usuário. Desse modo, seria possivel haver uma grande quantidade de serviços disponiveis em ambiente quaisquer apoiando usuários na realização de diversas atividades. O uso transparente das aplicações distingue-se dos meios limitados de interação permitidos pelos computadores convencionais. Assim, para atingir esse objetivo é necessário criar meios que facilitam as tarefas cotidianas através do fornecimento transparente, 
contínuo e onipresente de informações e serviços.

Em seu trabalho, Abowd e Mynatt [2000] identificaram rumos para as pesquisas em computação ubíqua. Os autores determinaram três temas recorrentes em pesquisas dirigidas a aplicações nesta área: interfaces naturais, aplicações cientes de contexto e captura e acesso automatizados.

O objetivo de pesquisas em interfaces naturais é suportar formas comuns de interação humana, como a voz, escrita baseada em caneta ou gestos, considerando inclusive a utilização concorrente destes recursos em interfaces multimodais, enriquecendo a comunicação humano-computador. Na época em que foi escrito o trabalho de Abowd e Mynatt [2000], tais interfaces ainda eram difíceis de construir e não possuíam robustez para ao tratar erros, resultando em pesquisas nas áreas de tratamento de erros em interfaces baseadas em reconhecimento de interações. Observa-se que atualmente interfaces que utilizam reconhecimento da escrita por meio de tinta eletrônica e entrada de voz no idioma inglês estão bastante avançadas. No entanto, interfaces de reconhecimento de voz no idioma português, por exemplo, estão em um estágio de desenvolvimento menos avançado e ainda possuem diversos problemas. A interação baseada em toque dos dedos também não era uma tecnologia existente na época. Sendo uma tecnologia recente, ainda existem trabalhos que buscam aprimorar ainda mais este tipo de interação em diferentes aplicações.

Aplicações cientes de contexto recuperam informações de contexto para serem utilizadas de forma a auxiliarem ou se adaptarem à situação do usuário. Destaca-se que a recuperação ubíqua destas informações também é um desafio [Abowd e Mynatt, 2000]. A identidade do usuário, sua localização, sua tarefa e o momento de ocorrência são algumas das informações que podem ser capturadas e utilizadas para diferentes finalidades. Por exemplo, Sama et al. [2008] utilizam informações de localização, velocidade e ambiente para configurar perfis de celulares automaticamente, enquanto o trabalho de Liu et al. [2009] estuda como um mundo rico em sensores poderia ser explorado para enriquecer mídias com informações de contexto, melhorando atividades de busca de conteúdo, principalmente em imagens e vídeos.

Por fim, aplicações de captura e acesso são aquelas que permitem automatizar o processo de captura de experiências cotidianas, provendo, posteriormente, acesso flexível e universal do conteúdo gerado [Abowd e Mynatt, 2000]. Podem ser citados, como exemplos dessas experiências, eventos como aulas, reuniões, visitas culturais e viagens. Na fase de captura, as informações das experiências são capturadas, já na fase de acesso são gerados documentos automaticamente, com o objetivo de permitir o acesso ao conteúdo gerado no evento correspondente. 
Truong et al. [2001] discutem o espaço de design de aplicações de computação ubíqua, em particular aplicações de captura e acesso. Segundo o trabalho, além dos dados capturados, existem informações de contexto que devem ser consideradas. São cinco as dimensões de contexto definidas pelos autores:

-Who: informações relativas a quem são os usuários envolvidos.

- What: dados sobre as mídias capturadas durante a interação.

-When: instantes em que a captura ocorreu.

- Where: local físico da captura.

- How: dispositivos de captura.

\subsection{Captura e Acesso}

Como já mencionado, sistemas de captura e acesso permitem automatizar o processo de captura de eventos e provêem acesso às informações geradas [Abowd e Mynatt, 2000]. Com isto definido, nesta seção o tema de captura e acesso é discutido com mais detalhes no contexto de anotações multimídia.

Truong et al. [2001] definem captura e acesso como uma atividade de preservação de uma experiência. A captura resulta em um documento com os dados capturados ao decorrer do tempo. Segundo sua definição, objetos simples como lápis e papel constituem ferramentas de captura e acesso, sendo anotações em papel os dados resultantes do processo.

Outro conceito importante no contexto de captura e acesso é a indexação. Índices são marcações temporais que apontam para um instante em gravações multimídias auxiliando o acesso aleatório a pontos de interesse [Geyer et al., 2005]. Minneman et al. [1995] classificam os possiveis índices de uma gravação em quatro classes: anotações intencionais, índices colaterais, índices derivados e anotações post-hoc. Anotações intencionais são aquelas que os participantes criam de forma explícita durante uma atividade com o objetivo de marcar momentos específicos. Índices colaterais são gerados por ações cujo objetivo inicial não é a marcação de um instante, no entanto estas ações são acontecimentos que podem auxiliar a navegação em uma mídia - um exemplo comum seria trocas de slides em uma apresentação. Já índices derivados são obtidos através da análise automática do conteúdo de gravações, por exemplo, identificação de mudanças de cenas. Por fim, anotações post-hoc são anotações intencionais criadas por qualquer usuário em um momento posterior à gravação.

Em termos de acesso, Minneman et al. [1995] destacam que as ferramentas devem não só reproduzir conteúdo, juntamente com os índices e anotações existentes, mas também permitir que usuários criem novos artefatos, adicionando novos índices e anotações. Neste sentido, Martins e Pimentel [2011] apresentam 


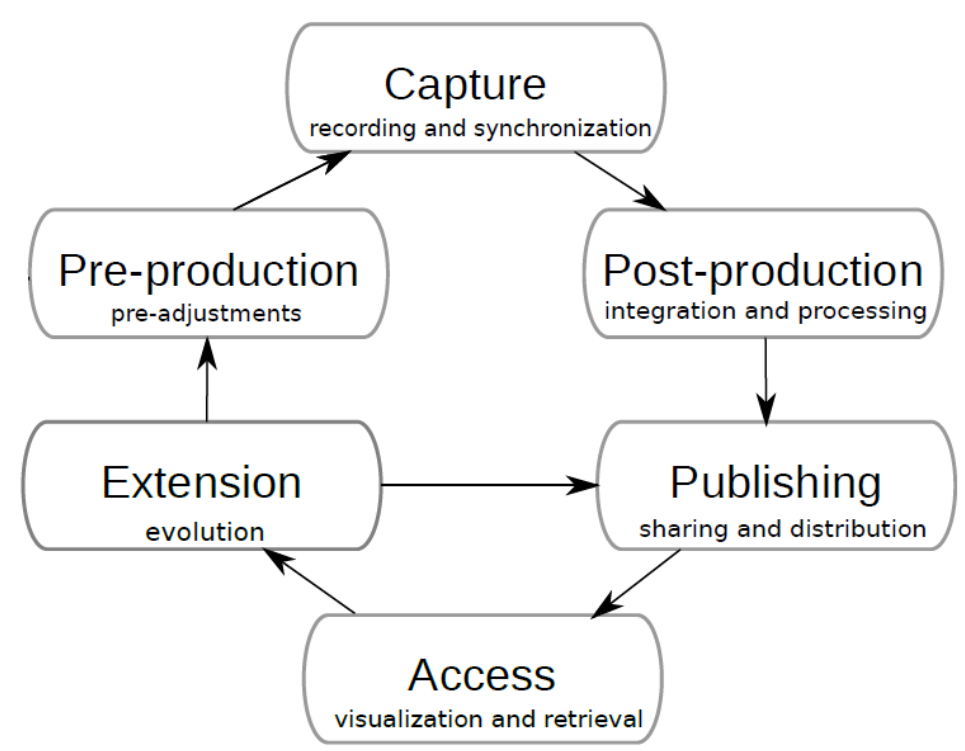

Figura 2.1: O processo evolutivo de produção multimídia [Martins e Pimentel, 2011].

um modelo de produção de conteúdo multimídia que considera os usuários não apenas como consumidores de conteúdo, mas como produtores em todo o processo de produção de conteúdo, que tem como principais fases a captura deste conteúdo e seu acesso posterior. A Figura 2.1 apresenta as fases do modelo proposto por Martins e Pimentel [2011], que é resultado da extensão dos trabalhos de Abowd et al. [1998] e Pimentel et al. [2001]. A fase de pré-produção trata das atividades de preparação do conteúdo a ser capturado e organização do ambiente e atividades envolvidas. A captura é o estágio de gravação e sincronização das mídias. Na pós-produção a mídia é preparada para o consumidor, processo que pode envolver edição do conteúdo. A publicação é a fase em que a mídia é efetivamente distribuída aos consumidores. Durante o acesso os usuários vão reproduzir o conteúdo interagindo de forma linear ou dinâmica (i.e., navegando pelo vídeo ou reproduzindo momentos específicos). Por fim, a fase de extensão identifica o processo de adição de novos elementos, ou seja, o usuário final pode adicionar anotações e estender o conteúdo original.

Anotações podem enriquecer o conteúdo por meio da adição de informações extras ou explicativas ou até mesmo pela indicação de momentos de destaque. A natureza temporal das anotações pode ser implícita ou explícita e sua representação pode ocorrer em diferentes formatos: texto, áudio, imagem, vídeo, rabiscos, entre outros. Agosti e Ferro [2007] diferenciam dois tipos de anotações: metadados, ou seja, dados descritivos, e conteúdo. Metadados possuem os papéis de descrever e esclarecer as propriedades e a semântica do conteúdo e seu principal uso é na organização e recuperação de informação que pode, inclusive, ser processada automaticamente por sistemas computacionais. Um exemplo 
relevante de uso deste tipo de anotações é o padrão MPEG-7 [ISO, 2002], que define um formato para armazenar informações sobre o conteúdo da mídia. Já anotações do tipo conteúdo têm como finalidade acrescentar informações, o que pode ser feito, por exemplo, em forma de comentários pessoais, ideias, destaques, esclarecimentos ou adição de conteúdo relacionado - este tipo de anotação é de grande utilidade para os usuários.

\subsection{Sistemas Colaborativos}

Em sociedade, as pessoas realizam grande parte de suas tarefas em grupo. O estudo e aprendizado são realizados em conjunto desde a infância e a interação nas escolas é considerada de grande importância para o desenvolvimento pessoal e social. No meio de trabalho, pessoas não apenas produzem como um grupo, mas pensam e criam em conjunto. A interação colaborativa é importante não apenas para o ser humano como indivíduo mas também para a criação de conhecimento e novas tecnologias. Com o objetivo de dar suporte a natureza do trabalho em grupo, muitas pesquisas na área de sistemas colaborativos, ou mais especificamente, trabalho cooperativo suportado por computador, têm sido conduzidas nos últimos anos [Schmidt e Bannon, 2013].

Pode-se dizer que um sistema colaborativo é um conjunto de componentes projetado para apoiar a natureza colaborativa e social do trabalho humano, auxiliando os usuários envolvidos a realizarem uma tarefa ou objetivo em comum [Miller et al., 2009]. Deste modo, sistemas colaborativos englobam todos os sistemas que apoiam de alguma forma a realização de tarefas por um conjunto de pessoas.

Sistemas colaborativos podem apresentar diferentes graus de complexidade e o modo com que apoiam a realização de tarefas é amplo. As funções podem ser simples, como auxiliar no processo de comunicação, ou mais completas, como prover mecanismos para a execução de uma tarefa em um ambiente colaborativo. E-mail, mensageiros instantâneos, wikis, videoconferências, editores de documentos online, aplicativos de acesso e controle remoto, entre outros, são exemplos de ferramentas colaborativas [Miller et al., 2009]. Com relação ao tempo, um fator de interesse é o sincronismo das ferramentas. O e-mail é uma ferramenta de comunicação assíncrona, ou seja, os envolvidos não precisam estar presentes ao mesmo tempo e a interação é feita de forma independente do outro usuário. Já ferramentas síncronas permitem a partição simultâneas dos usuários e troca de informações em tempo real. Em termos de complexidade, sistemas computacionais têm evoluído para suportar desde o compartilhamento de informações até ambientes virtuais colaborativos [Sallnäs, 2005].

Sistemas colaborativos são a base de trabalhos cooperativos suportados por 
computador e o reconhecimento de sua importância e a geração de novos requisitos só tem aumentado no decorrer dos anos. Isto pode ser observado em pesquisas que apoiam o aprendizado em grupo [Coopey et al., 2013; Giannoukos et al., 2008], utilizam redes sociais para melhorar a relação e desempenho de colegas de trabalho [DiMicco et al., 2008] e suportam o trabalho colaborativo de forma geral [Davis et al., 2001; Ebara, 2013]. As necessidades de um grupo que utiliza uma ferramenta colaborativa são muito diferentes das de um usuário trabalhando individualmente, e estas características devem refletir no design de soluções colaborativas [Tang, 1991]. Portanto, além de ser uma área de grande importância na computação, vários desafios ainda persistem [Schmidt e Bannon, 2013].

\subsection{Sistema Operacional Android}

O sistema operacional Android é um sistema de código aberto baseado em Linux desenvolvido atualmente pela empresa Google em conjunto com um consórcio de empresas de software, hardware e telecomunicações, dedicadas ao avanço de padrões abertos para dispositivos móveis [Android Developers, 2014]. O sistema Android foi projetado essencialmente para dispositivos móveis com telas sensíveis ao toque. Sua primeira versão comercial foi lançada em setembro de 2008, sendo considerado um sistema relativamente novo. Porém, o sistema tem evoluído rapidamente principalmente por ser uma alternativa de qualidade, livre e de código aberto. Deste modo, várias versões surgiram no decorrer dos anos. A Tabela 2.1 exibe a distribuição de dispositivos por versão do Android. O sistema Android foi rapidamente adotado por empresas com o intuito de criar concorrentes para as tecnologias móveis da empresa Apple, particularmente para o sistema operacional iOS.

Tabela 2.1: Distribuições das versões do Android coletadas em Julho de 2014 [Android Developers, 2014].

\begin{tabular}{|l|c|c|c|}
\hline Versão & Codinome & API & Distribuição \\
\hline \hline 2.2 & Froyo & 8 & $0.7 \%$ \\
$2.3 . \mathrm{x}$ & Gingerbread & 10 & $13.5 \%$ \\
$4.0 . \mathrm{x}$ & Ice Cream Sandwich & 15 & $11.4 \%$ \\
$4.1 . \mathrm{x}-4.3$ & Jelly Bean & 16 & $56.5 \%$ \\
4.4 & KitKat & 19 & $17.9 \%$ \\
\hline
\end{tabular}

A empresa Google disponibiliza um conjunto de ferramentas e bibliotecas, chamado Android SDK (Software Development Kit), que possibilita construir, testar e depurar os aplicativos para o sistema Android. Uma das maiores vantagens do desenvolvimento de aplicativos para sistemas Android é a flexibilidade 
em termos de plataforma de desenvolvimento. Não é necessário um hardware e sistema operacional especializado, sendo possivel desenvolver em sistemas Linux, Windows e Mac OS X, enquanto o ambiente de programação para o sistema iOS, utilizado em dispositivos móveis da Apple, demanda a utilização de um computador com o sistema operacional Mac OS [Goadrich e Rogers, 2011]. Porém, a principal desvantagem em desenvolver aplicativos para o sistema Android é que estes não poderão ser executados em dispositivos com outros sistemas operacionais. Uma alternativa é desenvolver sistemas com base na tecnologia HTML5 ${ }^{1}$. Sistemas criados em HTML5 são separados da plataforma e podem ser executados independentemente do sistema operacional. No entanto, é importante ressaltar que ao desenvolver aplicativos especializados para o sistema Android é possivel criar de aplicações que exploram a experiência do usuário e o desempenho do sistema e que não podem ser igualmente reproduzidas em sistemas para web atualmente.

\subsection{Métodos Estatísticos}

Avaliações realizadas na área de interação-usuário computador, quando quantitativas, fazem uso de métodos estatísticos para analisar e reportar resultados [MacKenzie, 2009; Sauro e Lewis, 2008]. Nos projetos relacionados a este trabalho foram utilizados alguns métodos para análise estatística de resultados de experimentos. Por este motivo, são apresentadas breves descrições sobre termos utilizados neste documento.

O coeficiente alfa de Cronbach [Cronbach, 1951] é utilizado para determinar a consistência interna ou correlação entre itens de um grupo, sendo uma ferramenta poderosa para avaliar a confiabilidade de questionários aplicados em pesquisas. A correlação entre os itens é calculada com base nos dados de respostas em um questionário. Quanto maior a correlação maior o coeficiente de confiabilidade alfa. O conceito de confiabilidade refere-se à consistência das medições e a garantia de que resultados semelhantes são obtidos a partir de aplicações repetidas.

A escala multidimensional (MDS) engloba um conjunto de técnicas matemáticas que utilizam como entrada proximidades entre objetos (variáveis) e tem como saída principal uma representação espacial composta por uma configuração geométrica de pontos. Os dados de entrada para a técnica são os coeficientes de correlação entre os objetos analisados, ou seja, a intensidade do relacionamento entre as variáveis. Cada objeto é representado por um ponto em um gráfico multidimensional em que a proximidade entre os pontos representa o nível de similaridade entre os mesmos. Tal representação torna os dados mais fáceis de

\footnotetext{
${ }^{1}$ http://www.w3.org/TR/html5/
} 
serem compreendidos. Para garantir que o gráfico gerado representa a distância dos dados com fidelidade é necessário calcular um valor de estresse. O valor de estresse varia entre 0 e 1 , sendo que valores próximos de 0 indicam um melhor ajuste dos dados [Kruskal e Wish, 1978].

A análise de variância (ANOVA) é uma técnica estatística utilizada para analisar a diferença entre grupos de médias, permitindo descobrir se três ou mais médias são iguais através do teste da hipótese nula. Esta técnica é uma ferramenta poderosa em experimentos cujo objetivo é comparar duas ou mais condições. Para que a técnica ANOVA seja aplicada, um conjunto de suposições sobre os dados deve ser obedecido: as amostras devem ser aleatórias, os dados devem apresentar uma distribuição normal dos resíduos e a variância em cada condição experimental deve ser igual. Existem diferentes tipos de ANOVA que variam de acordo com o design experimental, porém todas as técnicas têm em comum o fato de envolverem uma determinada quantidade de variáveis independentes que podem ser medidas com grupos de participantes que podem ser constituídos pelos os mesmos indivíduos ou não. Se os mesmos indivíduos participam do experimento em condições diferentes é utilizado o termo medidas repetidas. Caso os grupos sejam compostos por participantes diferentes o termo independente é utilizado [Field, 2013].

\subsection{Experiência do Usuário}

O conceito de experiência do usuário (UX), apesar de ser um tópico ainda jovem, tem tido um papel influente no desenvolvimento de diferentes produtos de tecnologia [Partala e Kallinen, 2012], mostrando que a preocupação no desenvolvimento de aplicações atuais não está mais apenas relacionada à facilidade de uso, mas também às emoções do usuário. A cláusula 2.15 da ISO 9241-110 [ISO, 2010] define experiência do usuário como as percepções e as respostas de uma pessoa que resultam do uso ou uso antecipado de um produto, sistema ou serviço. Esta definição formal pode ser complementada por outra interpretação: experiência do usuário investiga como uma pessoa se sente utilizando um determinado produto, o que vai além do componente subjetivo da usabilidade, a satisfação, pois aborda uma série de outras qualidades subjetivas [Vermeeren et al., 2010].

Segundo Law et al. [2009], em seu estudo que reuniu a visão de 275 pesquisadores na área, experiência do usuário é algo dinâmico, dependente de contexto e subjetivo. Os autores atribuem o grande interesse atual em experiência do usuário ao fato de pesquisadores da área de interação usuário-computador terem se tornados cientes das limitações do framework tradicional de usabilidade. É importante discutir qual a diferença entre métodos de experiências do usuário 
e métodos de usabilidade. Experiência do usuário engloba a usabilidade, implicando na extensão dos métodos de avaliação de usabilidade existentes [Law et al., 2008]. Considerando que experiência do usuário é um novo tópico, seus métodos de avaliação ainda são pouco definidos, diferentemente de métodos de usabilidade que, graças aos anos de esforços em pesquisas, estão em estágios de maturidade avançados [Vermeeren et al., 2010].

\subsection{Considerações Finais}

Os fundamentos de computação ubíqua (Seção 2.1) foram importantes para auxiliar na definição de requisitos deste trabalho e estruturá-lo dentro de seus princípios básicos. Interfaces naturais implicam em considerar a possibilidade de capturar anotações de forma espontânea, por meio de comentários em áudio por exemplo, e em permitir a utilização concorrente de outros métodos de entrada, o que caracteriza a multimodalidade. Em termos de ciência de contexto é importante considerar o princípio de captura imperceptível de informações de contexto e a importância desses dados no enriquecimento dos documentos multimídia. A definição das dimensões de contexto auxiliou a estabelecer quais informações deveriam ser recuperadas além de classificá-las dentro de um conjunto definido. Aplicações de captura e acesso (Seção 2.2) propõem a captura de experiências e geração de documentos automaticamente. Este trabalho se enquadra nesta categoria e envolve diferentes fases do processo de produção multimídia.

A Seção 2.3 apresenta a definição de sistemas colaborativos e destaca a importância de oferecer suporte a alguma forma de colaboração entre usuários. O capítulo de trabalhos relacionados apresenta um mapeamento sistemático sobre anotações colaborativas em vídeo (Seção 3.1). Além disso, neste trabalho é proposta uma solução de compartilhamento de anotações em vídeo que permite colaboração assíncrona.

As características descritas na Seção 2.4 sobre o sistema operacional Android, principalmente a flexibilidade em termos de plataforma de desenvolvimento e a possibilidade de uma melhor experiência do usuário, foram importantes para escolher esse sistema operacional como alvo para implementação da ferramenta de anotação.

Os métodos estatísticos citados na Seção 2.5 são utilizados na análise de dados de trabalhos relacionados. A experiência do usuário (Seção 2.6) é um conceito importante utilizado nos trabalhos relacionados e trabalhos futuros preveem a execução de experimentos que farão uso de métodos de avaliação da experiência do usuário. 


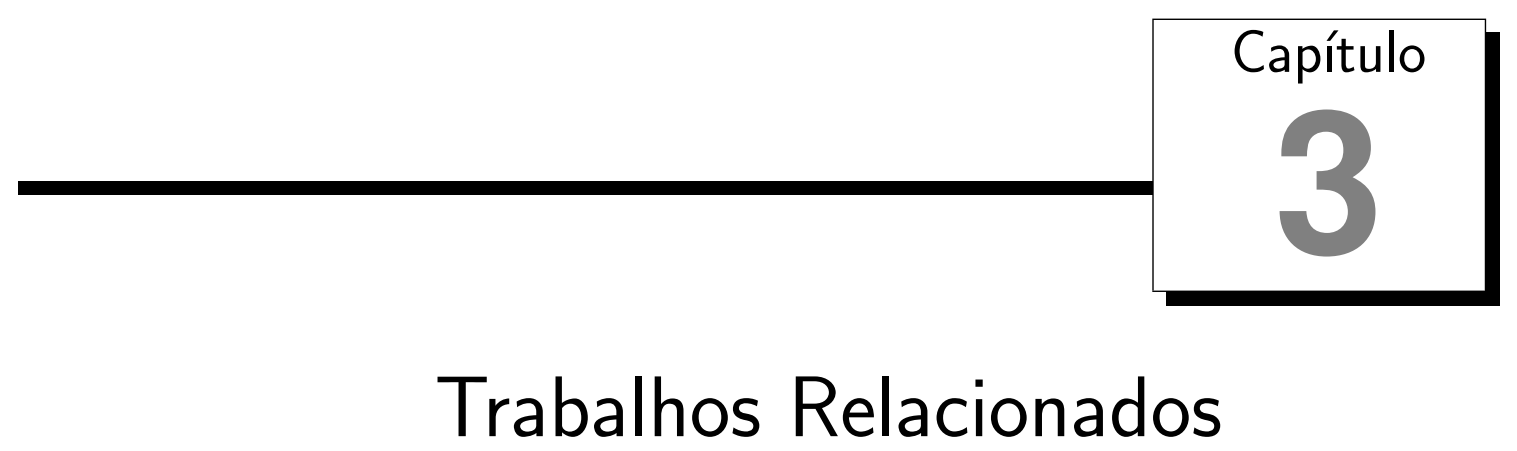

Este capítulo descreve os principais trabalhos relacionados a esta dissertação. A Seção 3.1 apresenta um mapeamento sistemático sobre o tema de anotações colaborativas em vídeo. A Seção 3.2 descreve a I+WaC-Editor, ferramenta que possui integração com o aplicativo desenvolvido neste trabalho, e um experimento de avaliação relacionado feito em colaboração com outros pesquisadores do grupo.

\subsection{Mapeamento Sistemático: Anotações Colaborativas em Video}

Como parte da disciplina de Metodologia de Pesquisa em Sistemas Web e Multimídia Interativos, cursada pela autora, foi proposta a execução de um mapeamento sistemático. Foi escolhido o tema de anotações colaborativas em vídeo, tópico diretamente relacionado ao projeto, com o objetivo de identificar ferramentas e pesquisas na área de modo a adquirir ideais e soluções para o projeto, além de identificar problemas relacionados. A análise dos trabalhos selecionados resultou na identificação do estado da arte e na percepção de tendências e deficiências que poderiam ser trabalhadas. Para compreensão do mapeamento executado é apresentado um resumo de seu planejamento e execução seguido por uma discussão dos trabalhos selecionados.

\subsubsection{Planejamento e Execução}

O mapeamento sistemático foi planejado e executado de acordo com o modelo apresentado por Biolchini et al. [2007]. O objetivo geral do mapeamento foi a identificação de trabalhos sobre anotações colaborativas em vídeo. Os objeti- 
vos específicos foram (a) descrição das ferramentas de anotação em vídeo encontradas, (b) identificação das soluções utilizadas para realizar a colaboração, (c) identificação de deficiências nos trabalhos selecionados. O mapeamento foi composto por quatro etapas: seleção inicial (busca), seleção preliminar (leitura de títulos e resumos), seleção final (leitura completa) e análise dos trabalhos selecionados.

A seleção inicial dos trabalhos foi realizada por meio de buscas em bibliotecas digitais que possuem publicações de qualidade. Devido a restrições de tempo foram consideradas três fontes: ACM DL ${ }^{1}$, IEEE Xplore ${ }^{2}$ e Springer Link ${ }^{3}$. O conjunto básico das palavras chaves utilizado para as buscas foi dado por: (video and annotation and (collaborative or share)). A escolha das palavras teve como objetivo obter o maior número de trabalhos na área, por isto foram consideradas também as variações das palavras-chave. A busca foi feita nos resumos e nos títulos dos trabalhos para restringir os resultados a trabalhos altamente relacionados ao tema. As buscas foram realizas em outubro de 2012 e atualizadas em maio de 2014. As buscas identificaram 278 trabalhos.

Após a realização das buscas, foram lidos os títulos e resumos dos trabalhos retornados e critérios de inclusão e exclusão foram aplicados para determinar sua inclusão na próxima etapa. O critério para inclusão de um artigo foi possuir anotações colaborativas em vídeo digital como tema principal de pesquisa. Foi definido que para ser considerado colaborativo é necessário que mais de um usuário possa contribuir com conteúdo.

Os critérios de exclusão estabelecidos foram:

- Anotações sem informações temporais.

- Anotações não exibidas de forma síncrona com o vídeo.

- Anotações somente automáticas.

- Colaboração com vários usuários utilizando um único dispositivo.

- Trabalhos que não possuem um detalhamento mínimo sobre a colaboração, compartilhamento, adição e exibição das anotações.

Também foram excluídos trabalhos que não estavam disponíveis nas bases de dados, chamadas para trabalhos, capas e trabalhos de autoria da mestranda. Como resultado da primeira seleção, foram identificados 54 artigos para o estágio de seleção final que consistiu na aplicação dos critérios de inclusão e exclusão após a leitura integral dos trabalhos. Entre os 54 candidatos, apenas

\footnotetext{
${ }^{1}$ http://dl.acm.org/

${ }^{2} \mathrm{http}: / /$ ieeexplore.ieee.org/Xplore/

${ }^{3} \mathrm{http}: / /$ link.springer.com/
} 
17 estavam de acordo com todos os critérios estabelecidos e foram incluídos na fase de análise. Para seleção dos trabalhos, também foi realizada a análise das referências relacionadas. A exploração das referências adicionou sete artigos à lista, destes, dois foram adicionados ao resultado final. Deste modo, 19 artigos fizeram parte da etapa de análise. A Tabela 3.1 apresenta a contagem de trabalhos envolvidos nas diferentes etapas do mapeamento sistemático. No caso da biblioteca da Springer Link, a busca sistemática não pôde ser reproduzida na fase de atualização (maio de 2014) devido a uma modificação recente no website que não permitiu definir buscas em títulos e resumos. Por este motivo, apenas para a Springer Link, foi feita uma revisão informal na fase de atualização, o que resultou na seleção de dois trabalhos listados em “Springer Link 2014*”.

Tabela 3.1: Número de trabalhos em cada estágio da revisão sistemática.

\begin{tabular}{|l|c|c|c|}
\hline Fontes & Total & Preliminar & Final \\
\hline \hline ACM DL & 132 & 24 & 5 \\
IEEE Xplore DL & 100 & 17 & 8 \\
Springer Link & 37 & 11 & 2 \\
Springer Link 2014* & 2 & 2 & 2 \\
Referências & 7 & 4 & 2 \\
\hline Soma & 278 & 58 & 19 \\
\hline
\end{tabular}

O método para extrair as informações consistiu em classificar as ferramentas apresentadas nos trabalhos selecionados de acordo com categorias definidas e listar seus diferenciais. Além disso foram gerados resumos dos trabalhos. As informações extraídas criaram uma base para a realização de uma análise crítica dos trabalhos. As categorias utilizadas na classificação foram definidas a partir de características consideradas pertinentes e identificadas durante a análise dos trabalhos na área. As categorias criadas e os possiveis valores encontrados foram:

- Tipo de colaboração: síncrona e assíncrona.

- Plataforma: web, desktop, tablet PC, celulares, TV digital (DTV) e dispositivos móveis atuais (Android). Um dos trabalhos [Pimentel et al., 2010] possui uma combinação de DTV para reprodução e celulares para entrada.

- Tipo de anotação: texto, tinta digital (neste caso, qualquer tipo de anotação gráfica, inclusive contornos), áudio, hyperlink, imagem, vídeo, arquivos, vocabulário controlado, comandos de controle (e.g., laço, salto), entradas numéricas e HTML.

- Formato de anotações: XML, semântica (RDF e OWL), SMIL, MPEG-7, JPEG, HTML e NCL. 
- Avaliação: informal (baseada em feedback), questionários, desempenho do sistema, desempenho da usabilidade, teste de usabilidade, avaliação heurística, percurso cognitivo, opinião de especialista, entrevistas, grupos foco e análise de log.

- Navegação por anotações: marcações na linha do tempo, estrutura em árvore, pré-visualização de anotações (texto ou tinta), lista de pontos anotados e busca textual.

\subsubsection{Discussão}

Entre os 19 trabalhos selecionados alguns descrevem uma mesma ferramenta em diferentes estágios, resultando em 16 ferramentas originais no total. As Tabelas 3.2, 3.3, 3.4 e 3.5 exibem os trabalhos e suas informações nas categorias definidas. Artigos que tratam de uma mesma ferramenta em diferentes estágios de desenvolvimento foram agrupados e as características listadas são relativas às suas versões mais recentes, como é o caso da ferramenta DiVA [Grunewaldt et al., 2006; Morisse e Sempf, 2005] e CWaCTool [Fagá et al., 2010; Motti et al., 2009].

Tabela 3.2: Classificação dos trabalhos: plataforma.

\begin{tabular}{|c|c|c|}
\hline Referências & Ferramenta & Plataforma \\
\hline Bargeron et al. [2001] & MRAS & Web \\
\hline Schroeter et al. [2004] & FilmEd & Desktop \\
\hline Zhai et al. [2005] & eSports & Web \\
\hline Grunewaldt et al. [2006]; Morisse e Sempf [2005] & DiVA & Desktop \\
\hline Schroeter et al. [2006] & Vannotea & Desktop \\
\hline Ferretti et al. [2007] & Sem nome (1) & Web \\
\hline Cattelan et al. [2008] & WaCTool & Tablet PC \\
\hline Wong e Reimann [2009] & EVA & Web \\
\hline Fagá et al. [2010]; Motti et al. [2009] & CWaCTool & Desktop \\
\hline Hosack $[2010]$ & VideoANT & Web \\
\hline Pimentel et al. [2010] & Match the Master & DTV com dispositivos móveis \\
\hline Singh et al. [2011] & The Choreographer's Notebook & Web \\
\hline Grassi et al. [2012] & SemTube & Web \\
\hline Huang e Fox [2012] & Sem nome (2) & Android/Desktop \\
\hline Kopf et al. [2012] & Hypervideo & Web \\
\hline Zhang et al. [2013] & Sem nome (3) & Tablet PC \\
\hline Cross et al. [2014] & VidWiki & Web \\
\hline
\end{tabular}

Entre os 19 trabalhos, 17 possuem texto como fonte de anotação. Observase que existe um esforço em permitir outras formas de entrada sendo a tinta eletrônica a alternativa utilizada por oito ferramentas. Anotações em áudio não se mostraram comuns, sendo um diferencial das ferramentas WaCTool e CWaCTool [Cattelan et al., 2008; Fagá et al., 2010; Motti et al., 2009]. Em termos de navegação, são vários os trabalhos [Bargeron et al., 2001; Cross et al., 2014; Grassi et al., 2012; Grunewaldt et al., 2006; Huang e Fox, 2012; Kopf et al., 
Tabela 3.3: Classificação dos trabalhos: tipo de anotação e formato.

\begin{tabular}{|l|c|c|}
\hline Ferramenta & Tipo & Formato \\
\hline \hline MRAS & Texto & Semântica \\
\hline FilmEd & Texto e vocabulário controlado & JPEG \\
\hline eSports & Texto e tinta & SPEG-7 \\
\hline DiVA & Texto e tinta & SMIL \\
\hline Vannotea & Texto & NCL e SMIL \\
\hline Ferretti et al. & Texto, hyperlinks, arquivos e vocabulário controlado & HTML \\
\hline WaCTool & Texto, áudio, tinta e comandos de controle & XML \\
\hline EVA & Texto, áudio e tinta & NCL \\
\hline CWaCTool & Texto & XML \\
\hline VideoANT & Valores numéricos & Semântica \\
\hline Match the Master & Texto, tinta e vídeo & XML \\
\hline The Choreographer's Notebook & Texto e vocabulário controlado & - \\
\hline SemTube & Texto e tinta & XML \\
\hline Huang e Fox & Texto, hyperlinks, imagem e vídeo & NCL \\
\hline Hypervideo & Tinta & \\
\hline Zhang et al. & Texto, tinta e imagem & \\
\hline VidWiki & & SML \\
\hline
\end{tabular}

Tabela 3.4: Classificação dos trabalhos: colaboração e navegação.

\begin{tabular}{|l|c|c|}
\hline Ferramenta & Colaboração & Navegação \\
\hline \hline MRAS & Assíncrona & Pré-visualização do texto \\
\hline FilmEd & Síncrona & Nenhuma \\
\hline eSports & Síncrona & Nenhuma \\
\hline DiVA & Síncrona & Pré-visualização do texto \\
\hline Vannotea & Síncrona & Marcações na linha do tempo \\
\hline Ferretti et al. & Assíncrona & Nenhuma \\
\hline WaCTool & Assíncrona & Nenhuma \\
\hline EVA & Síncrona & Lista de pontos anotados \\
\hline CWaCTool & Síncrona & Nenhuma \\
\hline VideoANT & Assíncrona & Nenhuma \\
\hline Match the Master & Assíncrona & Busca textual \\
\hline The Choreographer's Notebook & Síncrona & Pré-visualização do texto e marcac̃os na linha do tempo \\
\hline SemTube & Síncrona & Pré-visualização do texto \\
\hline Huang e Fox & Síncrona & Estrutura em árvore \\
\hline Hypervideo & Síncrona & Pré-visualização da tina \\
\hline Zhang et al. & Síncrona & Pré-visualização do texto \\
\hline VidWiki & Assíncrona & \\
\hline
\end{tabular}


Tabela 3.5: Classificação dos trabalhos: avaliação.

\begin{tabular}{|l|c|}
\hline Ferramenta & Avaliação \\
\hline \hline MRAS & Questionários \\
\hline FilmEd & Sem avaliação \\
\hline eSports & Sem avaliação \\
\hline DiVA & Sem avaliação \\
\hline Vannotea & Informal \\
\hline Ferretti et al. & Desempenho do sistema \\
\hline WaCTool & Teste de usabilidade, heurística e opinião de especialista \\
\hline EVA & Questionários e percurso cognitivo \\
\hline CWaCTool & Sem avaliação \\
\hline VideoANT & Sem avaliação \\
\hline Match the Master & Teste de usabilidade \\
\hline The Choreographer's Notebook & Desempenho do sistema \\
\hline SemTube & Questionários \\
\hline Huang e Fox & Questionários e desempenho da usabilidade \\
\hline Hypervideo & Questionários e desempenho da usabilidade \\
\hline Zhang et al. & \\
\hline VidWiki & \\
\hline
\end{tabular}

2012; Morisse e Sempf, 2005; Schroeter et al., 2006; Singh et al., 2011; Wong e Reimann, 2009; Zhang et al., 2013] que se preocupam em permitir que os usuários naveguem pelas anotações realizadas. São utilizadas diferentes soluções, como através de marcação de pontos na linha do tempo [Schroeter et al., 2006; Singh et al., 2011], pré-visualização da anotação [Bargeron et al., 2001; Grunewaldt et al., 2006; Morisse e Sempf, 2005; Singh et al., 2011; Zhang et al., 2013], buscas por conteúdo [Grassi et al., 2012] ou por meio de uma estrutura de navegação em árvore [Kopf et al., 2012].

Alguns trabalhos [Grunewaldt et al., 2006; Schroeter et al., 2006, 2004] se preocupam em utilizar web semântica, ontologias e padrões de documentos de anotação disponíveis para permitir interoperabilidade da ferramenta. Porém nota-se que ainda não existe um consenso sobre qual padrão utilizar e esforços em criar novos padrões ainda persistem [Grassi et al., 2012]. A análise indica que os padrões atuais ainda não são robustos ou adequados o suficiente para serem utilizados nos diferentes cenários propostos por cada ferramenta.

Nota-se uma tendência à criação de ambientes colaborativos síncronos, pois 11 dos trabalhos escolheram essa abordagem. Em vários cenários a colaboração síncrona é desejada, porém a interação assíncrona entre os usuários é essencial para possibilitar flexibilidade de uso do sistema e permitir que o vídeo também seja anotado individualmente. Em casos em que existe um papel de moderador, como na ferramenta eSports [Zhai et al., 2005], os autores não deixam claro 
se é possivel que os usuários realizem suas anotações assincronamente sem a presença de um moderador. Além disso, apesar de reportarem suporte à colaboração síncrona, alguns autores não detalham como o processo de colaboração é realizado, deixando espaço para supor possíveis limitações. Os autores da ferramenta The Choreographer's Notebook [Singh et al., 2011], por exemplo, declaram que a colaboração síncrona do sistema é mínima, mas não esclarecem quais são as limitações associadas.

São diversos os diferenciais de cada ferramenta, variando muito com os prérequisitos definidos nos trabalhos. Kopf et al. [2012] propõem uma ferramenta integrada ao Facebook que permite realizar anotações em objetos do vídeo, possuindo de um sistema de rastreamento de objetos. A ferramenta DiVA [Grunewaldt et al., 2006; Morisse e Sempf, 2005] realiza segmentação automática do vídeo e, utilizando meta-dados, reconhece objetos em vídeos modelados em computador. A ferramenta SemTube [Grassi et al., 2012] utiliza um conceito de "caderno" (notebook) para facilitar a colaboração. A funcionalidade adicional mais popular é o mensageiro instantâneo [Cattelan et al., 2008; Fagá et al., 2010; Motti et al., 2009; Schroeter et al., 2006; Zhai et al., 2005].

Apesar do atual crescimento do uso de smartphones e tablets que possuem alto desempenho e recursos que permitem multimodalidade, observa-se que a maior parte dos trabalhos ainda não explora o uso destes dispositivos. Entre os trabalhos, oito são desenvolvidos para plataforma web, porém não há preocupação com portabilidade, tanto em termos de tecnologia como de leiaute, para acesso em dispositivos móveis. A ferramenta Match the Master [Pimentel et al., 2010] utiliza celulares, mas a interface neste caso é extremamente limitada, permitindo apenas que o usuário pressione as teclas numéricas dos dispositivos, sendo que a reprodução, tanto do vídeo quanto das anotações, é feita exclusivamente em TV. Zhang et al. [2013] propõem uma ferramenta para tablet PC que permite anotações síncronas com tinta digital. A aplicação permite que o usuário pule para o instante da anotação assim que ela é recebida de outro colaborador. Interações por toque é o foco do trabalho, sendo exploradas em anotações e em operações de controle e navegação pelo vídeo. Huang e Fox [2012] apresentam o único trabalho que estuda anotação em vídeo em dispositivos móveis equipados com o sistema Android. A ferramenta desenvolvida permite anotação síncrona de texto e tinta eletrônica em uma transmissão de vídeo. É possível saltar para anotações realizadas por outros clientes e existe integração com a versão desktop da ferramenta. Porém o aplicativo é executado em tablets, não é relatado se o sistema é também adequado para smartphones.

Uma questão não discutida pela maioria dos trabalhos é o tratamento de múltiplas anotações realizadas por usuários distintos em um mesmo instante. 
No caso de anotações que são exibidas de forma síncrona com o vídeo seria importante delimitar o tratamento para este problema. A ferramenta VideoANT [Hosack, 2010], por exemplo, deixa claro que no seu sistema não é possivel ter múltiplas anotações ao mesmo tempo. Se uma anotação for editada ou removida, independente do usuário, dado que a ferramenta não possui autenticação, essa será a ação assumida, sem retorno. Um problema desta abordagem é perder o controle sobre a origem de cada anotação ou modificação. Ressaltando que, mesmo havendo identificação do usuário, é necessário discutir se usuários poderiam editar anotações não originalmente criadas por eles. Ferretti et al. [2007] realizaram o controle de mudanças através de um sistema de wiki. Essa solução tem a desvantagem de permitir apenas uma anotação, de forma similar a legendas, para todos os usuários. A ferramenta Vannotea [Schroeter et al., 2006] exibe as anotações em trilhas coloridas para cada usuário simultaneamente, mas não discute o problema de espaço disponível em tela. Já a ferramenta EVA [Wong e Reimann, 2009] exibe as várias anotações concorrentes ao mesmo tempo em uma página HTML em uma área reservada. Neste caso, é necessário que a maior parte da tela seja dedicada para exibição das anotações.

Em termos de metodologias, no trabalho de Singh et al. [2011] foi realizado um estudo etnográfico minucioso para entender o processo de produção de dança para uma ferramenta de anotação para coreógrafos. Os demais trabalhos utilizaram apenas de revisão da literatura.

Sobre a avaliação dos trabalhos pode-se observar que a utilização de questionários é a forma mais comum, porém seis trabalhos não realizaram avaliação das ferramentas desenvolvidas e dois realizaram avaliações informais com alguma opinião dos usuários apenas. Citam-se as avaliações que merecem destaque. Singh et al. [2011] fizeram uma avaliação ampla para a ferramenta The Choreographers Notebook, utilizando entrevistas com coreógrafos e grupos foco com os dançarinos, além de uma análise de log de utilização para identificar padrões de uso. A avaliação da WaCTool [Cattelan et al., 2008] foi composta por uma avaliação heurística, opinião de um especialista e teste de usabilidade, porém este foi feito com apenas um usuário. Em um trabalho posterior da CWaCTool, Motti et al. [2009] estendeu a avaliação utilizando percurso cognitivo com especialistas e questionários com usuários.

A análise crítica apresentada permitiu perceber as tendências, inovações e deficiências do tema explorado. Nota-se que as avaliações realizadas, quando existentes, são deficitárias e não possuem uma metodologia bem definida em sua maioria. Além disso, observa-se que, apesar de não se tratar de um tópico novo, possuindo trabalhos desde o início de 2001, ainda existem problemas a serem explorados, entre eles, destaca-se a investigação de soluções para a re- 
produção síncrona de anotações multimodais de diferentes usuários e propostas de interfaces adequadas para dispositivos com telas de tamanho limitado.

\subsection{Interactors+WaC-Editor}

Um dos projetos de um aluno de doutorado da orientadora resultou em uma ferramenta web de reprodução e edição de sessões multimídia, a Interactors+WaCEditor (I+WaC-Editor) [Martins, 2014]. A ferramenta I+WaC-Editor é de grande importância neste trabalho pois foi desenvolvido um componente de integração para permitir que as anotações geradas por dispositivos móveis fossem reproduzidos pela ferramenta web que, sendo baseada na tecnologia HTML5, é independente de plataforma. Vários conceitos e funcionalidades da ferramenta surgiram a partir de resultados de pesquisas anteriores. Nesta seção é apresentado um breve histórico da ferramenta, uma descrição de suas atuais funcionalidades e um experimento com usuários em que a autora colaborou.

\subsubsection{A História da Ferramenta I+WaC-Editor}

Dentro do contexto de captura e acesso, muitas vezes é de interesse capturar diversas fontes de mídia, como por exemplo, em uma aula é possível capturar o vídeo do professor, a apresentação de slides e as interações com uma lousa digital. Estas mídias são capturadas separadamente mas podem ser integradas, muitas vezes por meio da geração automática de um documento multimídia, e o resultado desta integração é chamado de sessão multimídia. Em qualquer sessão existem momentos de maior destaque, como eventos específicos ou a exibição de informações de maior importância, e facilitar o acesso a um conteúdo específico pode melhorar não só a velocidade ao acesso da informação desejada, mas também a experiência dos usuários que assistem à sessão. Por exemplo, podemos considerar que a mudança de um slide ou momentos em que o professor escreve na lousa são eventos importantes em uma aula. Abordando este problema foram criados os Interactors, operadores multimídia que permitem gerar, de forma automatizada, índices em uma sessão multimídia para eventos de interação, de forma a permitir a navegação por pontos de interesse em uma sessão [Vega-Oliveros et al., 2011a].

Os Ink-teractors compõem o primeiro conjunto de Interactors. Definidos por Pimentel et al. [2005], estes operadores capturam eventos de interação de canetas em lousas eletrônicas ou outras superfícies adequadas, como PCs do tipo tablet, e geram composições baseados nos traços realizados com caneta. A aplicação dos operadores possibilita a geração de documentos com fragmentos de anotações realizadas com tinta eletrônica, permitindo que os usuários visualizem os passos intermediários resultantes da interação com caneta. Inicialmente 
os fragmentos gerados não eram utilizados como índices para pontos de interesse, mas o trabalho de Martins et al. [2011] apresenta uma solução em que é possível navegar por uma sessão por meio da interação com linhas do tempo, geradas automaticamente, que possuem marcações que permitem que o usuário salte para pontos de interesse. O trabalho foi expandido para capturar interações feitas com áudio, texto, vídeo e outras ações em superfícies interativas [Vega-Oliveros et al., 2011a] e, para melhorar o processo de interação com os pontos de interesse, foi desenvolvido um sistema de visualização baseado em combinações lógicas de operadores [Vega-Oliveros et al., 2011b].

Mais especificamente na fase de acesso, ou seja, a fase em que usuários assistem um vídeo ou sessão multimídia, uma atividade muito comum é a realização de comentários. Enquanto assistem vídeos em seu tempo de lazer, é comum pessoas realizarem comentários e discutirem o conteúdo com seus amigos e familiares. Em sistemas como o YouTube este comportamento fica ainda mais claro. Em casos mais específicos, como em revisão de vídeos educacionais, tutoriais ou gravações relacionados a alguma pesquisa ou trabalho, anotações auxiliam no processo de revisão e enriquecem o conteúdo por meio da adição de ideias e opiniões. A Watch and Comment (WaCTool), desenvolvida por Cattelan et al. [2008], é uma ferramenta de autoria multimídia que explora a prática de realizar comentários e anotações durante a reprodução de um vídeo. A ferramenta foi inicialmente desenvolvida para tv digital e permitia anotações multimodais (voz, texto e tinta eletrônica) e anotações baseadas em comandos de controle (pause, laço, salto, etc). Outra funcionalidade da ferramenta WaC era a colaboração através de chat e compartilhamento assíncrono das anotações criadas. Posteriormente a ferramenta foi modificada para a plataforma desktop e para permitir anotações síncronas, esta nova versão foi nomeada CWaCTool [Fagá et al., 2010].

As soluções desenvolvidas nos trabalhos anteriores dos operadores Interactors e da ferramenta de autoria WaC foram integradas por Martins [2014] em uma ferramenta web para edição, enriquecimento e compartilhamento de documentos multimídia, a I+WaC-Editor (Interactors + Watch and Comment Editor). O sistema possui a funcionalidade de navegação por índices gerados de forma automática, durante a fase de captura, e também por índices criados manualmente pelos usuários, em forma de anotações, durante a fase de acesso, expandindo o trabalho dos operadores Interactors para um cenário de autoria por parte do usuário. Em termos de autoria, o sistema permite a adição de anotações textuais e anotações na forma de comandos de controle (e.g., pausa e laço). Um grande diferencial da ferramenta I+WaC-Editor é a possibilidade de impor- 


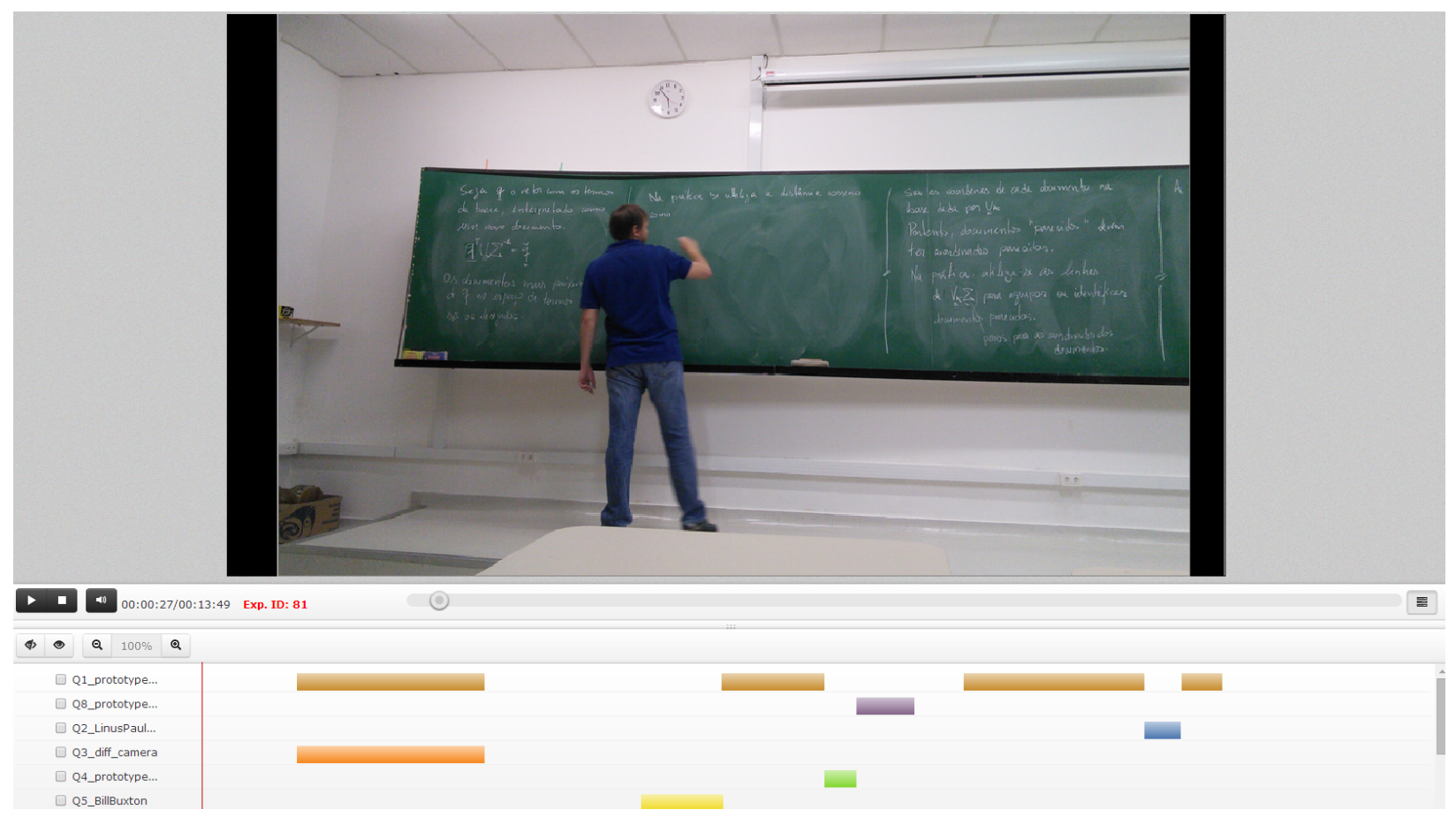

Figura 3.1: Exemplo da interface da ferramenta $I+W a C$-Editor em funcionamento.

tação de sessões dos sistemas BigBlueButton ${ }^{4}$, Matterhorn ${ }^{5}$ e DiGaE [Moraes et al., 2010]. A ferramenta recebe um documento de intercâmbio gerado pelo sistema original e converte em um documento de integração no formato $\mathrm{JSON}^{6}$. A ferramenta também recebe vídeos hospedados na web como entrada. Neste caso é necessário receber apenas a URL do vídeo como entrada que o sistema irá se encarregar de gerar automaticamente o documento de integração com os metadados e de recuperar o vídeo remotamente para reprodução.

A Figura 3.1 mostra a interface da I+WaC-Editor em funcionamento. O vídeo é reproduzido na parte superior da tela enquanto a linha do tempo de anotações é exibida abaixo. A I+WaC-Editor foi desenvolvida em HTML5, o que a torna independente de plataforma, podendo ser executada inclusive em dispositivos móveis. No entanto sua interface não foi desenhada para ser adequada a estes dispositivos.

\subsubsection{Colaboração em um Experimento com a Ferramenta I+WaC-Editor}

No contexto da ferramenta I+WaC-Editor foi realizada uma avaliação sobre o tema de anotações em vídeo. Este experimento em particular teve a colaboração da aluna nas etapas de planejamento, execução e análise. O objetivo do experimento foi investigar se o uso de anotações em vídeos educativos podem melhorar o desempenho de alunos, considerando pontuação (notas) e tempo de execução,

\footnotetext{
${ }^{4}$ http://bigbluebutton.org/

${ }^{5}$ http://opencast.org/matterhorn/

${ }^{6}$ http://json.org/
} 
e sua experiência, em termos de facilidade, esforço e performance percebida, na execução de uma tarefa específica.

\subsubsection{Planejamento e Execução}

Neste experimento, os vídeos escolhidos seguem o modelo de uma aula tradicional com exposição de conteúdo por um professor utilizando um conjunto de slides. Este tipo de vídeo é muito comum em cursos online oferecidos por universidades através de portais como o Coursera ${ }^{7}$ e o edX ${ }^{8}$. As anotações utilizadas consistem em marcações de pontos de interesse no vídeo, mais especificamente, momentos em que o professor realiza uma mudança de slide da sua apresentação. Um fato interessante sobre este tipo de anotação é a possibilidade de identificação automática de momentos de mudança de slides, o que pode ser investigado por meio de técnicas de segmentação de vídeo.

A tarefa escolhida foi a resolução de exercícios baseados na aula apresentada pelo vídeo. Esta tarefa foi escolhida pois facilita a comparação dos resultados obtidos. O grupo alvo do experimento foram alunos de graduação. O experimento foi realizado em laboratório utilizando computadores desktop. A ferramenta I+WaC-Editor foi utilizada com plataforma de execução do experimento devido a suas funcionalidade de anotação e navegação.

Os vídeos foram selecionados de acordo com o grupo de participantes, que neste caso eram alunos de computação que estavam cursando a disciplina de Interação Usuário-Computador. Assim foram selecionados dois vídeos do curso de Human-Computer Interaction, ministrado pelo Dr. Scott Klemmer da Stanford University, disponibilizados na plataforma Coursera ${ }^{9}$. Foram escolhidos os vídeos The Power of Prototyping e Evaluating Designs, temas que os alunos já haviam estudado, garantindo que o contato análogo com o assunto. Para cada vídeo foram criadas oito questões abertas sobre o seu conteúdo. A ferramenta utilizada para a tarefa de resolução das questões foi a plataforma de ensino Tidia-Ae ${ }^{10}$, utilizada pelos alunos durante a disciplina.

Os participantes foram divididos em dois grupos por meio de sorteio. O experimento foi planejado da seguinte forma:

- Antes da tarefa todos os participantes assistem ao vídeo juntos.

- Durante a tarefa os dois grupos têm acesso ao vídeo, porém em duas condições diferentes: com anotações e sem anotações.

\footnotetext{
${ }^{7}$ https://www.coursera.org

${ }^{8}$ https://www.edx.org

${ }^{9}$ https://class.coursera.org/hci/lecture

${ }^{10}$ http://www.tidia-ae.usp.br
} 
O processo é repetido para o segundo vídeo, porém a condição é invertida, sendo que o grupo que utilizou anotações no primeiro vídeo deve utilizar a versão sem anotações durante a segunda tarefa e o grupo sem anotações na primeira tarefa terá acesso às mesmas na segunda.

Ao final do experimento os participantes tinham de responder um questionário sobre a sua experiência avaliada em três dimensões: esforço, facilidade, e performance percebida. O questionário continha seis questões do tipo Likert, com escala variando de 1 a 7 , sendo duas questões para cada dimensão medida.

Antes da execução do experimento foram realizados testes pilotos com dois alunos voluntários da pós-graduação com o objetivo de identificar problemas de execução. A execução real do experimentou contou com 20 alunos. A participação no experimento foi voluntária e os alunos não receberam pagamento em dinheiro. Porém, como incentivo, as notas obtidas nas tarefas poderiam contribuir com a melhoria da nota do aluno na disciplina, caso este desejasse.

O experimento seguiu o seguinte protocolo de execução:

- Explicação do experimento aos participantes.

- Assinatura do termo de consentimento.

- Sorteio dos grupos (Grupo A e Grupo B).

- Introdução da ferramenta I+WaC-Editor e demonstração de uso.

- Todos os participantes assistem ao vídeo The Power of Prototyping no projetor.

- Cada um assiste ao vídeo The Power of Prototyping individualmente utilizando a ferramenta e, ao mesmo tempo, responde uma série de exercícios no Tidia-Ae. O Grupo A não tem acesso às anotações enquanto o Grupo B pode visualizá-las.

- Todos os participantes assistem ao vídeo Evaluating Designs no projetor.

- Cada um assiste ao vídeo Evaluating Designs individualmente utilizando a ferramenta e, ao mesmo tempo, responde uma série de exercícios no TidiaAe. O Grupo B não tem acesso às anotações enquanto o Grupo A pode visualizá-las.

- No final, todos os participantes respondem um questionário sobre sua experiência.

\subsubsection{Análise}

A análise de desempenho dos participantes foi baseada apenas nos resultados do primeiro vídeo, ou seja, foi comparado o desempenho com anotações e sem anotações entre os participantes, configurando um design entre sujeitos (between subjects). Esta estratégia de análise foi escolhida pois a execução do método 
ANOVA misto mostrou que o vídeo foi o fator de maior influência no desempenho. Além disso, a segunda parte do experimento foi afetada porque houve desistência de alguns participantes. Assim, apenas os resultados do primeiro vídeo foram considerados na análise de pontuação e tempo de execução.

Os dados relativos ao tempo apresentaram normalidade dos resíduos e igualdade das variâncias. Foi aplicado um teste t de comparação de duas médias e os resultados obtidos apontaram que não houve diferença significativa para as médias do tempo $(\mathrm{t}(18)=-0.97, \mathrm{p}=.34)$.

Os dados para pontuação não apresentaram igualdade das variâncias, por este motivo foi necessário aplicar um teste $t$ de comparação com correção de Welch [Welch, 1947]. Inicialmente não foi possivel constatar uma diferença significativa entre as médias $(\mathrm{p}=.66)$, porém a análise da pontuação identificou dois dados discrepantes que foram removidos. Mesmo após a exclusão dos dados discrepantes os dados não apresentaram igualdade das variâncias e novamente foi aplicado o teste de Welch. Os resultados do teste apontaram que existe uma diferença significativa entre as médias de notas $(\mathrm{p}=.035)$, sendo que alunos que utilizaram a ferramenta com anotações tiveram uma média maior (7,5 contra 7,1$)$. Contudo, como foi realizada a exclusão de duas notas, a análise foi prejudicada. Assim é fundamental a execução de mais experimentos para que seja possível confirmar que o uso de anotações pode auxiliar a melhorar o desempenho nessa tarefa específica.

Para os resultados do questionário de avaliação da experiência do usuário foi calculado o coeficiente de confiabilidade para as dimensões medidas. O cálculo do alfa de Cronbach constatou que os itens possuem alta confiabilidade, com valores acima de 0.7. Os valores para performance percebida, facilidade e esforço resultaram em 0.93, 0.77 e 0.62. No caso do esforço, o valor baixo ocorreu devido a uma resposta inconsistente de um participante, que atribuiu os valores 6 e 2 para as questões relacionadas ao esforço (em uma escala de 1 a 7). Isto pode ter ocorrido devido a uma distração. Excluindo a resposta deste participante específico o coeficiente de confiabilidade para esforço passa a ser 0.74 .

As notas relativas à experiência foram positivas, sendo que os participantes declararam que quando utilizaram anotações foi mais fácil realizar a tarefa, que um esforço menor foi necessário e que sua performance foi melhor. Entre 1 a 7 , os valores apresentados para menor esforço, facilidade e performance foram 5.5, 5.5 e 5 respectivamente, com valores de desvio padrão baixos. O gráfico com os intervalos de confiança para as médias é apresentado na Figura 3.2.

Neste experimento pode-se observar que participantes declaram uma boa experiência ao utilizar as anotações relativas à mudança de slides em vídeos edu- 


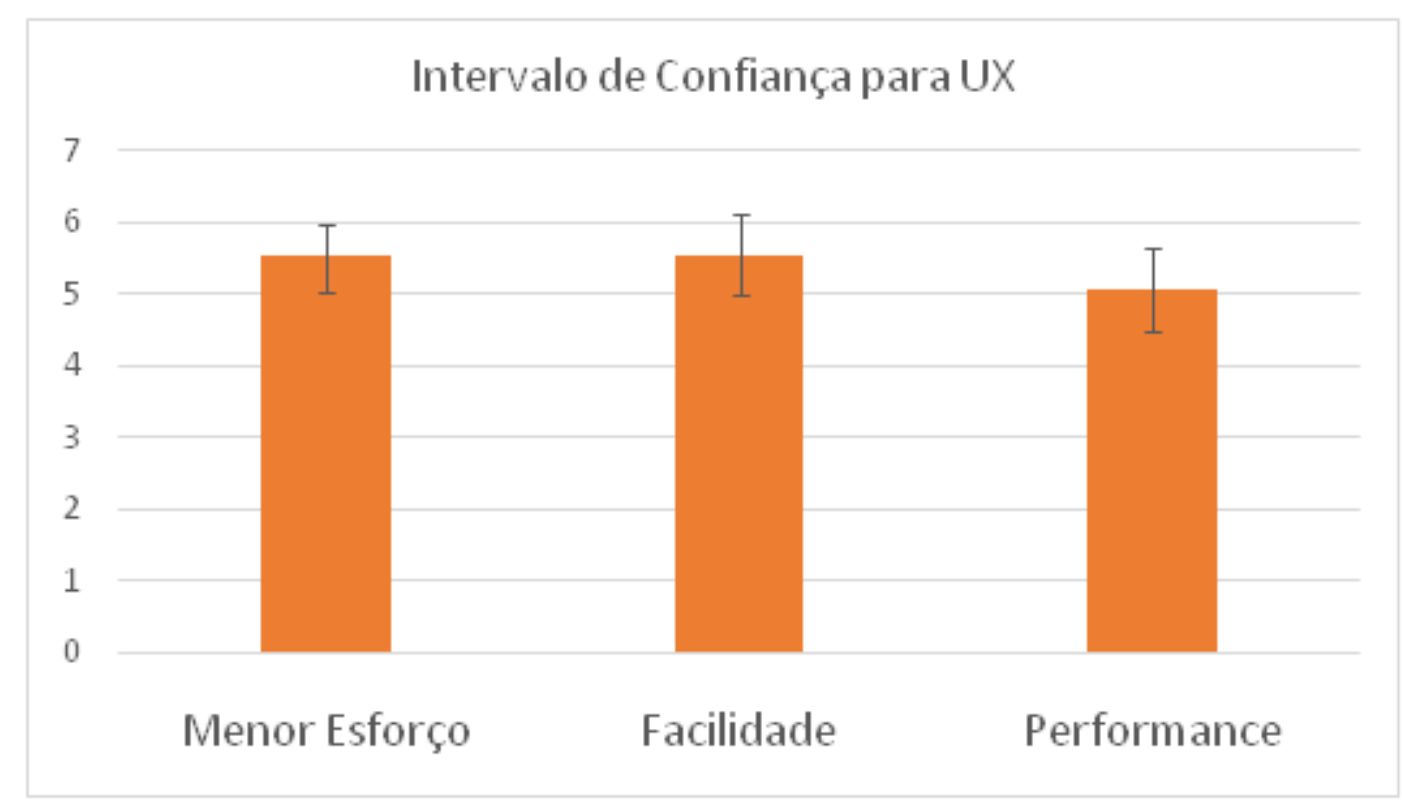

Figura 3.2: Gráfico para medidas de menor esforço, facilidade e performance para anotações

cacionais, porém, com relação ao desempenho, apesar das notas terem sido melhores a avaliação foi limitada de forma que não é possível realizar generalizações. Apesar disso, foi possível observar o potencial deste tipo de anotação nesse cenário. Serão realizados experimentos futuros para que os resultados observados sejam confirmados.

\subsection{Considerações Finais}

Os resultados do mapeamento sistemático sobre o tema de anotações colaborativas em vídeo, juntamente com os objetivos do trabalho, auxiliaram a definir os principais problemas investigados neste trabalho, já descritos na introdução (Seção 1.2). Também foi possivel confirmar tendências que podem ser vistas como requisitos fundamentais para ferramentas de anotação em vídeo, como a multimodalidade e a navegação. Apesar de ter sido identificada uma tendência ao desenvolvimento de soluções que permitem a colaboração síncrona, a solução proposta neste trabalho considera o compartilhamento de anotações para uma colaboração assíncrona. Assim, tendências identificadas pelo mapeamento também justificam oportunidades de trabalhos futuros. Além disso, o mapeamento sistemático confirmou a escassez de trabalhos que envolvem dispositivos móveis no processo de anotação em vídeo que possuam funcionalidades de compartilhamento ou colaboração.

A ferramenta I+WaC-Editor foi desenvolvida com a tecnologia HTML5 sendo independente de plataforma. Os documentos de anotações gerados pela ferramenta desenvolvida neste trabalho podem ser convertidos e executados na ferramenta I+WaC-Editor. Além disso, o experimento realizado com anotações 
em vídeo mostra um potencial do uso de anotações no contexto educacional. Assim, a possibilidade de exibir e realizar anotações em vídeos educacionais via dispositivos móveis se mostra importante. 


\section{Capítulo 4}

\section{MoViA: Uma Ferramenta de Anotação em Vídeo em Dispositivos Móveis}

Os objetivos propostos e os problemas específicos foram investigados por meio do desenvolvimento de uma ferramenta para anotação em vídeo em dispositivos móveis. A ferramenta chamada Mobile Video Annotation Tool (MoViA) é um aplicativo desenvolvido para o sistema Android e é executável em smartphones e tablets. O aplicativo não foi idealizado para um cenário específico, de forma que as soluções desenvolvidas procuram ser adequadas para diferentes contextos da melhor forma possível. As próximas seções reportam os estágios de desenvolvimento da aplicação (Seção 4.1), sua arquitetura (Seção 4.2), suas principais funcionalidades (Seções 4.3 a 4.6) de acordo com os objetivos definidos, identificando os principais desafios e as soluções propostas, e, por fim, os resultados de avaliações realizadas (Seção 4.7).

\subsection{Processo de Desenvolvimento}

O processo de desenvolvimento deste trabalho foi interativo. Os objetivos do trabalho (Seção 1.1) foram determinados por meio de uma revisão da literatura e, com a finalidade de investigá-los, foi concebida a primeira versão do aplicativo. A partir da primeira versão foi possível realizar avaliações com o objetivo de identificar novos requisitos e problemas. Além das avaliações foi realizado um mapeamento sistemático que, juntamente com os objetivos iniciais, auxiliou a definir a lista dos principais problemas a serem investigados, como apresentado na Seção 1.2. Assim, os requisitos aumentarem de acordo com as revisões da literatura e avaliações realizadas. A ferramenta desenvolvida neste trabalho 
passou por quatro estágios e contou com três avaliações. Esta seção descreve os diferentes estágios do aplicativo desenvolvido e os trabalhos realizados para sua concepção e identificação de requisitos.

No primeiro estágio foram trabalhados os problemas de geração de documentos baseados na adição de anotações textuais sobre o vídeo e navegação pelas anotações geradas. Estas funcionalidades podem ser observadas na interface do aplicativo em sua primeira versão, apresentada pela Figura 4.1. A Figura 4.1 (a) mostra a tela de reprodução do vídeo em que pode ser visto o campo para adição de anotações textuais. A Figura 4.1 (b) exibe a tela de navegação que consiste em anotações acompanhadas por miniaturas de imagens capturadas do vídeo. Uma avaliação de usabilidade foi realizada nesta primeira versão do aplicativo. A avaliação e seus resultados são apresentados na Seção 4.7.1.
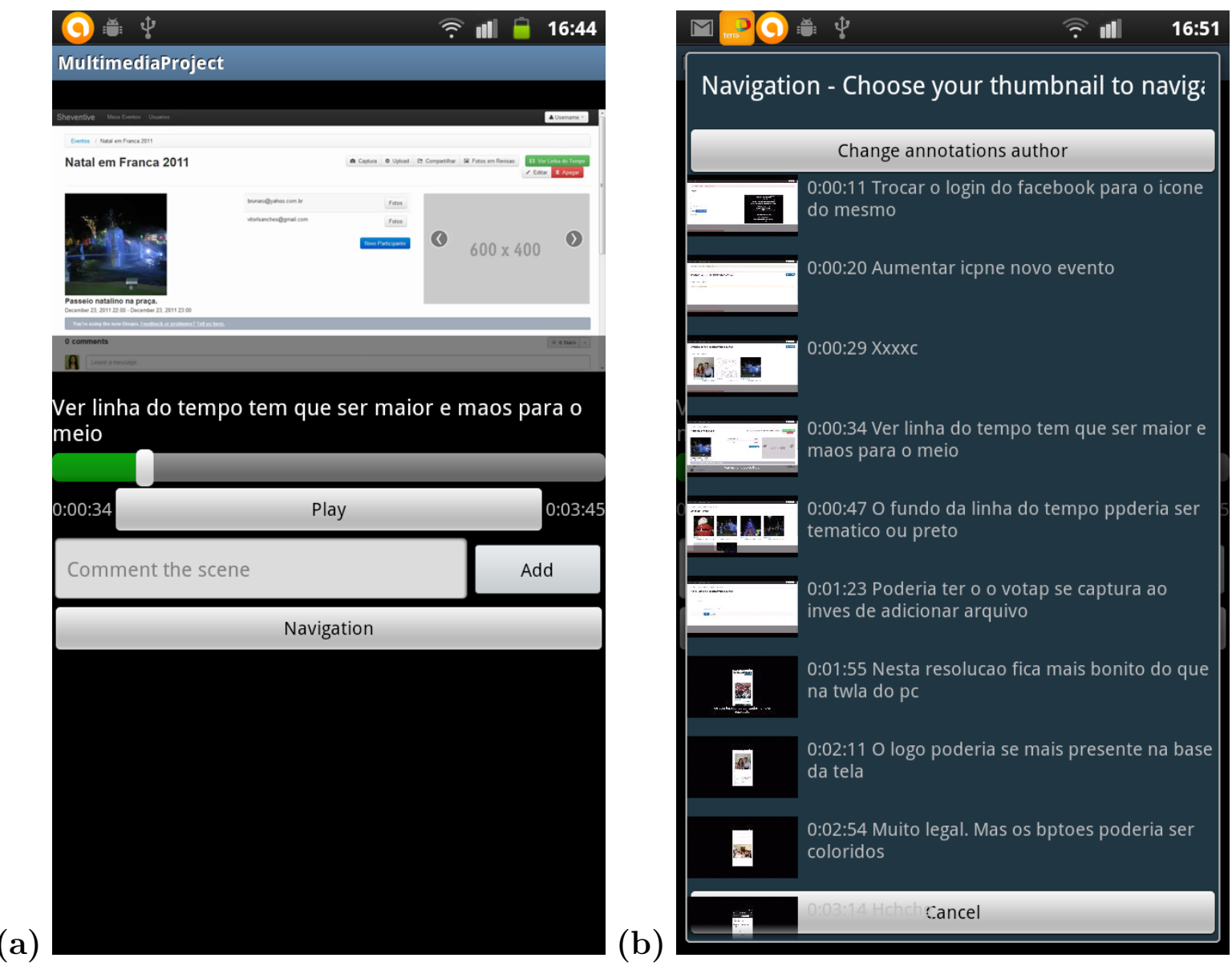

Figura 4.1: Telas do primeiro estágio da ferramenta: (a) Reprodução e anotação e (b) Navegação.

O segundo estágio da ferramenta corrigiu os problemas identificados no teste de usabilidade, descritos em detalhes na Seção 4.7.1, e inclui funcionalidades de multimodalidade, permitindo anotações em áudio e tinta eletrônica, captura de informações de contexto e compartilhamento de anotações textuais. A Figura 4.2 exibe um exemplo da interface no segundo estágio. Esta versão passou por uma 
avaliação heurística com especialistas na área de computação. A Seção 4.7.2 descreve a avaliação e seus resultados.

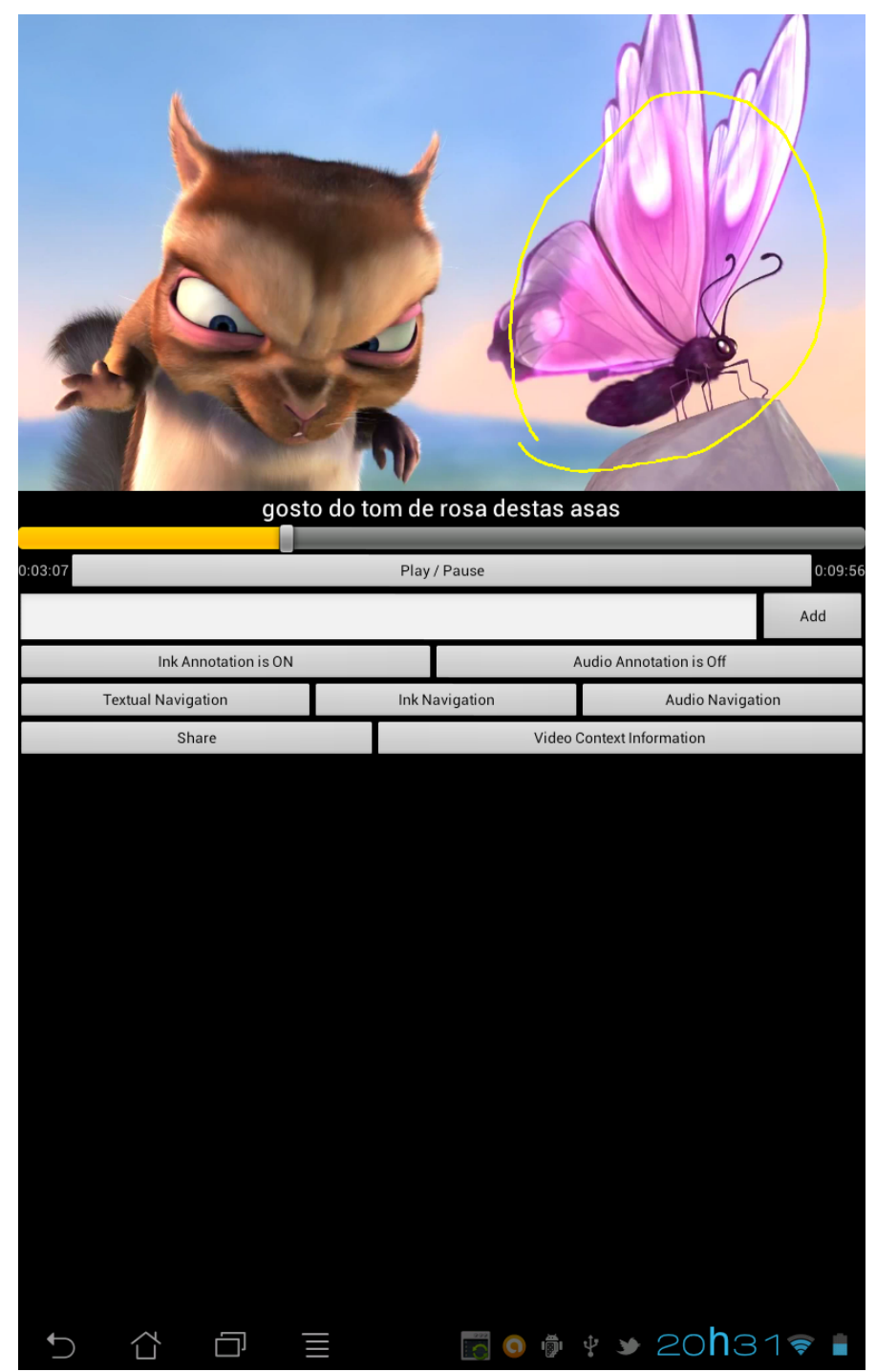

Figura 4.2: Tela de anotação do segundo estágio da ferramenta.

O terceiro estágio da ferramenta se apoiou não apenas no produto da avaliação heurística, mas também em um mapeamento sistemático no tema de anotações colaborativas em vídeo. Além da melhoria do aplicativo por meio da correção de problemas apontados na avaliação, novos problemas foram identificados pelo mapeamento e abordados neste estágio, cita-se a exibição simultânea de múltiplas anotações e a proposta de um leiaute adequado para a exibição de várias anotações textuais simultaneamente. Uma avaliação colaborativa com uma especialista na área de terapia ocupacional foi realizada e esta interação revelou novos requisitos e problemas, sendo que alguns foram implementados, o que deu origem a versão final do aplicativo. A Seção 4.7.3 descreve esta avaliação, assim como os requisitos e problemas identificados, discriminando quais foram contemplados e suas soluções associadas. O terceiro estágio da ferra- 
menta difere da versão final apenas em funcionalidades adicionais e correção de problemas menores, não havendo mudanças na interface. Uma descrição do terceiro estágio do aplicativo foi publicada em um artigo curto [Cunha et al., 2013a]. As próximas seções detalham o estágio final do aplicativo resultante das últimas interações.

\subsection{Arquitetura}

Primeiramente, é apresentada a arquitetura de alto nivel do sistema e as principais soluções utilizadas no desenvolvimento do projeto.

\section{Desafios Especificos}

A decisão arquitetural depende das necessidades do projeto. Para este projeto em particular, era preciso definir uma arquitetura genérica que previsse extensões para aplicações e cenários específicos, de modo que surgiu uma preocupação com sua organização. Houve também uma preocupação com reuso, pois a ferramenta deveria facilitar a implementação das anotações em outros tipos de mídias. Outro problema foi em relação à tecnologia para armazenamento das anotações: é necessária uma solução eficiente em dispositivos móveis em termos de desempenho, espaço de armazenamento, flexibilidade e legibilidade.

\section{Descrição da Solução}

A Figura 4.3 ilustra a arquitetura básica da ferramenta de anotação. O componente de reprodução integrada é responsável pela reprodução, controle do vídeo e integração das funcionalidades de anotação, navegação e captura de informações de contexto. O container de anotações unifica os diferentes tipos de anotações para facilitar o acesso e manipulação. Quando a reprodução do vídeo é iniciada as anotações são carregadas no container, assim qualquer anotação pode ser lida diretamente acessando o container. Um componente de operadores possui métodos de alto nível para realizar operações específicas na aplicação. $O$ pacote de operadores possui três componentes independentes: operadores de autoria, operadores de conteúdo e operadores de contexto. Os operadores de autoria são responsáveis por operações de escrita, remoção, atualização e ativação de anotações. Operadores de conteúdo são responsáveis por retornar os pontos de ocorrência de diferentes tipos de anotações. Os operadores de contexto são responsáveis por prover as informações de contexto capturadas. Essa estrutura facilita a extensão da ferramenta. Em caso de anotações em imagens, por exemplo, o mesmo container de anotação e os mesmos operadores podem ser utilizados. 


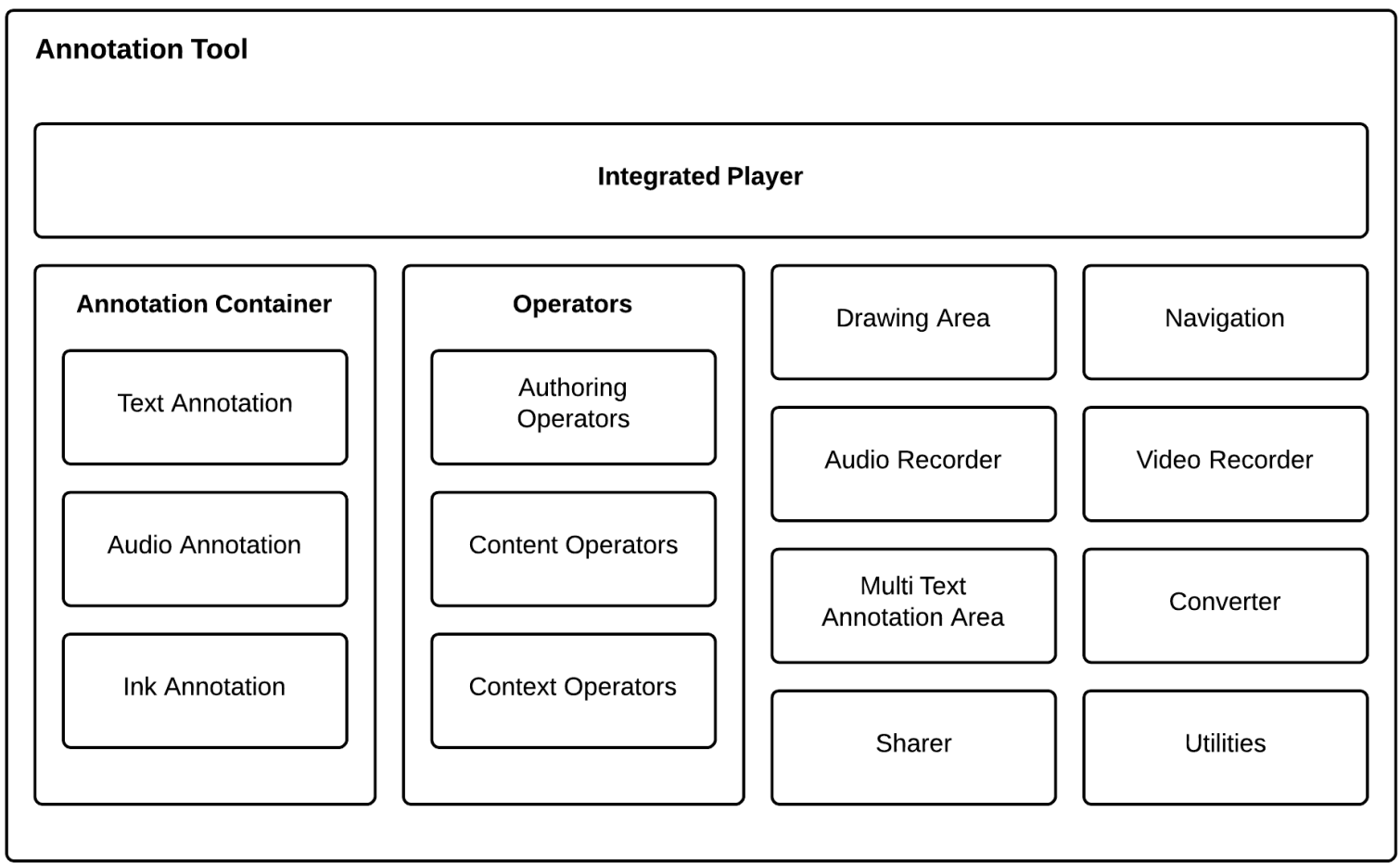

Figura 4.3: Arquitetura da ferramenta de anotação em vídeo desenvolvida.

Os outros componentes independentes são: a área de desenho, a área de múltiplas anotações textuais, o gravador de áudio, o gravador de vídeo, o componente de navegação, o componente de compartilhamento, o conversor de anotações e o pacote de utilitários. A área de desenho é responsável por controlar a adição e exibição de tinta eletrônica. A área para múltiplas anotações textuais é responsável pela exibição simultânea de anotações em texto realizadas por outros usuários. O gravador de áudio é utilizado para a captura de anotações em áudio. O gravador de vídeo é utilizado para captura de vídeo integrada e marcação de pontos de interesse. Tanto o gravador de áudio quanto o de vídeo possuem implementações próprias, não sendo dependentes de outros aplicativos externos à ferramenta. Detalhes relacionados aos componentes de captura e anotação são descritos na Seção 4.3. O componente de navegação é responsável por gerar as telas de navegação de forma automática. As funcionalidades de navegação são detalhadas na Seção 4.5. O componente de compartilhamento permite enviar documentos de anotações e vídeos, enquanto o conversor de anotações gera um novo arquivo de anotações compativel com a ferramenta I+WaCEditor. Detalhes sobre as funções destes dois componentes são descritos na Seção 4.6. Por fim, o pacote de utilitários possui diversas funcionalidades genéricas que podem ser utilizadas por todos os outros pacotes.

Os vídeos capturados e as anotações adicionadas geram arquivos separados. 
Além disso, para cada tipo de anotação (texto, tinta e áudio) é gerado um arquivo de anotação separado. Esta configuração mantém a independência entre as mídias. Deste modo, o vídeo e cada tipo de anotação podem ser compartilhados separadamente. Esta escolha facilita o reuso para outras mídias e a modificação da ferramenta para cenários em que as mídias não são acessadas localmente.

Em termos de tecnologia, para o desenvolvimento do protótipo foram utilizados o Android SDK e as APIs incorporadas. A exceção é a API Simple XML ${ }^{1}$ utilizada para a manipulação de arquivos XML. O formato XML é utilizado para armazenar as anotações e suas informações de contexto. A biblioteca Simple XML realiza o mapeamento de esquemas XML em classes Java e permite a criação de códigos simples e elegantes. Não é necessário realizar o processamento explícito do XML. A Simple XML possui alto desempenho e requer pouco espaço, o que a torna muito adequada para o desenvolvimento em aplicações Android. Apesar do XML ser um formato com desempenho inferior, quando comparado com o formato JSON [Sumaray e Makki, 2012], o formato escolhido garante a legibilidade dos arquivos gerados, qualidade que facilita o processo de desenvolvimento e análise dos documentos.

A Listagem 4.1 exibe um exemplo para anotação em texto e a Listagem 4.2 para tinta eletrônica. Os arquivos de anotação são compostos por um cabeçalho que contém sua data de criação, última data de modificação e o autor original. Após o cabeçalho segue uma lista de anotações, que serão de apenas um tipo (texto, áudio ou tinta), dado que são gerados arquivos separados para cada tipo de anotação. Cada anotação possui obrigatoriamente: o autor da anotação, o tempo de adição real e o tempo relativo de adição no vídeo. Além destes dados, cada tipo de anotação exige outras informações específicas. A anotação em áudio necessita do caminho para o arquivo de áudio gravado, no caso um arquivo .3gp. Para a anotação em texto é necessário o texto adicionado e a duração. Já a anotação em tinha precisa das coordenadas $\mathrm{x}$ e y e do tipo de ação realizada: mover cursor (valor igual a 2) ou desenhar linha (valor igual a 1). Por fim, o arquivo de anotações termina com as informações de contexto do usuário, como apresentado na Listagem 4.3.

$\mathrm{O}$ arquivo de anotações foi modelado de forma a facilitar a conversão para outros modelos e, ao mesmo tempo, poder ser utilizado por outras ferramentas. Assim são incluídas informações não necessariamente obrigatórias para o funcionamento da ferramenta MoViA, como o tempo real de adição da anotação, o usuário responsável pela adição e a possibilidade de múltiplas informações de contexto. O tempo de adição real não é necessário pois é utilizado o tempo relativo ao vídeo. Já a informação de qual usuário adicionou a anotação não é

\footnotetext{
${ }^{1} \mathrm{http}: / /$ simple.sourceforge.net/
} 


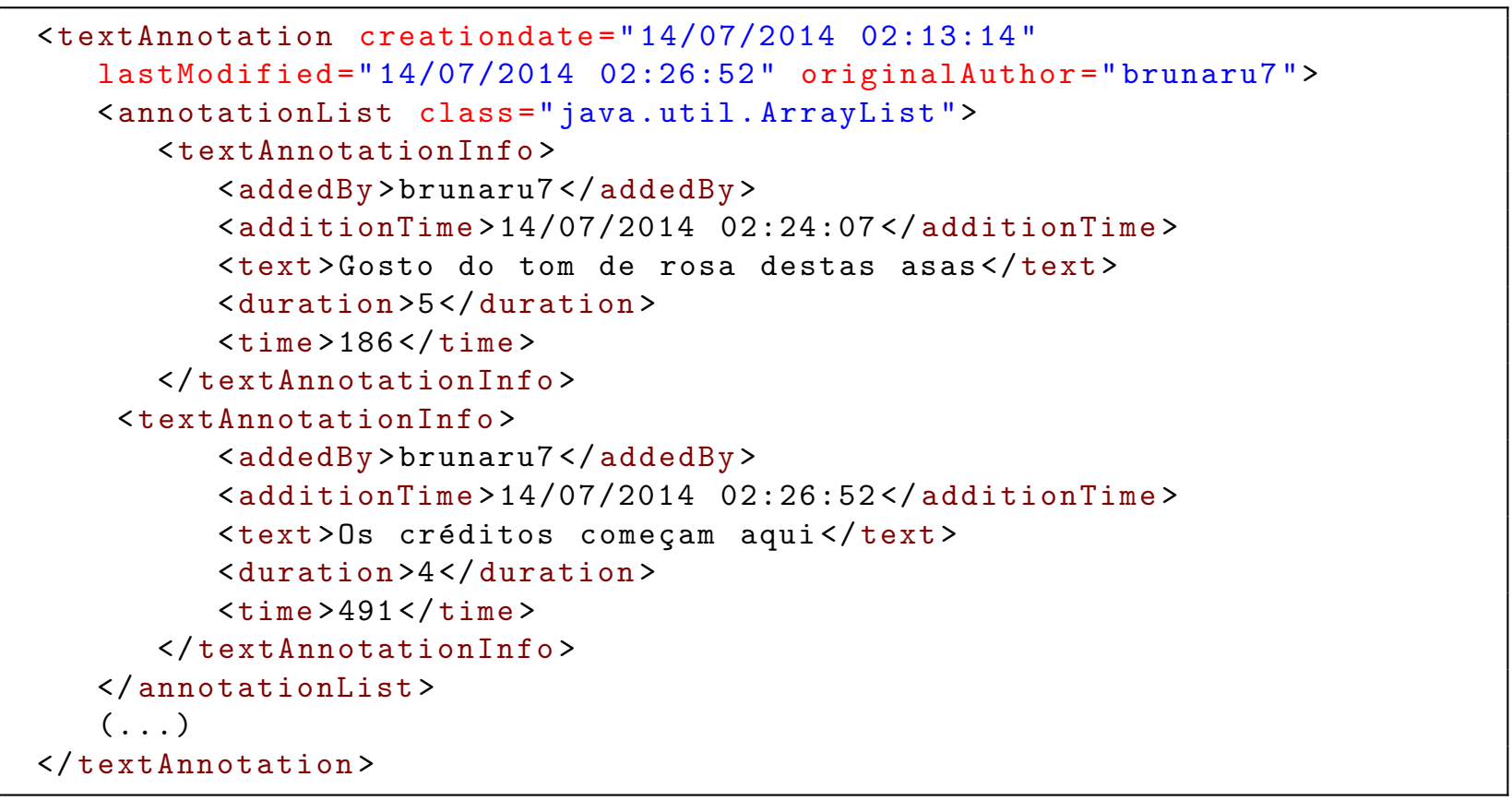

Listagem 4.1: Trecho XML para anotação em texto

necessária pois a ferramenta gera arquivos de anotação para cada usuário e não permite modificação de arquivos criados por outros autores. Esta decisão foi feita não apenas para facilitar a compatibilidade com outras ferramentas, mas também para que o modelo fosse preparado para modificações no sistema de colaboração da aplicação.

\subsection{Anotações e Captura}

No contexto deste trabalho, as interações dos usuários capturadas pelos seus dispositivos móveis durante os processos de gravação ou reprodução do vídeo são anotações. As anotações são realizadas em vídeo e são dependentes do instante de interação com o conteúdo: ao adicionar uma anotação, esta é relacionada ao instante de execução do vídeo. Durante a gravação do vídeo é possível realizar marcações de pontos de interesse. Esses pontos de interesse podem ser posteriormente editados pelo usuário que pode adicionar mais informações. Durante a reprodução do vídeo o sistema permite incluir anotações em texto e, buscando permitir a interação ubíqua com o sistema, foram desenvolvidas formas de captura que são consideradas naturais, como áudio e tinta eletrônica.

\section{Desafios Especificos}

Problemas específicos das funcionalidades de anotação foram identificados no estudo de trabalhos relacionados, em problemas encontrados durante a atividade de design e implementação e também em avaliações (Seção 4.7). Entre os 


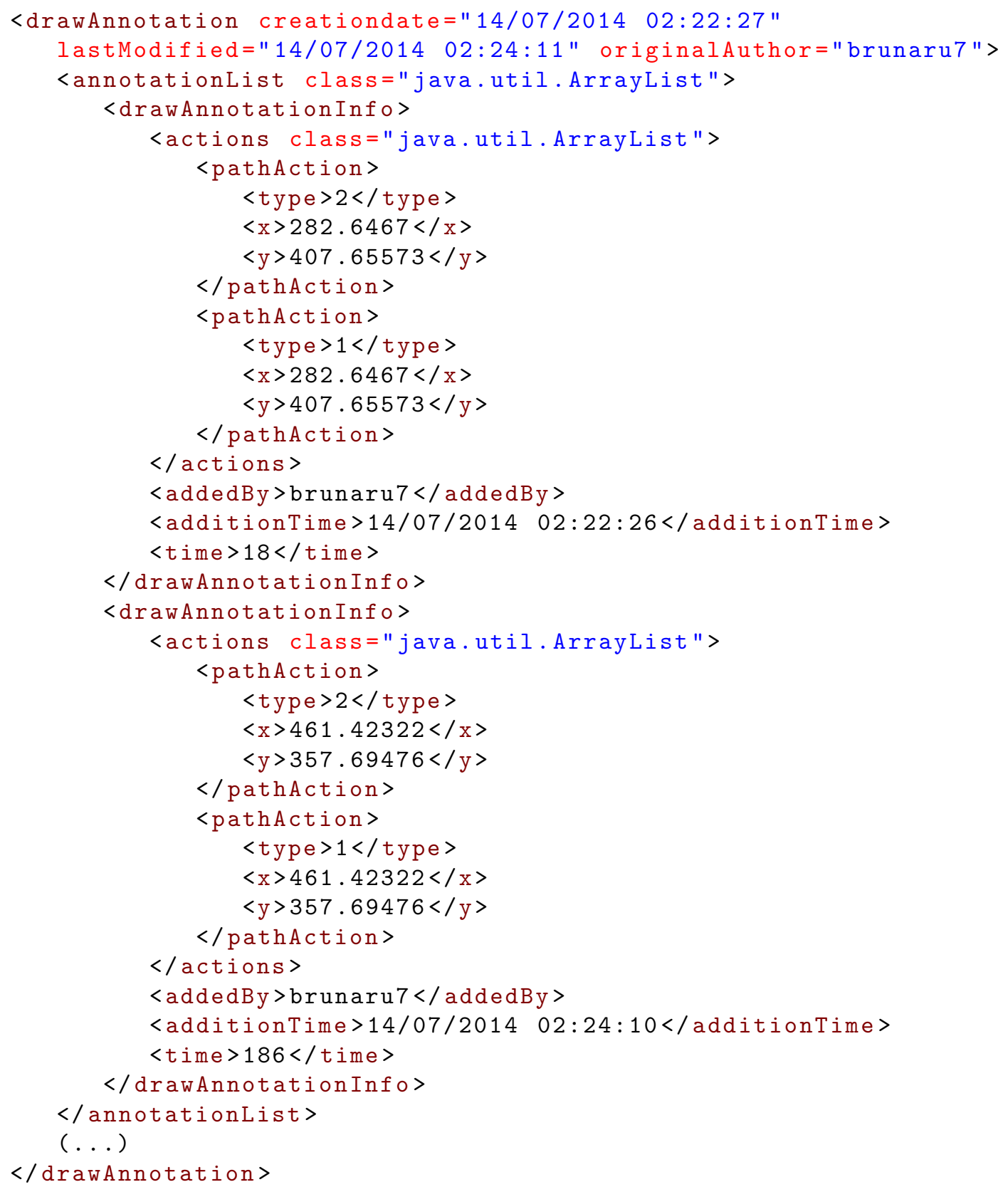

Listagem 4.2: Trecho XML para anotação em tinta eletrônica

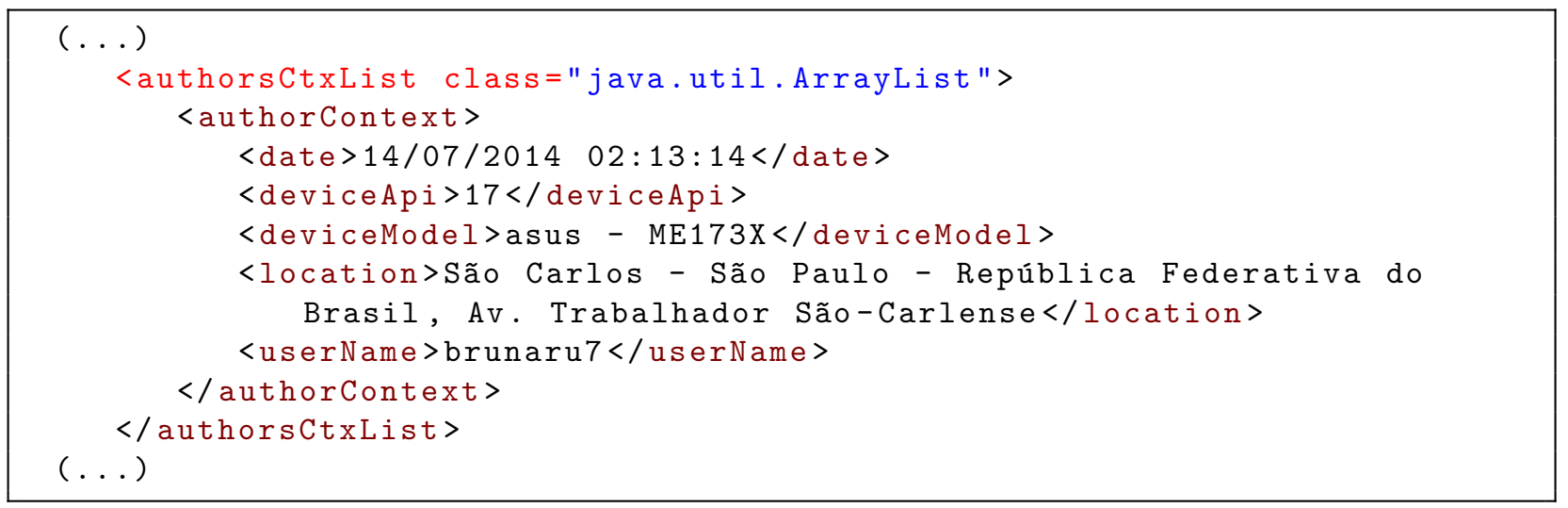

Listagem 4.3: Trecho XML para informações de contexto 
problemas tratados destacam-se:

- Dificuldade de escolha do vídeo por meio do nome do arquivo: este problema foi identificado durante o teste de usabilidade. Apesar de grande parte dos gerenciadores de arquivos para o sistema Android mostrarem apenas o nome do vídeo, este comportamento não é adequado.

- Exibição em diferentes tamanhos de tela: o aplicativo deve ser executável em smartphones e tablets, seu leiaute deve ser adaptável e funcional em diferentes tamanhos de telas.

- Exibição em diferentes posições (vertical e horizontal).

- Região para exibição do teclado virtual.

- Cálculo de proporção para o vídeo.

- Tempo de exibição de anotações textuais: o tempo de exibição deve ser calculado com base no tamanho do texto inserido.

- Controle de adição de anotações em tinta eletrônica.

- Controle de adição de anotações de áudio.

- Exibição de múltiplas anotações ao mesmo tempo (cenário colaborativo): dado que é possível compartilhar anotações e reproduzi-las ao mesmo tempo o sistema deve prover formas de exibir múltiplas anotações ao mesmo tempo.

- Adição de anotações durante a captura do vídeo: durante a gravação do vídeo as ações do usuário são limitadas dado que o dispositivo deve ficar em uma posição fixa pois a movimentação afeta diretamente a qualidade do vídeo.

A próxima parte descreve a ferramenta MoViA no contexto das funcionalidades de captura e exibição de anotações e discute as soluções para os desafios identificados.

\section{Descrição da Solução}

A primeira tela do aplicativo apresenta opções para anotação de um vídeo existente, criação de um novo vídeo e importação de um arquivo de anotações. Após escolher entre gravar um novo vídeo ou anotar um vídeo existente, é apresentada a tela de seleção de usuário. Esta tela lista as contas de usuário Google registradas no dispositivo. A conta de usuário Google é o endereço de correio eletrônico do usuário cadastrado no serviço de e-mail provido pelo Google, o Gmail ${ }^{2}$. O cadastro de uma conta de usuário Google é obrigatório no sistema Android, deste modo sempre existirá pelo menos uma conta cadastrada. A tela de seleção

\footnotetext{
${ }^{2}$ https://mail.google.com/
} 
de usuário do aplicativo MoViA é exibida apenas se existir mais de uma conta Google cadastrada no dispositivo, caso contrário a única conta cadastrada será escolhida automaticamente. O usuário selecionado será registrado como autor das anotações criadas.

Se o usuário optar por anotar um vídeo existente, a tela de escolha do vídeo será exibida, como na Figura 4.4 (a). Miniaturas com a pré-visualização dos vídeos auxiliam na seleção. É possível também trocar o diretório de vídeos caso necessário. Após escolher o vídeo, caso existam anotações criados por outros autores para o vídeo selecionado, é apresentada uma tela para seleção de autores adicionais. A Figura 4.4 (b) mostra tela de seleção de autores adicionais. Caso o usuário queira exibir as anotações destes autores deve marcar suas caixas de seleção. A Seção 4.6 apresenta mais detalhes sobre as funcionalidades relacionadas à colaboração. Em seguida o aplicativo pergunta ao usuário se deseja manter ligadas as anotações feitas em áudio. Por fim, a tela de reprodução é iniciada.
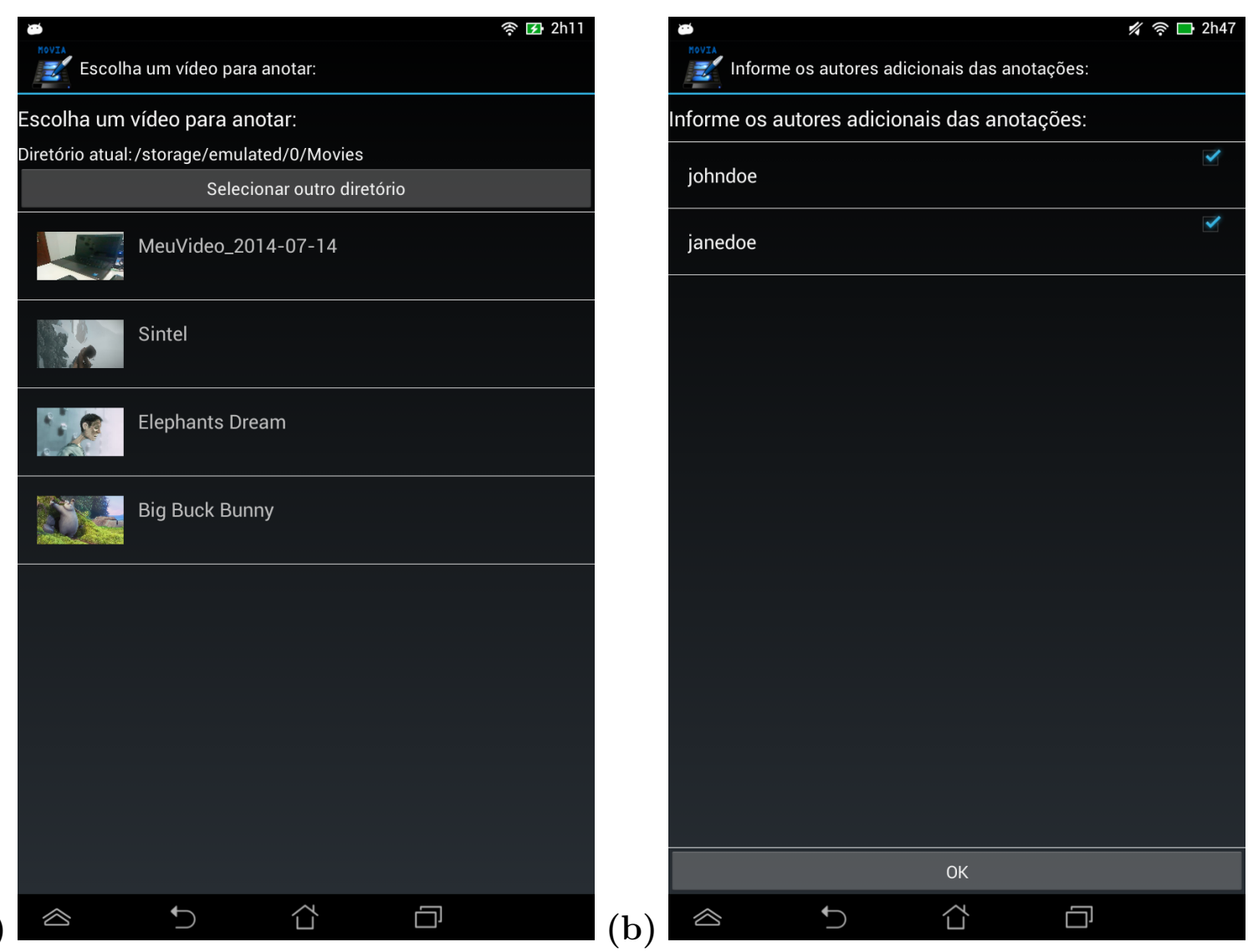

Figura 4.4: Telas de seleção: (a) Seleção de vídeo e (b) Seleção de autores adicionais.

A Figura 4.5 exibe a interface de reprodução e anotação. Os componentes de interface seguem as dimensões sugeridas pelas diretrizes de design de interfaces para o sistema Android, além disso a interface foi testada em dispositivos com diferentes tamanhos de tela para garantir que a disposição e o tamanho 
dos componentes são adequados. Deste modo é possível executar a aplicação independentemente do tamanho da tela. A Figura 4.6 mostra um exemplo da interface em um smartphone com tela de tamanho reduzido e resolução baixa (4 polegadas e 480 x 854 pixels, respectivamente).

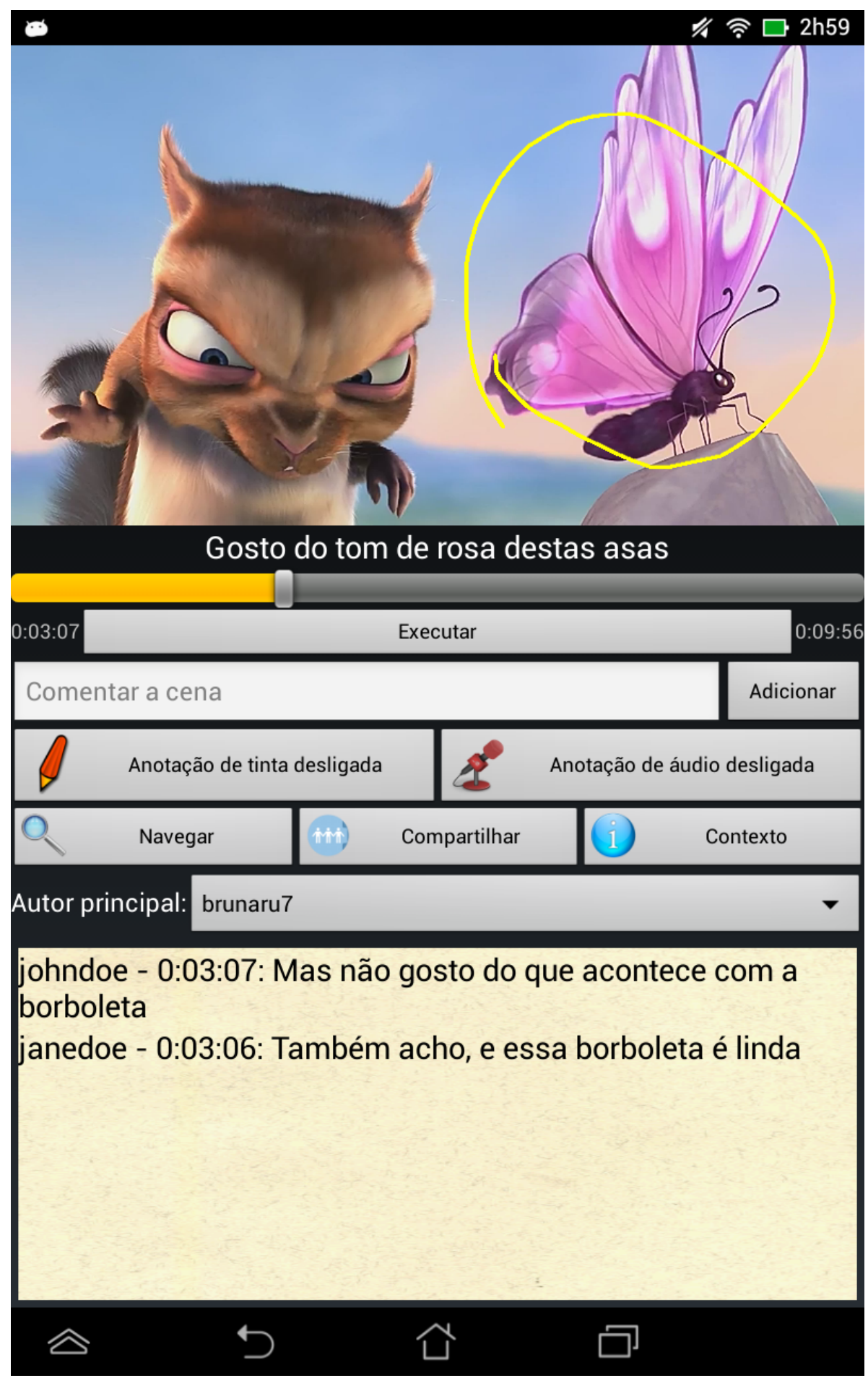

Figura 4.5: Tela de reprodução e anotações visualizada em um tablet com 7".

O leiaute vertical é denominado como modo de edição. Nesta posição é possível adicionar anotações, navegar pelo vídeo, exibir informações contextuais e 


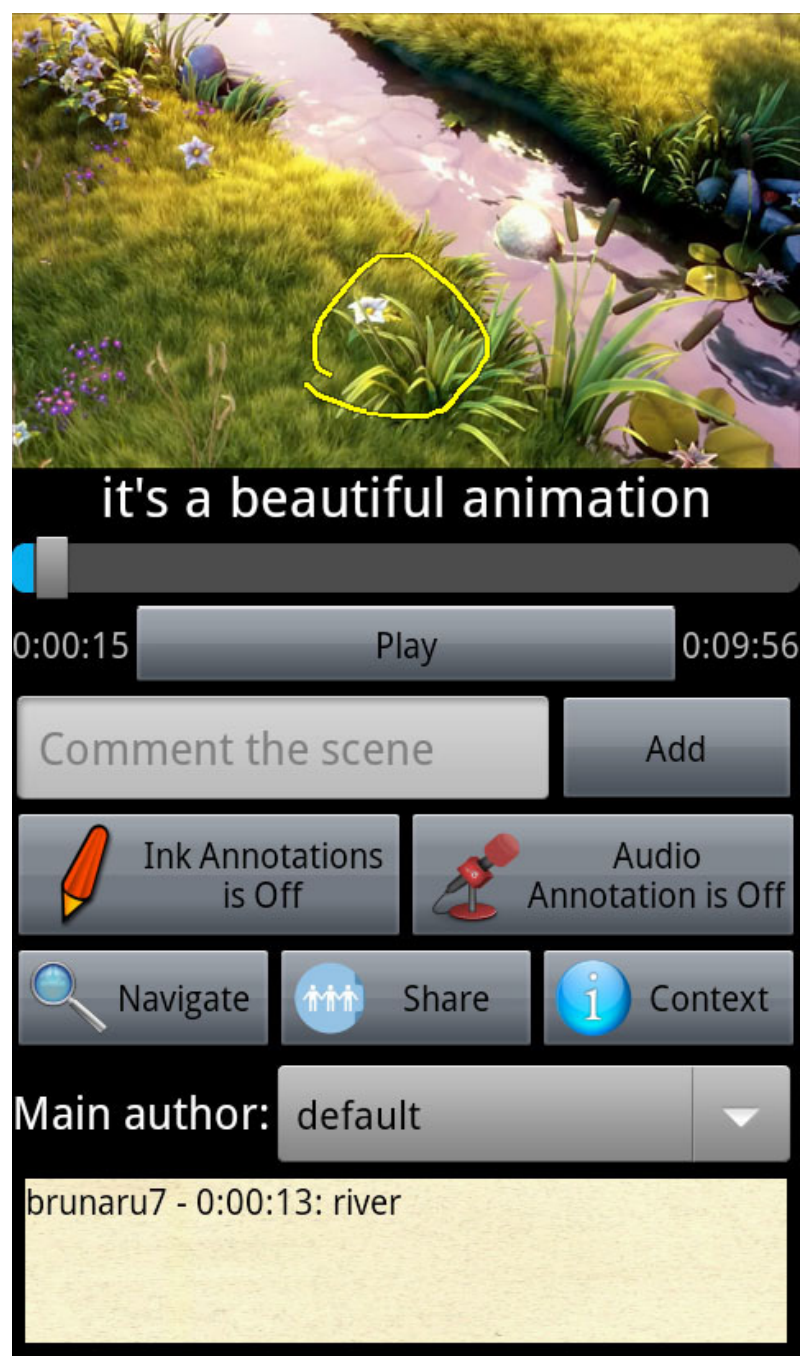

Figura 4.6: Tela de reprodução e anotações visualizada em um smartphone com 4".

utilizar as opções de compartilhamento. Na posição horizontal (Figura 4.7) a aplicação reproduz o vídeo e anotações em tela cheia, sem permitir adição de novas anotações. O comportamento de exibição em vertical (modo de edição) e horizontal (modo exibição) foi baseado no aplicativo do YouTube para o sistema Android com o objetivo de ser familiar aos usuários. Além disso, no leiaute vertical o teclado virtual do dispositivo móvel não obstrui a visualização do vídeo, o que seria um problema na visualização horizontal.

Em ambos os leiautes, o vídeo é exibido com proporções calculadas de acordo com o tamanho da tela do dispositivo e a relação de aspecto do vídeo. Em especial, vídeos gravados em dispositivos móveis na posição vertical apresentam proporções diferenciadas, sendo a altura maior que a largura. Para tratar este problema é considerada a rotação do vídeo.

Como pode ser observado na Figura 4.5, no modo de edição, abaixo do vídeo são exibidas as anotações textuais, em seguida são exibidos os controles de reprodução constituídos por uma barra de progresso e um botão de pausa, uma 


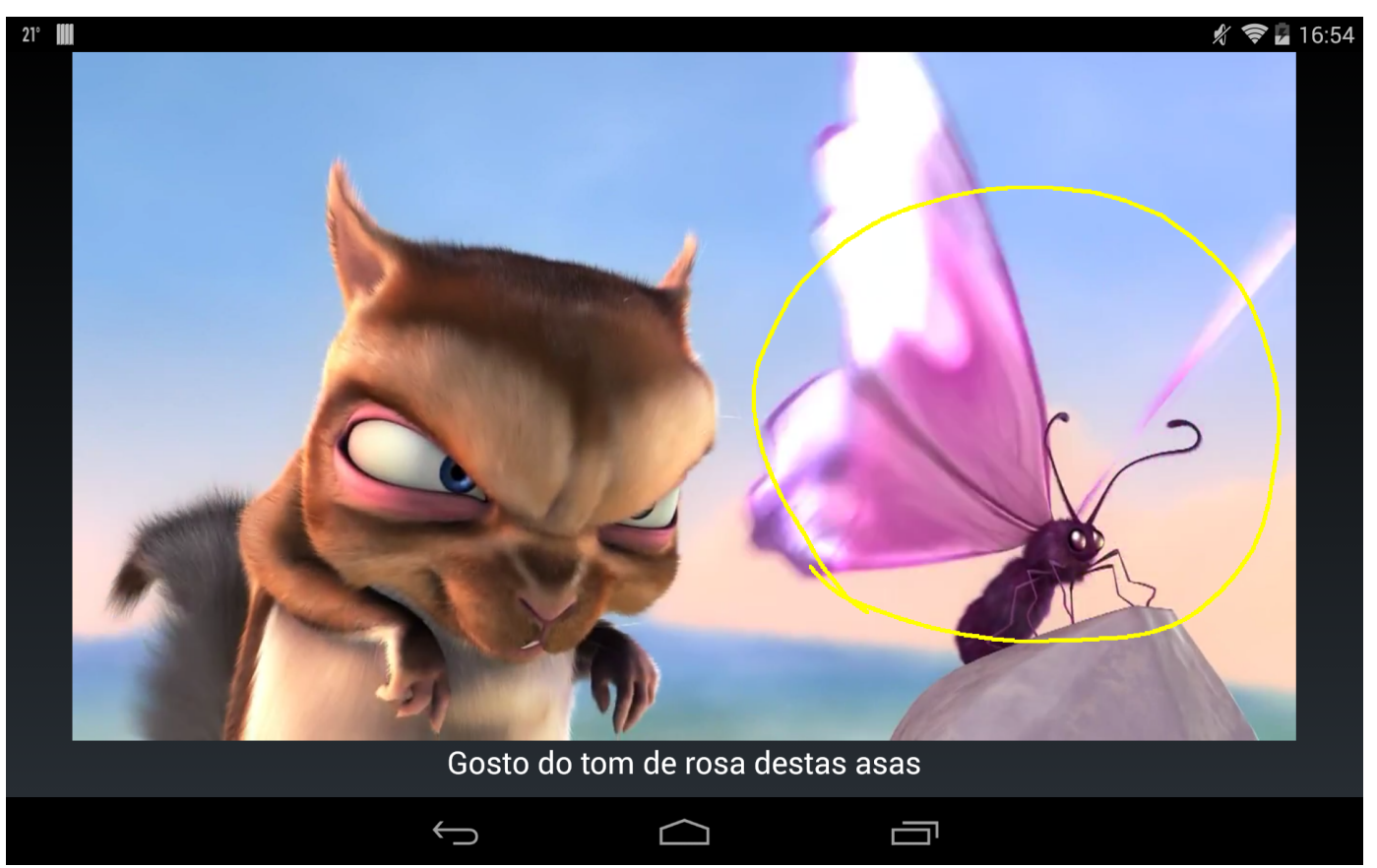

Figura 4.7: Tela de reprodução visualizada na posição horizontal.

caixa de texto para adição de anotações textuais, botões para ativação de anotações em tinta e áudio, botões de navegação, compartilhamento e informações de contexto, uma caixa de combinação (combo box) para escolha do autor principal e, por fim, uma área reservada para exibição de anotações textuais adicionais. Cada um destes componentes é explicado em detalhes a seguir.

Para adição de anotação textual existe uma caixa de texto acompanhada de um botão que gera uma anotação a partir do texto digitado. Logo abaixo do vídeo é exibida a anotação textual realizada, se existir, no instante de tempo em que foi adicionada. Caso a caixa de texto seja selecionada o vídeo é automaticamente pausado e o teclado virtual é exibido para que o usuário digite. A anotação textual exibida logo abaixo do vídeo foi adicionada pelo "Autor Principal”, ou seja, o usuário indicado na caixa de combinação (combo box). O tempo de duração de exibição da anotação textual é calculado por uma fórmula que considera a média de palavras lidas por minuto em dispositivos móveis. A fórmula para estimar o tempo de duração é dada por: $\mathrm{d}=\mathrm{n} /(\mathrm{wm} / 60)+3$. Onde $d$ é a duração em segundos, $n$ o número de palavras no texto e $w m$ o número de palavras lidas por minuto. O valor de $w$ m é fixo e igual a 200. O valor médio de 200 palavras por minuto (200wpm) foi escolhido com base em diversos valores apresentados por trabalhos que investigam a velocidade de leitura em dispositivos móveis [Biedert et al., 2012; Georgiev, 2012; Öquist e Lundin, 2007; Schildbach e Rukzio, 2010]. Já o tempo de 3 segundos foi escolhido para que o texto fique visivel por um tempo superior ao tempo de leitura. No contexto desta aplicação as anotações adicionam informação ao conteúdo, não dispondo o papel de simples legendas, 
assim é interessante que sejam exibidas por um tempo maior para que o usuário absorva a informação ou possa tomar a ação de pausar o vídeo.

O controle de adição de tinta eletrônica é realizado por meio de um botão que ativa e desativa a funcionalidade. No caso de anotações em tinta, pode ser incômodo que fiquem sempre ativas, pois se o usuário tocar na tela sobre o vídeo será registrada uma anotação. Ao clicar no botão de anotação em tinta o aplicativo informa que a tinta eletrônica está ativa por meio de uma mensagem de alerta, pela mudança de cor do ícone de anotação de vermelho para verde e pela da mudança de rótulo do botão, que passa a ser “Anotação em tinta ligada”. Este mesmo feedback é utilizado para anotações em áudio. Quando as anotações em áudio são ativadas, o vídeo é automaticamente pausado e traços desenhados sobre o ele são convertidos em tinta eletrônica. No entanto, o usuário pode tirar a pausa do vídeo e realizar as anotações em tinta durante a reprodução. Cada traço de uma anotação em tinta é exibido por 3 segundos sobre o vídeo. Deste modo, anotações em tinta podem ser adicionadas acompanhando a reprodução do vídeo.

O controle de adição de anotações em áudio é realizado de forma similar ao de anotações em tinta. Para as anotações em áudio a ativação explícita é necessária para evitar a gravação desnecessária de som e delimitar o início e o fim de uma anotação. Além disso, ao se habilitar a anotação em áudio, o vídeo é pausado para que a gravação seja feita. A pausa do vídeo durante a gravação é necessária para que o áudio do vídeo não interfira na gravação. Em testes anteriores foi identificado que o som emitido pelo vídeo bloqueia a gravação da voz do usuário. Durante a reprodução da anotação em áudio o vídeo é novamente pausado para que não haja interferência do som do vídeo e apenas o áudio da anotação seja reproduzido. Em vídeos com uma grande quantidade de anotações em áudio esse comportamento pode se tornar um problema, pois o vídeo será pausado diversas vezes. Para evitar este incômodo, antes de entrar no modo de reprodução é exibida uma tela com a opção de desligar as anotações em áudio. Mesmo desligadas as anotações de áudio podem ser acessadas pela tela de navegação e podem ser reproduzidas caso sejam selecionadas.

A escolha do autor principal é feita através da caixa de combinação (combo box), que contém os usuários que realizaram anotações para aquele vídeo. Durante o processo de reprodução, as anotações em áudio e tinta originadas por diferentes usuários não são reproduzidas simultaneamente para evitar conflitos de anotações que ocorrem ao mesmo tempo. Outro problema é a necessidade de identificação do autor de anotações. Assim, ao selecionar o autor principal, as anotações em tinta eletrônica e em áudio reproduzidas são referentes ao autor escolhido. Ao mesmo tempo, anotações textuais do autor principal são exibidas 
logo abaixo do vídeo. O autor principal pode ser alterado a qualquer momento durante a reprodução do vídeo. Imediatamente após a troca, as anotações reproduzidas serão de autoria do autor selecionado e as telas de navegação serão atualizadas.

A limitação de reprodução simultânea não existe para anotações textuais, que podem ser exibidas ao mesmo tempo na área reservada para anotações em texto. Na parte inferior da tela de anotações, como pode ser visto na Figura 4.5, há uma área reservada para exibição de múltiplas anotações textuais realizadas por outros autores. Enquanto anotações textuais do autor principal são exibidas abaixo do vídeo, anotações feitas por outros autores são exibidas na área reservada. As anotações são empilhadas a medida que surgem e são retiradas da área após expirar seu o tempo. Existe um cuidado especial com a sincronização deste conjunto de anotações. Anotações que estão sendo exibidas são armazenadas em uma lista. A lista é verificada por uma função responsável pela sincronização da reprodução e, para cada anotação, é examinado se seu tempo não expirou ou se o usuário navegou para outro ponto do vídeo não compatível com seu tempo de exibição.

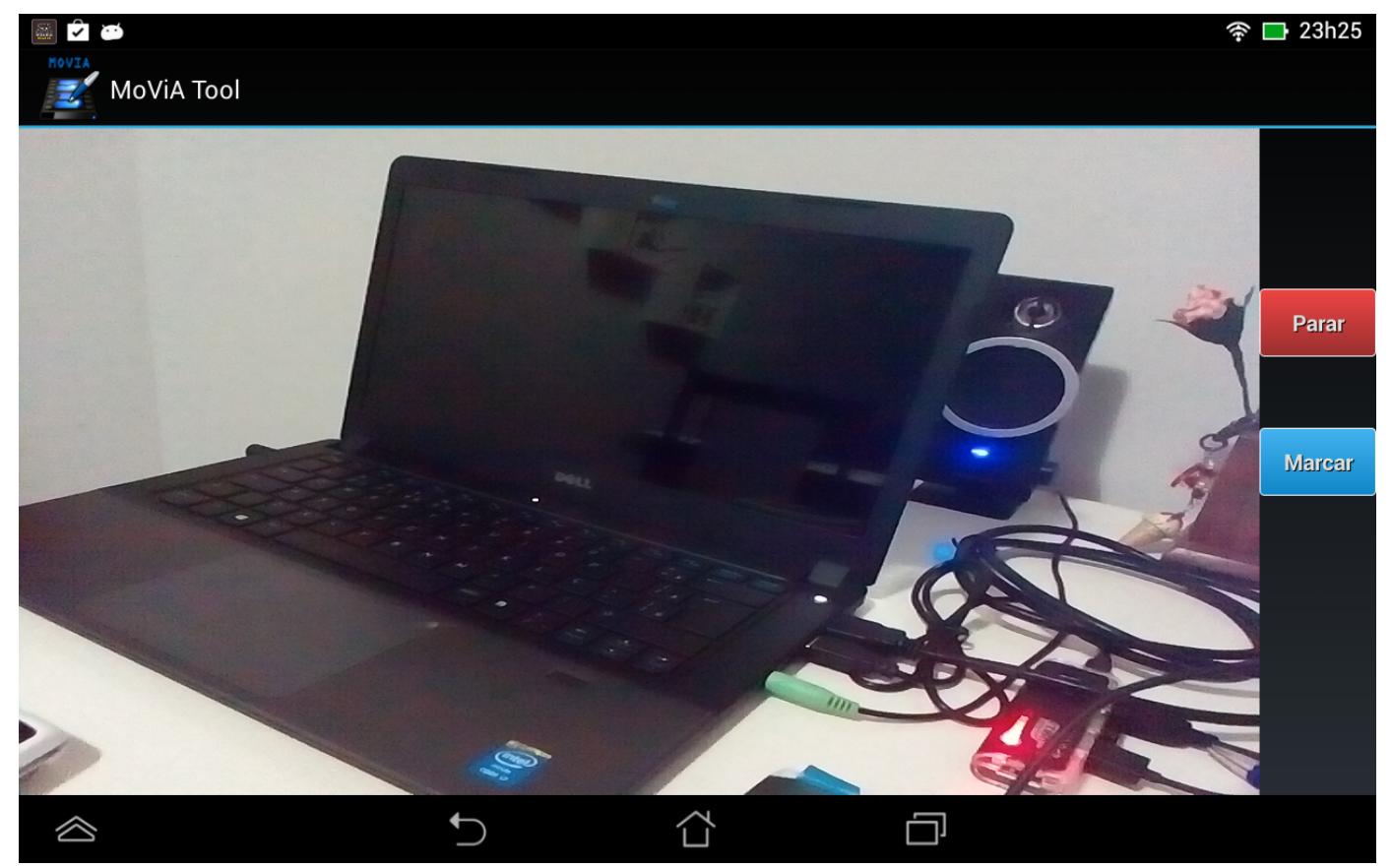

Figura 4.8: Tela de captura com botões para marcar o vídeo e parar a captura.

Com relação à adição de anotações durante a captura do vídeo, foi adotada a solução de marcação de pontos de interesse para não afetar o processo de gravação do vídeo. A Figura 4.8 mostra um exemplo da tela de gravação. Durante a captura o usuário pode pressionar o botão de marcação em momentos de interesse ou em situações em que deseja adicionar informações adicionais. Após a gravação, é gerado um documento com anotações textuais que contém os pontos 
selecionados. Ao reproduzir o vídeo na ferramenta, o usuário pode navegar pelos pontos marcados e adicionar novas anotações.

\subsection{Informações de Contexto}

O sistema captura informações de contexto durante a atividade de anotação. As informações de contexto são armazenadas juntamente com as anotações.

\section{Desafios Especificos}

Visando a captura ubíqua de informações referentes ao usuário e seu contexto, os dados não devem ser coletados por meio da entrada explícita e manual. Assim, a captura de informações de contexto está limitada às informações armazenadas no dispositivo e às funcionalidades de captura disponíveis.

\section{Descrição da Solução}

As informações são exibidas ao clicar no botão de contexto. A Figura 4.9 ilustra um exemplo. As informações capturadas têm o objetivo de auxiliar não apenas ao usuário, mas a análise de resultados das avaliações aplicadas no sistema. Por exemplo, para o usuário as informações de local, horário e evento podem ser informações importantes sobre contexto do vídeo capturado. É importante ressaltar que essas informações serão geradas durante a captura do vídeo somente se o vídeo foi gravado pela ferramenta e recebeu alguma marcação. Já para pesquisadores, as informações relativas à configuração do dispositivo são importantes para auxiliar na identificação de problemas de funcionamento ou usabilidade em dispositivos específicos.

As informações capturadas consideram as dimensões de contexto citadas na Seção 2.1 da seguinte forma:

- Who: armazenamento do usuário que realizou a interação, o nome do usuário da conta Google é armazenado. Foi escolhido o usuário da conta Google pois seu registro no dispositivo com sistema Android é obrigatório.

- What: tipo de anotação capturada (texto, tinta ou áudio) e atividade realizada pelo usuário no momento. As informações sobre a atividade são retiradas de eventos da agenda Google.

- When: momento da adição da primeira anotação. Indica a data de criação do arquivo de anotações.

- Where: local físico (i.e., endereço) onde foi realizada a interação. 


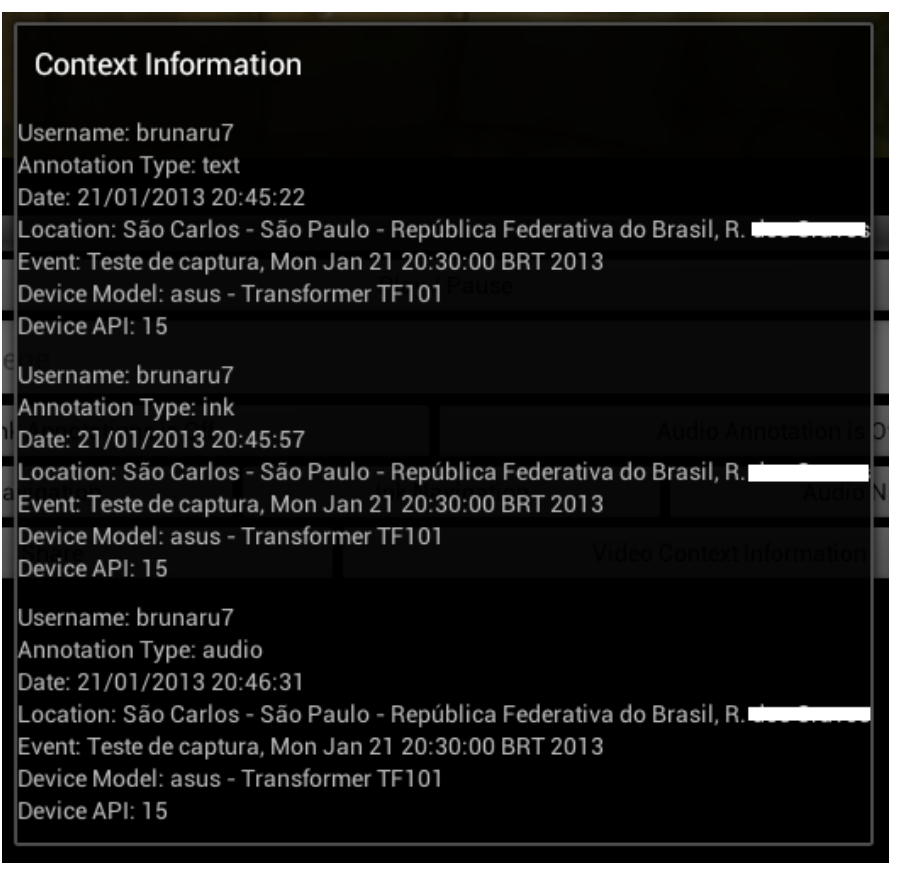

Figura 4.9: Informações de contexto na aplicação.

- How: modelo do dispositivo de captura e versão do sistema Android utilizado.

\subsection{Navegação}

Um dos objetivos do trabalho previa criar mecanismos para a autoria de documentos multimídia que permitissem a navegação não linear através da interação com o conteúdo gerado. Usuários enriquecem o vídeo com anotações que se tornam pontos de interesse naturais. A possibilidade de criar pontos anotados e posteriormente navegar entre eles possibilita que o usuário crie seu próprio vídeo interativo. A funcionalidade de navegação foi criada com o intuito de facilitar a visualização de pontos de interesse, neste caso, momentos de anotação.

\section{Desafios Especificos}

Uma estratégia simples para navegar por pontos de interesse é a marcação desses pontos na barra de progresso (linha do tempo) do vídeo. Porém, essa estratégia não é eficiente quando consideramos as características dos dispositivos móveis atuais. A tela sensível ao toque é uma das principais características de dispositivos móveis que utilizam sistemas como o Android. Além disso, esses dispositivos apresentam uma grande variação nos tamanhos de tela. Assim, os principais desafios identificados para navegação em vídeo utilizando dispositivos móveis são relacionados ao tamanho da tela, à quantidade de anotações e à precisão do toque dos dedos. 


\section{Descrição da Solução}

A Figura 4.10 mostra um exemplo de tela de navegação para anotação do tipo texto. A tela é gerada automaticamente com base nos documentos de anotações. Para cada anotação disponível é exibida uma miniatura da imagem do vídeo capturada no momento da anotação juntamente com o tempo que a anotação foi realizada, o texto adicionado e um botão para edição ou remoção da anotação. Ao tocar a miniatura ou texto o progresso do vídeo é definido para o momento da anotação correspondente, ou seja, ocorre um salto para o determinado ponto de interesse. Essa estratégia procura facilitar encontrar o ponto de interesse e selecionar o momento desejado com precisão. A opção de edição ou remoção permite alterar o texto da anotação ou realizar sua exclusão. A tela de navegação para áudio e tinta eletrônica segue o mesmo modelo e pode ser selecionada através dos botões de rádio no topo da tela de navegação. Para anotações em tinta ou áudio, é exibida uma miniatura do instante do vídeo em que ocorreu a anotação e o tempo de sua ocorrência, porém no local no texto é exibida apenas uma indicação do tipo da anotação (tinta ou áudio) e a opção de edição é substituída pela opção de remoção da anotação apenas.

\subsection{Compartilhamento e Exportação}

As anotações geradas por um indivíduo podem ser compartilhadas e visualizadas por outros usuários. A aplicação permite o compartilhamento assíncrono de anotações que são enviadas utilizando os aplicativos e sistemas de comunicação disponíveis nos dispositivos móveis. Arquivos de anotação podem ser reproduzidos em conjunto de forma que usuários podem assistir a um vídeo enriquecido por contribuições de vários usuários. Além do compartilhamento de anotações existe a possibilidade de exportar as anotações para a ferramenta I+WaC-Editor. Desta forma é possivel que anotações geradas na ferramenta MoViA sejam reproduzidas pela I+WaC-Editor.

\section{Desafios Especificos}

Considerando o compartilhamento assíncrono, os desafios em destaque são a determinação da forma de envio e recebimento das anotações pela aplicação e o controle de mudanças de anotações realizadas por diferentes usuários. A funcionalidade de compartilhamento em dispositivos móveis deve considerar a facilidade de uso. Com relação ao controle de mudanças, decisões de projeto devem ser realizadas, por exemplo, se usuários poderão editar anotações de outros autores. Problemas específicos relacionados a exportação de documentos gera- 


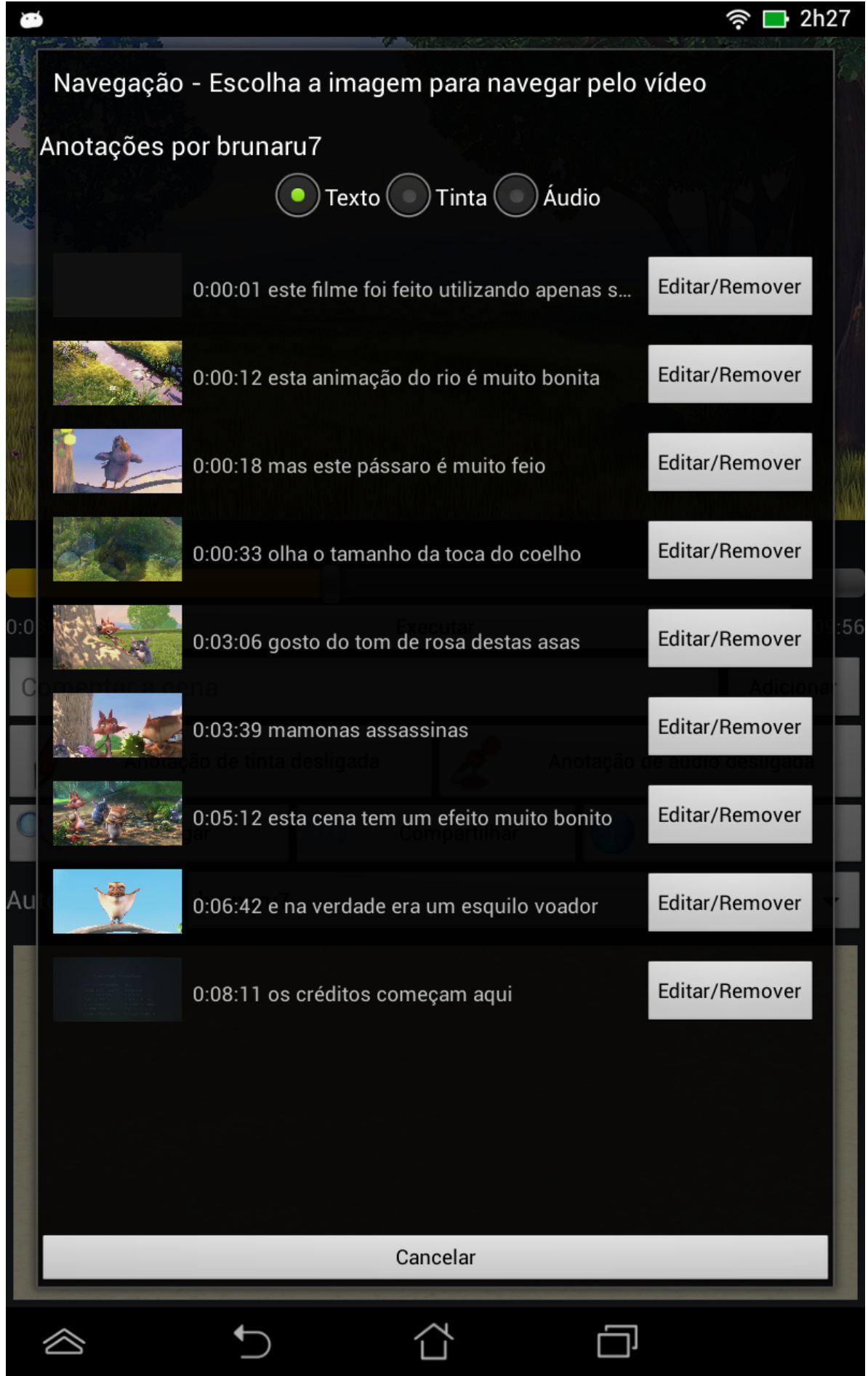

Figura 4.10: Tela de navegação por anotações.

dos para outras ferramentas podem existir caso haja incompatibilidade entre os documentos utilizados, no caso, o maior problema seria a ferramenta de destino exigir um dado inexistente no documento de origem.

\section{Descrição da Solução}

Como apresentado pela Figura 4.5 existe um botão para compartilhamento de 
anotações. Ao pressionar o botão de compartilhamento são exibidas as opções compartilhamento de vídeo, anotações textuais, anotações em tinta eletrônica e anotações para a ferramenta I+WaC-Editor. O compartilhamento de anotações em áudio não foi implementado. É importante lembrar que as anotações não são vinculadas ao vídeo, são arquivos individuais. Deste modo o vídeo pode ser compartilhado separadamente.

Após escolher qual arquivo será compartilhado, são apresentadas as opções de envio de arquivo: e-mail, mensageiros instantâneos, Dropbox ${ }^{3}$, Bluetooth ${ }^{4}$, Wi-Fi Direct ${ }^{5}$, entre outros. As opções exibidas dependem dos aplicativos e tecnologias disponíveis no dispositivo móvel. Deste modo o usuário pode compartilhar anotações usando a infraestrutura existente dos sistemas que utiliza. Utilizando a opção de compartilhamento do serviço Dropbox, por exemplo, é possível tornar o arquivo público para qualquer usuário ou para pessoas específicas.

Apenas o usuário criador do arquivo de anotações pode adicionar ou editar anotações no mesmo. Esse controle é realizado através do usuário da conta Google registrada no dispositivo. A estratégia utilizada é similar ao uso de transparências. Em um cenário tradicional, um papel de transparência com anotações feitas por um indivíduo pode ser colocado sobre um texto original para enriquecê-lo. Cada indivíduo tem uma transparência que pode ser colocada sobre o texto acrescentando mais informações, sem afetar as transparências dos outros. Uma pessoa não escreve em uma transparência que não lhe pertence. A Figura 4.11 ilustra este conceito. Estendendo o conceito de transparências para a ferramenta, usuários possuem arquivos de anotação associados aos seus nomes de usuário e somente o proprietário pode modificar seu arquivo. No entanto, os arquivos podem ser agrupados para que os usuários possam visualizar todo o conjunto de anotações sobre o vídeo ao mesmo tempo. Em resumo, o aplicativo permite que vários arquivos de anotação estejam associados ao vídeo durante sua reprodução, mas não é permitida a edição de arquivos de terceiros. Para que um usuário compartilhe suas anotações é necessário compartilhar explicitamente os seus arquivos de anotação. No entanto, o modelo utilizado pelos documentos de anotação possui suporte para múltiplos usuários.

Para que as anotações sejam reconhecidas pelo aplicativo é necessário que os arquivos estejam em um diretório específico no sistema (diretório "notes", localizado dentro do diretório padrão de vídeos). Para evitar que o usuário precise copiar o arquivo manualmente, tarefa que pode ser complicada dependendo do seu nível de experiência, o sistema contém uma função de importação em sua

\footnotetext{
${ }^{3}$ https: //www.dropbox.com/

${ }^{4}$ http://www.bluetooth.com/

${ }^{5}$ http://www.wi-fi.org/discover-wi-fi/wi-fi-direct
} 


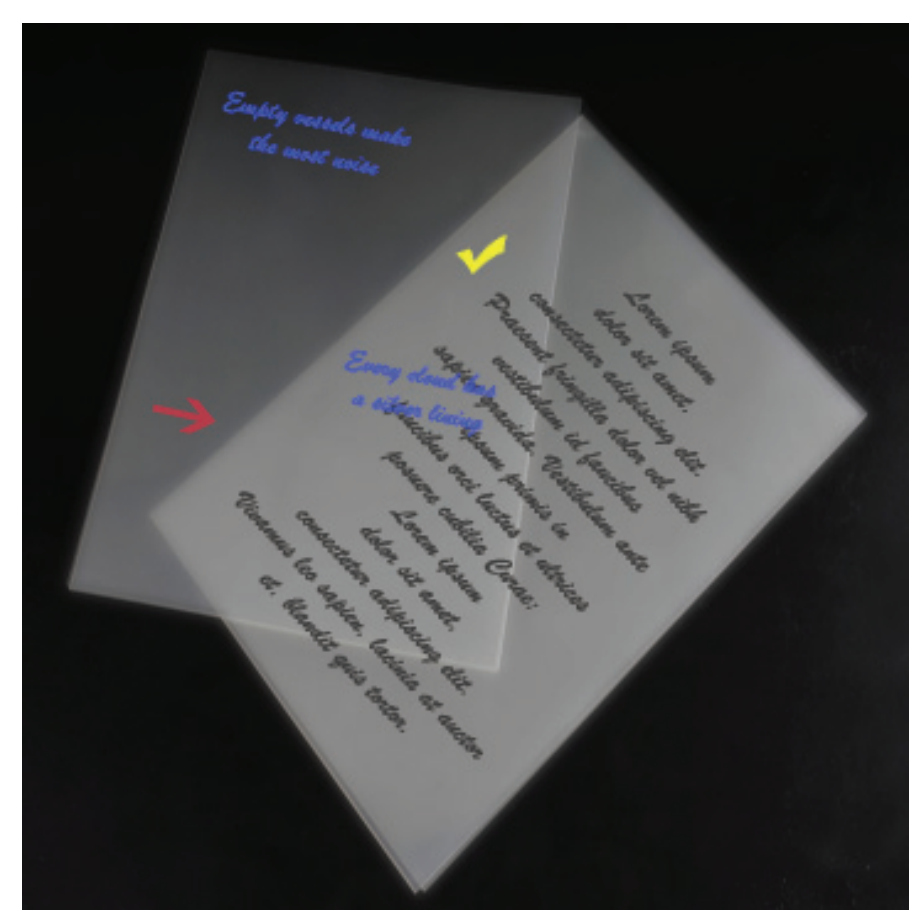

Figura 4.11: Ilustração do conceito de transparência em textos.

tela inicial.

Para a exportação das anotações para a ferramenta I+WaC-Editor foi preciso implementar um conversor interno. O formato executado pela I+WaC-Editor é um documento de integração no formato JSON, como já mencionado na Seção 3.2. Devido ao o fato do modelo do documento de anotação desenvolvido para ferramenta MoViA conter informações adicionais, como explanado na Seção 4.3, a exportação do documento de anotações não enfrentou problemas. No momento em que a função de compartilhamento para a ferramenta I+WaCEditor é acionada, o arquivo convertido é gerado automaticamente. Atualmente a ferramenta I+WaC-Editor reproduz apenas anotações textuais, devido a isto apenas as anotações textuais são convertidas.

\subsection{Sintese dos Resultados das Avaliações}

Foram realizadas três avaliações em diferentes versões da ferramenta com o objetivo de testar sua facilidade de uso, corrigir problemas de usabilidade e identificar novos requisitos. As três avaliações realizadas em ordem foram: avaliação de usabilidade, avaliação heurística e avaliação com uma usuária especialista na área de terapia ocupacional. Esta seção apresenta uma síntese dos resultados das três avaliações apontando os principais problemas e requisitos encontrados, além disso é apresentada uma discussão para cada item identificado. 


\subsubsection{Avaliação de Usabilidade}

A avaliação de usabilidade foi realizada na versão inicial da ferramenta, como apresentado na Seção 4.1, que pode ser vista na Figura 4.1. Esta versão permitia apenas anotações textuais e navegação por anotações. Funcionalidades de edição de anotações e compartilhamento não estavam disponíveis. O experimento relatado e seus resultados associados foram publicados em um artigo resumido [Cunha et al., 2012].

O teste de usabilidade foi realizado com alunos voluntários de pós-graduação que cursaram a disciplina de Interação Usuário-Computador. Durante a disciplina os alunos produziram vídeos que apresentavam diferentes estágios de um projeto que desenvolveram. O conteúdo dos vídeos correspondia à apresentação de protótipos desenvolvidos pelos alunos na disciplina. Neste experimento foram utilizados três vídeos e foi dada a opção de escolha do vídeo aos participantes.

Foi planejado um questionário que foi respondido pelos participantes no final da avaliação. As questões do questionário foram relacionadas à dificuldade de cada funcionalidade do sistema e a informações pertinentes sobre os participantes, como experiência com dispositivos móveis, idade e profissão.

Seis alunos foram voluntários do experimento que ocorreu em laboratório, utilizando um dispositivo provido pelos moderadores, um tablet Galaxy Tab com 7" e Android na versão 2.2. Três dos participantes eram da área de computação, os outros três eram das áreas de arquitetura, imagem e som, e física. Houve participantes do sexo masculino e feminino, com idades entre 24 a 46 anos. Os participantes declararam diferentes níveis de experiência com dispositivos de tela sensivel ao toque e a maioria revelou que assiste vídeos usando seus dispositivos móveis. Seis participantes é considerado um número suficiente para um teste de usabilidade dado que, segundo Nielsen [Nielsen Norman Group, 2000], cinco usuários são suficientes, pois essa configuração possui um custobenefício ideal para a maioria dos experimentos do tipo.

A avaliação adotou uma estratégia cooperativa, na qual os usuários são encorajados a colaborar na avaliação. Nesta avaliação, o usuário primeiro interage com o sistema enquanto os moderadores o observam. Ao terminar a interação, usuário e moderadores discutem os problemas encontrados [Frokjaer e Hornb, 2005].

Cada sessão de avaliação foi dividida em três tarefas e teve duração total de aproximadamente 25 minutos. Na primeira parte, o participante assiste a um vídeo utilizando a aplicação e adiciona anotações que considera pertinentes. Em uma segunda parte, o participante apresenta aos moderadores suas anotações explicando sua motivação e, ao mesmo tempo, é realizada uma discussão sobre os problemas encontrados. Na parte final, o usuário responde ao questionário. 
As interações dos participantes com o aplicativo e a sessão de discussão foram filmadas com consentimento.

A análise dos resultados foi realizada por meio da observação dos vídeos gravados e das respostas aos questionários. São listados os principais problemas identificados e as soluções desenvolvidas:

- Dificuldade na criação de novo autor: nesta versão da ferramenta era necessário entrar com um nome de usuário. Esta ação não foi intuitiva para os participantes. Este processo foi automatizado em versões posteriores por meio da seleção da conta Google cadastrada no dispositivo.

- Dificuldade na seleção do vídeo: a tela de seleção de vídeo exibia só o nome dos arquivos. Alguns participantes tinham dificuldades para selecionar o vídeo baseando-se apenas no texto. Para contornar este problema, além do nome do arquivo é exibida uma miniatura de um de seus primeiros quadros.

- Ação de pressionar o botão de adicionar uma nova anotação sem inserir um texto: vários participantes pressionaram o botão adicionar antes de inserir um texto de anotação. Neste caso a solução foi exibir um aviso alertando que o usuário deve inserir um texto.

- Problemas de precisão do toque na tela de navegação: para navegar pela anotação era necessário que o usuário tocasse o texto ou a miniatura da anotação de interesse. Porém a área de seleção não era suficientemente grande para garantir que a seleção fosse sempre bem sucedida e alguns participantes tiveram de tocar a anotação desejada mais de uma vez. Para corrigir este problema a área de seleção foi ampliada para uma região, ao invés de ser restrita a imagem e ao texto.

- Tempo de exibição das anotações: as anotações eram exibidas por um tempo fixo. Este tempo foi suficiente para a maioria dos participantes pois geralmente são adicionadas anotações curtas em dispositivos móveis. Porém um dos participantes adicionou anotações longas e o tempo determinado não foi suficiente. Em versões posteriores o tempo de exibição passou a ser dependente do número de palavras no texto.

Além desses problemas, algumas funcionalidades previstas, porém não disponíveis quando da realização do teste, tiveram sua necessidade reforçada, são elas: edição e remoção de anotações e exibição do vídeo em tamanho maior em leiaute horizontal.

O protótipo atendeu às expectativas de funcionamento e foi bem recebido pelos usuários, que consideraram as funcionalidades, em sua maioria, entre muito 
fáceis ou fáceis de utilizar e conseguiram realizar as tarefas que lhe foram atribuídas com sucesso. A facilidade de ler as anotações foi considerada regular por metade dos usuários, o que, associado à discussão e análise da interação gravada, foi consequência do tempo insuficiente para leitura do texto. A Tabela 4.1 apresenta o resultado do questionário para cada funcionalidade, avaliada em cinco níveis: muito fácil, fácil, regular, difícil e muito difícil.

Tabela 4.1: Resultados do questionário para avaliação das funcionalidades

\begin{tabular}{|c|l|l|l|l|l|}
\hline Participante & Escolher vídeo & Escolher autor & Adição de anotação & Navegação por anotação & Leitura de anotação \\
\hline \hline 1 & Muito Fácil & Fácil & Fácil & Muito Fácil & Muito Fácil \\
2 & Muito Fácil & Muito Fácil & Fácil & Fácil & Fácil \\
3 & Muito Fácil & Fácil & Muito Fácil & Muito Fácil & Muito Fácil \\
4 & Muito Fácil & Fácil & Regular & Regular & Regular \\
5 & Muito Fácil & Muito Fácil & Fácil & Fácil & Regular \\
6 & Fácil & Fácil & Muito Fácil & Muito Fácil & Regular \\
\hline
\end{tabular}

\subsubsection{Avaliação Heurística}

Após a avaliação de usabilidade, os problemas descritos foram corrigidos e foram adicionadas funcionalidades de compartilhamento e anotações multimodais (áudio e tinta eletrônica). A versão avaliada pelas heurísticas corresponde ao segundo estágio do aplicativo, apresentado pela Figura 4.2 e descrito em na Seção 4.1. Os resultados da avaliação heurística foram reportados em um artigo curto [Cunha et al., 2013b].

Heurísticas de usabilidade são uma ferramenta útil para a avaliação de interfaces devido a sua praticidade, facilidade de uso e baixo custo [Nielsen, 1994]. A avaliação heurística envolve um pequeno conjunto de avaliadores especialistas que exploram a interface de uma aplicação e associam problemas de usabilidade encontrados com um conjunto de diretrizes de usabilidade, denominadas heurísticas.

$\mathrm{Na}$ avaliação realizada, foram utilizados dois conjuntos de heurísticas: o tradicional, proposto por Nielsen [1994], e um conjunto estendido de heurísticas proposto especificamente para avaliação de interfaces em dispositivos móveis [Machado Neto e Pimentel, 2013]. Ambos conjuntos de heurísticas seguem o mesmo procedimento: cada problema encontrado deve ser associado a uma heurística e um grau de severidade deve ser atribuído. Ao final é gerada uma lista unificada de problemas.

Dado que Nielsen e Molich [1990] propõem a participação de três a cinco especialistas para realizar uma avaliação heurística, cada conjunto de heurísticas foi utilizado por cinco avaliadores diferentes. Foram convidados dez avaliadores que já haviam concluído o curso de Interação Humano-Computador e já tinham aplicado avaliações heurísticas em outros sistemas. O experimento ocorreu em 
laboratório e foi utilizado um tablet Motorola XOOM com tela de 10.1" e Android na versão 4.0 .

Os principais problemas encontrados e as soluções desenvolvidas e propostas são listados a seguir:

- Botões de ativação de áudio e tinta: o funcionamento dos botões de anotação em áudio e tinta eletrônica não era evidente. Para melhorar a compreensão foram adicionados ícones com figuras familiares: um microfone para áudio e um lápis para tinta. Para reforçar o feedback, quando o usuário pressiona o botão, além do rótulo do botão ser modificado, é apresentada uma mensagem que indica que a funcionalidade foi ativada ou desativada e a cor do ícone é alterada. A cor vermelha é utilizada para o valor desligado e verde para ligado.

- Tela de seleção de autores adicionais: a tela de seleção de autores adicionais era muito similar à tela de seleção do usuário. Além disso, a diferença entre os papéis não era clara o suficiente. Como aplicações Android possuem componentes padronizados e leiaute uniformizado, erros deste tipo podem ser comuns. Para solucionar este problema as telas foram modificadas para utilizar componentes de leiautes diferentes e um texto mais explicativo.

- Posicionamento das mensagens de feedback: por padrão o sistema Android posiciona as mensagens de feedback (mensagens do tipo Toast ${ }^{6}$ ) na parte inferior da tela. Nesta aplicação o foco do usuário é no centro da tela, além disso, a avaliação foi realizada em um tablet. Logo, foi identificado que mensagens na parte inferior da tela eram facilmente perdidas. Para corrigir o problema foi necessário modificar todas as mensagens para que fossem exibidas no centro da tela. Este é um problema que pode ocorrer em qualquer aplicação, principalmente quando executadas em telas de tamanho grande.

- Agrupamento da funcionalidade de navegação: a versão avaliada apresentava um botão de navegação para cada tipo de anotação (Figura 4.2). Em dispositivos móveis, é importante otimizar o uso do espaço de tela. A versão atual implementa uma única tela de navegação em que as anotações podem ser alternadas através de botões de radio (Figuras 4.10).

- Pausa automática: identificou-se que é desejável que o vídeo pause automaticamente quando o usuário ativar anotações em tinta ou áudio. Este já era o comportamento padrão para anotações em texto. No caso do áudio, 
a pausa é obrigatória pois o áudio do vídeo atrapalha a gravação e a reprodução da anotação. Já no caso de texto e tinta, a pausa ocorre apenas para facilitar a adição da anotação e a pausa pode ser retirada pelo usuário. Como já descrito, anotações em texto e tinta são exibidas durante um intervalo de tempo, acompanhando a reprodução do vídeo.

- Anotações em leiaute paisagem: a maioria dos especialistas considerou que os usuários devem ser capazes de adicionar anotações no leiaute na posição paisagem (horizontal). A aplicação deve fornecer uma maneira de ativar os comandos de anotação neste esquema de visualização. Esta funcionalidade não foi desenvolvida, pois, além de exigir tempo de desenvolvimento, os desafios de usabilidade relacionados são diversos.

\subsubsection{Avaliação com Especialista na Área de Terapia Ocupacional}

A última avaliação da ferramenta consistiu em uma avaliação colaborativa com uma usuária em potencial da ferramenta. Uma profissional especialista na área de terapia ocupacional e, também, professora doutora da Universidade de São Paulo, demonstrou interesse em utilizar o aplicativo desenvolvido, pois faz uso direto de gravação de vídeos em seu trabalho. O principal objetivo desta avaliação foi realizar a investigação de uma situação real de uso da ferramenta em um contexto específico.

A especialista trabalha com pacientes que necessitam realizar uma série de exercícios com o objetivo de melhorar sua movimentação e coordenação. Neste sentido, o trabalho da profissional é propor exercícios específicos para seus pacientes que devem repeti-los várias vezes por dia. A presença de um profissional durante todas as sessões de exercícios nem sempre é possível, consequentemente, pacientes devem lembrar os exercícios e reproduzi-los sem a orientação de um profissional. Para apoiar este processo a especialista em questão utiliza os dispositivos móveis de seus pacientes para gravar vídeos dos mesmos executando exercícios. Assim, os pacientes possuem seus exercícios gravados em seus próprios dispositivos para consulta em caso de esquecimento ou dúvida.

Segundo a especialista, a utilização de anotações nos vídeos de exercícios que grava durante sessões com pacientes é de grande utilidade. Após a gravação, ela poderia rever o vídeo e adicionar informações relevantes para o seu paciente, utilizando texto e áudio para adicionar comentários e tinta para marcar problemas de posicionamento, por exemplo. A funcionalidade de compartilhamento também se faz extremamente útil neste cenário. Dado que a profissional utiliza os dispositivos de seus pacientes, é interessante que compartilhe o vídeo e as anotações para acessá-los posteriormente em seu próprio dispositivo. A navegação é útil principalmente para o paciente que, caso não queira rever o vídeo inteiro, 
possa saltar para os pontos em que a profissional fez anotações. As informações de contexto podem auxiliar a profissional a recordar detalhes da sessão, mais especificamente, quando e onde foi realizada.

Em vista disso, foi planejada a demonstração do aplicativo MoViA e uma avaliação colaborativa em que a especialista e os experimentadores pudessem discutir problemas e novos requisitos para utilização no cenário descrito.

A versão utilizada nesta avaliação se difere da versão final apenas por não possuir a funcionalidade de marcação de vídeo durante a captura e não incluir a correção de dois problemas menores que foram identificados após a avaliação com a usuária e são descritos a seguir. Todas as modificações feitas no aplicativo são descritas nesta seção.

A avaliação, realizada em laboratório, consistiu em uma demonstração da ferramenta, seguida pela utilização da ferramenta pela usuária especialista acompanhada por uma discussão com os experimentadores. A avaliação seguiu um protocolo de avaliação colaborativa [Frokjaer e Hornb, 2005]. Uma limitação deste experimento foi o fato da avaliação da ferramenta não ter sido executada no ambiente de trabalho da especialista, dado que tal configuração traria obstáculos adicionais, como o fato de envolver o consentimento de terceiros (pacientes). Foi utilizado um tablet Nexus 7 (modelo 2012), com tela de 7 " e versão 4.1 do sistema Android.

A utilização da ferramenta pela especialista e a discussão realizada com os experimentadores resultaram na identificação de problemas e requisitos discutidos a seguir.

\section{Problemas:}

- Reprodução de vídeos gravados na vertical: geralmente, a especialista grava seus vídeos segurando o dispositivo na vertical. Isto faz com que as proporções do vídeo sejam diferentes do usual, ou seja, a altura é maior que a largura. A ferramenta não possuía suporte adequado para este tipo de vídeo, causando distorção em sua reprodução. Para corrigir o problema o aplicativo checa a rotação do vídeo e realiza um cálculo diferenciado para vídeos gravados em leiaute vertical.

- Telas consideradas irrelevantes: a especialista constatou que antes de iniciar a anotação do vídeo é necessário passar por telas que considerou não serem importantes para ela, como a tela de confirmação do usuário. O aplicativo foi modificado para minimizar o número de telas, omitindo a exibição de telas em casos identificados como desnecessários. 


\section{Requisitos:}

- Marcação do vídeo durante a captura: durante a gravação do vídeo a profissional pode observar momentos em que pretende adicionar anotações. Para facilitar esse processo foi desenvolvida uma solução que permite marcar pontos de interesse durante a captura do vídeo. Após a captura, os pontos de interesse podem ser facilmente acessados através da funcionalidade de navegação da ferramenta.

- Customização da tela: a especialista observou que, em seu caso, não são necessárias todas as funcionalidades da ferramenta, como a exibição de múltiplas anotações realizadas por usuários diferentes. Assim, seria interessante poder omitir a apresentação de certos componentes. Apesar de não ter sido implementado, este recurso possui uma solução simples. Poderia ser adicionada uma tela de configuração que permitisse o usuário selecionar quais componentes deseja ativar ou desativar.

- Acompanhamento de exercícios: a especialista declarou que uma das funcionalidades que gostaria que a ferramenta provesse seria a possibilidade de acompanhar o progresso dos exercícios realizados pelos seus pacientes. Além de gravar as sessões e anotá-las, é de seu interesse saber se o paciente realizou os exercícios com sucesso nos horários agendados ou se deixou de fazê-los por ter alguma dificuldade. O aplicativo também poderia emitir alertas aos pacientes, auxiliando-os a lembrar de seus exercícios. Estas funcionalidades são específicas para o contexto do tratamento descrito e demonstram potencial de extensão da ferramenta para cenários similares. Trabalhos futuros devem investigar esses requisitos.

\subsubsection{Dispositivos Testados}

Além dos dispositivos utilizados em avaliações, a aplicação MoViA foi testada durante o seu desenvolvimento em outros dispositivos. O aplicativo foi testado principalmente em dispositivos do tipo tablet, pois o acesso a smatphones foi limitado. A Tabela 4.2 resume os dispositivos em que o aplicativo foi testado e o contexto do teste, assim como suas especificações, em termos de tamanho de tela e versão do sistema Android.

Apesar de ter sido avaliado na versão 2.2 (Froyo) do Android, a implementação atual do aplicativo MoViA não mantém compatibilidade com essa versão. Isto não é um problema dado que, como apresentado na Tabela 4.2, a versão 2.2 conta apenas com 0,7\% dos usuários atuais do sistema Android. 
Tabela 4.2: Dispositivos em que a aplicação foi testada.

\begin{tabular}{|l|l|l|l|l|}
\hline Modelo & Tipo & Tela & Versão do Android & Contexto \\
\hline \hline Sony Ericsson Xperia PLAY & Smartphone & $4 "$ & Gingerbread 2.3 & Desenvolvimento \\
\hline Asus Transformer TF101 & Tablet & $10.1 "$ & Ice Cream Sandwich 4.0 & Desenvolvimento \\
\hline Asus Memo Pad HD7 & Tablet & $7 "$ & Jelly Bean 4.2 & Desenvolvimento \\
\hline Asus Google Nexus 7 (2013) & Tablet & $7 "$ & KitKat 4.4 & Desenvolvimento \\
\hline Samsung P1000 Galaxy Tab & Tablet & $7 "$ & Froyo 2.2 & Avaliação de Usabilidade \\
\hline Motorola XOOM MZ601 & Tablet & $10.1 ”$ & Jelly Bean 4.1 & Avaliação Heurística \\
\hline Asus Google Nexus 7 (2012) & Tablet & $7 "$ & Jelly Bean 4.1 & Avaliação com Especialista \\
\hline
\end{tabular}

\subsection{Considerações Finais}

Neste capítulo foi descrita a ferramenta desenvolvida para a investigação dos problemas identificados juntamente com as soluções propostas. A ferramenta desenvolvida é um aplicativo para o sistema Android chamado MoViA. A ferramenta permite adicionar anotações multimodais em vídeos gravados, adicionar marcações durante a captura, capturar informações de contexto, navegar pelas anotações criadas e compartilhar os documentos gerados. Na primeira seção são descritos os passos de desenvolvimento e evolução do aplicativo em diferentes etapas de acordo com os resultados do mapeamento sistemático e das avaliações realizadas.

A arquitetura do aplicativo priorizou a organização, o reuso e a independência de componentes. O aplicativo apresenta soluções para a captura de anotações, captura de informações de contexto, navegação em vídeo e compartilhamento de mídias. As principais soluções no contexto de captura de anotações envolvem a captura de anotações multimodais e a adequação das funcionalidades desenvolvidas à interação baseada em toque dos dedos e a telas de tamanho reduzido. Informações de contexto são capturadas de forma não intrusiva e são adicionadas aos documentos de anotações. A navegação do aplicativo é baseada no uso de miniaturas dos vídeos capturadas no momento em que as anotações ocorrem. O aplicativo permite o compartilhamento assíncrono de anotações e vídeos, porém na solução proposta é possível agrupar vários documentos de anotação durante a execução do vídeo e executar anotações de diferentes usuários simultaneamente.

Resultados da avaliação de usabilidade com usuários e da avaliação heurística com especialistas auxiliaram a identificar diversos problemas de usabilidade que foram trabalhados nas versões posteriores da ferramenta. Já a avaliação final realizada com uma usuária profissional da área de terapia ocupacional auxiliou principalmente na confirmação da utilidade da ferramenta no contexto específico de seu trabalho e na definição de novos requisitos para o cenário de acompanhamento de pacientes. Por fim, são listados todos os dispositivos em 
64 MOVIA: UMA FERRAMENTA DE ANOTAÇÃO EM VÍDEO EM DISPOSITIVOS MÓVEIS 4.8 que a ferramenta foi testada e executada com sucesso. 


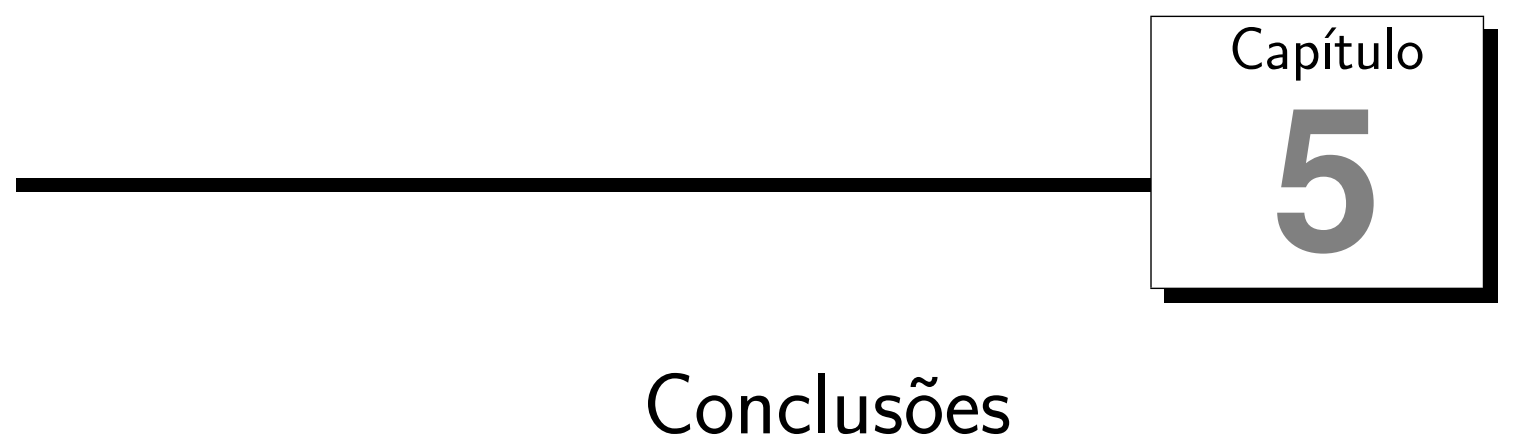

As próximas seções apresentam a síntese das contribuições deste trabalho, avaliações realizadas, resultados obtidos e um comparativo com trabalhos na área de anotações em vídeo (Seção 5.1), uma discussão das limitações deste trabalho, da ferramenta de anotação e possíveis melhorias que poderiam ser realizadas (Seção 5.2), descrições de trabalhos futuros (Seção 5.3) e uma listagem das publicações resultantes (Seção 5.4).

\subsection{Sumário e Discussão}

Considerando a oportunidade de pesquisa indentificada na área de autoria multimídia em dispositivos móveis, mais especificamente em anotações em vídeo, este trabalho investigou alternativas de interação entre usuários e seus dispositivos para a captura e compartilhamento de anotações. Resultados de um mapeamento sistemático em anotações colaborativas em vídeo auxiliaram na obtenção de tendências e pontos deficitários em trabalhos na área e assim identificar problemas específicos, sendo alguns deles selecionados e investigados neste trabalho. Resumidamente, as principais contribuições deste trabalho foram:

- A proposta de uma interface e um conjunto de interações para captura de anotações multimodais em vídeos, na forma texto, áudio e tinta eletrônica, e para captura de pontos de interesse durante o processo de gravação do vídeo explorando os recursos de dispositivos móveis do tipo tablets e smartphones.

- A proposta de uma interface e um conjunto de interações para anotação e navegação em vídeo em dispositivos móveis com tamanhos de tela variados 
e interação baseada em toque dos dedos.

- A proposta de um método para compartilhamento de anotações e para visualização síncrona e simultânea de múltiplas anotações, originadas por diferentes usuários, em dispositivos com tamanho de tela reduzido.

Foi desenvolvido um aplicativo de anotação em vídeo para o sistema operacional Android que implementa as soluções para os problemas investigados. O aplicativo desenvolvido é único e apresenta soluções originais para dispositivos móveis, podendo ser executado em tablets e smartphones.

Foram realizadas três avaliações durante o desenvolvimento da ferramenta: um teste de usabilidade com usuários, uma avaliação heurística com especialistas em computação e uma avaliação colaborativa com uma usuária especialista na área de terapia ocupacional. Resultados das avaliações de usabilidade contribuíram para identificar novos problemas e requisitos que foram solucionados em diferentes etapas de desenvolvimento. A avaliação realizada com a especialista na área de terapia ocupacional identificou que a ferramenta é de grande utilidade em seu trabalho, pois permite que a profissional capture e enriqueça vídeos de exercícios com anotações para seus pacientes, além de permitir uma forma dos pacientes navegarem pelos pontos de interesse. Além disso, é interessante estender a ferramenta para o contexto específico de acompanhamento de pacientes.

Para facilitar a comparação com outros trabalhos na área de anotação em vídeo, foram selecionados os trabalhos com maior nível de complexidade resultantes da revisão da literatura e do mapeamento sistemático. A seleção incluiu trabalhos para diferentes plataformas: desktop, web, tablet $\mathrm{PC}$ e dispositivos móveis com sistema Android. Por serem escassos, dois trabalhos desenvolvidos para a plataforma Android foram incluídos na comparação que foi resumida nas Tabelas 5.1, 5.2, e 5.3.

A ferramenta CWaCTool [Fagá et al., 2010; Motti et al., 2009] permite colaboração síncrona de anotações em texto, áudio e tinta e sua avaliação incluiu questionários e um percurso congnitivo. Porém a ferramenta está restrita à plataforma desktop. A ferramenta The Choreographer's Notebook [Singh et al., 2011] é para plataforma web e permite colaboração síncrona, porém limitada, de anotações em texto, tinta e vídeo. Sua avaliação foi complexa, envolvendo dois tipos de usuários e utilizando técnicas de entrevista e grupos foco. Zhang et al. [2013] apresentam uma ferramenta para tablet PCs que permite anotações colaborativas síncronas feitas em tinta eletrônica. Nenhuma destas ferramentas foi idealizada para dispositivos móveis atuais do tipo tablets e smartphones.

O aplicativo de Huang e Fox [2012] foi desenvolvido para Android e permite anotações colaborativas em texto e tinta. Porém o trabalho principal dos auto- 
res foi testar um framework idealizado para colaboração e, devido a este objetivo, foi realizada uma avaliação de desempenho. Não existiu uma preocupação em testar a usabilidade do aplicativo Android apresentado ou propor soluções com relação à captura de anotações e interações. Já o aplicativo apresentado por Lux e Riegler [2013] possui uma interface mais detalhada, permitindo anotações em texto, tinta e áudio, porém o áudio é armazenado em forma de texto apenas. Em seu trabalho é possível notar uma preocupação com a usabilidade, no entanto não foi executada nenhuma avaliação com resultados formalizados. Os trabalhos apresentados por Huang e Fox [2012] e Lux e Riegler [2013] também não apresentam soluções válidas para smartphones, ficando claro que os aplicativos foram idealizados apenas para uso em telas maiores.

Com relação aos seus concorrentes, os principais diferenciais da ferramenta MoViA são o foco na interação usuário-computador, com preocupações relativas à usabilidade e soluções de interação adequadas para dispositivos móveis. Entre outros diferenciais destaca-se a adequação em telas de tamanho reduzido, a reprodução de múltiplas anotações síncronas, a marcação de vídeos durante a captura, a possibilidade de execução em tablets e smartphones e o fato de ter passado por um processo de avaliação de usabilidade em três etapas. Contudo, sua principal limitação é a falta de suporte à colaboração síncrona.

Tabela 5.1: Tabela Comparativa de Ferramentas: plataforma e tipo de anotação.

\begin{tabular}{|c|c|c|c|}
\hline Referências & Ferramenta & Plataforma & Tipo \\
\hline Fagá et al. [2010]; Motti et al. [2009] & CWaCTool & Desktop & Texto, áudio e tinta \\
\hline Singh et al. [2011] & The Choreographer's Notebook & Web & Texto, tinta e vídeo \\
\hline Zhang et al. [2013] & (Zhang et al.) & Tablet PC & Tinta \\
\hline Huang e Fox [2012] & (Huang e Fox) & Android (Tablets) & Texto e tinta \\
\hline Lux e Riegler [2013] & (Lux e Riegler) & Android (Tablets) & Texto, tinta e áudio (limitado) \\
\hline Cunha 2014 & MoViA Tool & Android (Tablets e Smartphones) & Texto, tinta e áudio \\
\hline
\end{tabular}

Tabela 5.2: Tabela Comparativa de Ferramentas: formato, colaboração e navegação.

\begin{tabular}{|l|c|c|c|}
\hline Ferramenta & Formato & Colaboração & Navegação \\
\hline \hline CWaCTool & XML, SMIL e NCL & Síncrona & Tradicional \\
\hline The Choreographer's Notebook & XML & Síncrona (limitada) & Pré-visualização do texto e marcações na linha do tempo \\
\hline (Zhang et al.) & XML & Síncrona & Pré-visualização da tinta \\
\hline (Huang e Fox) & XML & Síncrona & Pré-visualização do texto \\
\hline (Lux e Riegler) & - & Sem colaboração & Marcações na linha do tempo \\
\hline MoViA Tool & XML, JSON & Assíncrona & Pré-visualização do texto e miniaturas \\
\hline
\end{tabular}

\subsection{Limitações}

Considerando as funcionalidades relacionadas a anotações disponíveis na ferramenta desenvolvida, existem limitações que podem ser trabalhadas em versões futuras melhorando a experiência do usuário. No caso da anotação em tinta, não existe uma opção para alterar a cor do desenho. Outra funcionalidade útil seria 
Tabela 5.3: Tabela Comparativa de Ferramentas: avaliação.

\begin{tabular}{|l|c|}
\hline Ferramenta & Avaliação \\
\hline \hline CWaCTool & Questionários e percurso cognitivo \\
\hline The Choreographer's Notebook & Entrevistas, grupos foco e análise de log \\
\hline (Zhang et al.) & Avaliação de desempenho da usabilidade e questionários \\
\hline (Huang e Fox) & Avaliação de desempenho do sistema \\
\hline (Lux e Riegler) & Informal \\
\hline MoViA Tool & Teste de usabilidade, avaliação heurística e avaliação no contexto de TO \\
\hline
\end{tabular}

a possibilidade de adicionar formas ou figuras prontas, facilitando o processo de anotação. Anotações em áudio são capturadas e executadas em momentos de pausa do vídeo. Esta é uma solução adequada para casos genéricos, porém seria interessante atribuir este controle ao usuário, de forma que o mesmo poderia definir se pretende pausar o vídeo ou se prefere que o vídeo e o áudio sejam executados ao mesmo tempo, em casos que não existe conflito entre os áudios.

Como mencionado, não é possivel realizar anotações em leiaute horizontal, apenas visualizá-las. A avaliação heurística apontou que essa seria uma funcionalidade importante, porém não foi possivel desenvolve-la neste trabalho.

A tela de navegação para anotações de áudio exibe apenas o tempo e uma miniatura do momento de anotação do vídeo. Essa estratégia é limitada já que não permite que o usuário identifique o conteúdo da anotação. O áudio poderia ser convertido para texto e utilizado na tela de navegação para facilitar a identificação do ponto de interesse. O mesmo problema se aplica à tinta eletrônica, mas neste caso seria interessante a pré-visualização da anotação em tinta. Outra possibilidade para melhorar a navegação seria utilizar um sistema de busca textual, além do sistema de navegação por miniaturas existente. A navegação por busca é uma solução interessante caso existam muitas anotações e seja preciso encontrar uma anotação específica. A conversão de áudio em texto seria muito importante para este caso.

Em termos de colaboração, foi abordada apenas a colaboração assíncrona. A análise dos trabalhos selecionados pelo mapeamento sistemático identificou uma tendência a colaboração síncrona, portanto é interessante que este problema seja investigado. Além disso, a estratégia utilizada não permite que um arquivo de anotação seja modificado por múltiplos autores e não foi desenvolvido um sistema de controle de mudanças. Os documentos de anotação gerados possuem suporte a múltiplos usuários, prevendo essa possível melhoria.

O formato do arquivo de anotações escolhido foi o XML. Como mencionado, esta é uma opção flexível e legivel, porém perde em desempenho para outros formatos como o JSON, atualmente muito popular por ser um formato leve e eficiente, sendo adequado, principalmente, como formato de intercâmbio. 
Por fim, seria interessante a condução de uma avaliação de experiência do usuário com vários participantes. Uma avaliação deste tipo permitiria uma visão subjetiva sobre o uso da ferramenta, em termos de esforço, conforto e confiança do usuário. Essa avaliação deve ser considerada em trabalhos futuros.

\subsection{Trabalhos Futuros}

Além do desenvolvimento de soluções para as limitações apresentadas na Seção 5.2, as oportunidades para trabalhos futuros envolvem a realização de experimentos adicionais para avaliação da experiência do usuário, a extensão do aplicativo desenvolvido para o contexto de acompanhamento de pacientes de terapia ocupacional e um estudo no contexto educacional.

Uma avaliação de experiência do usuário com a participação de vários usuários traria resultados significativos de usabilidade e experiência, auxiliando a aprimorar o trabalho de forma geral. Em vista disso, é planejado mais um experimento para avaliação do aplicativo proposto. Para isto, será necessário realizar um experimento controlado e com uma tarefa planejada com rigor, para permitir a comparação entre os resultados obtidos por diferentes participantes. Outro fator importante é a utilização do mesmo dispositivo, dado que o aplicativo não foi testado em todas as versões do sistema Android e em todos os tamanhos de tela disponíveis, é necessário certificar-se que o aplicativo irá funcionar de forma idêntica para todos os usuários. Além da usabilidade, que está diretamente relacionada à facilidade de uso e satisfação, os conceitos de interesse relacionados a uma boa experiência de uso, no caso da ferramenta MoViA, seriam relacionados ao esforço cognitivo e confiança ao utilizar o aplicativo. Estes conceitos guiam a escolha das questões do questionário. Assim, é interessante utilizar múltiplos questionários para uma avaliação abrangente da experiência.

Resultados da avaliação realizada com a profissional em terapia ocupacional identificaram novos requisitos específicos do cenário de acompanhamento de pacientes. Havendo grande interesse de usuários em potencial, é benéfico, para ambas as partes, que o trabalho seja estendido para este contexto específico. Este mesmo cenário é existente na área de fisioterapia, por exemplo, podendo atrair o interesse de outros usuários. Assim, é interessante o estudo e a incorporação de funcionalidades relativas ao acompanhamento de pacientes em sessões de terapia ocupacional e fisioterapia. Além disso, é importante investigar uma solução eficiente, no que diz respeito ao desempenho e a usabilidade, para comunicação entre pacientes e profissionais. Também se faz necessário um estudo mais aprofundado do problema de acompanhamento de atividades para identificação de peculiaridades e requisitos adicionais, além dos já identificados. Isto deve ser realizado por meio de estudos de caso e investigações contextu- 
ais no ambiente de trabalho de profissionais da área de terapia ocupacional e fisioterapia.

Além da utilidade no cenário de terapia ocupacional, existe um grande potencial para a aplicação deste trabalho no contexto educacional. Como reportado na Seção 3.2.2, anotações podem auxiliar na revisão de vídeos educacionais. Com a popularidade de dispositivos móveis como reprodutores de vídeo, a possibilidade de realizar anotações pelo mesmo pode ser de grande ajuda. Estudos de caso de caso na área podem ser conduzidos com o intuito de melhor compreender o uso da ferramenta em situações de ensino.

\subsection{Publicações Resultantes}

\section{Artigos curtos diretamente relacionados ao trabalho:}

1. Cunha, Bruna C.R.; Pedrosa, Diogo; Goularte, Rudinei and Pimentel, Maria da Graça. 2012. Video Annotation and Navigation on Mobile Devices. In Proceedings of the 18th Brazilian Symposium on Multimedia and the Web (WebMedia '12). ACM, New York, NY, USA, 261-264.

2. Cunha, Bruna C.R.; Machado Neto, Olibário J. and Pimentel Maria da Graça. 2013. MoViA: a Mobile Video Annotation Tool. In Proceedings of the 2013 ACM Symposium on Document Engineering (DocEng '13). ACM, New York, NY, USA, 219-222.

3. Cunha, Bruna C.R.; Machado Neto, Olibário J. and Pimentel Maria da Graça. 2013. A Heuristic Evaluation of a Mobile Annotation Tool. In Proceedings of the 19th Brazilian Symposium on Multimedia and the Web (WebMedia '13). ACM, New York, NY, USA, 89-92. 


\section{Referências Bibliográficas}

Abowd, G. D., Atkeson, C. G., Brotherton, J., Enqvist, T., Gulley, P., e LeMon, J. (1998). Investigating the capture, integration and access problem of ubiquitous computing in an educational setting. In Proceedings of the SIGCHI Conference on Human Factors in Computing Systems, CHI '98, pages 440-447. ACM.

Abowd, G. D. e Mynatt, E. D. (2000). Charting past, present, and future research in ubiquitous computing. ACM Transactions on Computer-Human Interaction, 7(1):29-58.

ACM Multimedia (2014). ACM MM '14: Call for full and short papers - Multimedia, HCI and QoE. Acesso em: 26 de julho de 2014. Disponível em: http://acmmm.org/2014/call_full_short_papers.html\#MultimediaHCIandQoE.

ACM TOCHI (2014). Transactions on computer-human interaction: Physiological computing for human-computer interaction. Acesso em: 26 de julho de 2014. Disponível em: http://tochi.acm.org/si/physiological.shtml.

Agosti, M. e Ferro, N. (2007). A formal model of annotations of digital content. ACM Transactions on Information Systems (TOIS), 26(1).

Alexandros, L. e Michalis, X. (2013). The physiological measurements as a critical indicator in users' experience evaluation. In Proceedings of the 17th $\mathrm{Pa}$ nhellenic Conference on Informatics, PCI '13, pages 258-263. ACM.

Android Developers (2014). The official site for Android developers. Acesso em: 26 de julho de 2014. Disponível em: http://developer.android.com/index.html.

Bakopoulos, M., Tsekeridou, S., Giannaka, E., Tan, Z.-H., e Prasad, R. (2011). Mobile video annotation for enhanced rich media communication during emergency handling. In Proceedings of the 4th International Symposium on Applied 
Sciences in Biomedical and Communication Technologies, ISABEL '11, pages 32:1-32:5. ACM.

Bargeron, D., Gupta, A., Grudin, J., Sanocki, E., e Li, F. (2001). Asynchronous collaboration around multimedia and its application to on-demand training. In Proceedings of the 34th Annual Hawaii International Conference on System Sciences, HICSS '11.

Biedert, R., Dengel, A., Buscher, G., e Vartan, A. (2012). Reading and estimating gaze on smart phones. In Proceedings of the Symposium on Eye Tracking Research and Applications, ETRA '12, pages 385-388. ACM.

Biolchini, J. C. d. A., Mian, P. G., Natali, A. C. C., Conte, T. U., e Travassos, G. H. (2007). Scientific research ontology to support systematic review in software engineering. Advanced Engineering Informatics, 21(2):133-151.

Boll, S. e Bulterman, D. C. A. (2011). Technical area for requested research contribuitions: Multimedia authoring and production. ACM Multimedia 2011.

Boot, W. R., Charness, N., Czaja, S. J., Sharit, J., Rogers, W. A., Fisk, A. D., Mitzner, T., Lee, C. C., e Nair, S. (2013). Computer proficiency questionnaire: Assessing low and high computer proficient seniors. The Gerontologist.

Bulterman, D. C. A. (2004). Creating peer-level video annotations for web-based multimedia. In Proceedings of the 17th Eurographics Conference on Multimedia, EGMM '04, pages 49-57. Eurographics Association.

Cabral, D., Valente, J., Silva, J., Aragão, U., Fernandes, C., e Correia, N. (2011). A creation-tool for contemporary dance using multimodal video annotation. In Proceedings of the 19th ACM International Conference on Multimedia, MM '11, pages 905-908. ACM.

Cattelan, R. G., Teixeira, C., Goularte, R., e Pimentel, M. D. G. C. (2008). Watch-and-comment as a paradigm toward ubiquitous interactive video editing. ACM Transactions on Multimedia Computing, Communications, and Applications, 4(4):28:1-28:24.

Cho, Y. I. (2011). The future of intelligent ubiquitous computing systems. In Chaki, N. e Cortesi, A., editors, Computer Information Systems - Analysis and Technologies, volume 245, pages 1-3. Springer.

Concejero, P., Munuera, J., e Lorenz, M. (2008). The MESH mobile video annotation tool. In Proceedings of the 5th Nordic Conference on Human-computer Interaction: Building Bridges, NordiCHI '08, pages 583-584. ACM. 
Coopey, E., Danahy, E., e Schneider, L. (2013). InterLACE: Interactive learning and collaboration environment. In Proceedings of the 2013 Conference on Computer Supported Cooperative Work Companion, CSCW '13, pages 11-14. ACM.

Cronbach, L. J. (1951). Coefficient alpha and the internal structure of tests. Psychometrika, 16(3):297-334.

Cross, A., Bayyapunedi, M., Ravindran, D., Cutrell, E., e Thies, W. (2014). VidWiki: Enabling the crowd to improve the legibility of online educational videos. In Proceedings of the 17th ACM Conference on Computer Supported Cooperative Work \& Social Computing, CSCW'14, pages 1167-1175. ACM.

Cunha, B. C., Machado Neto, O. J., e Pimentel, M. d. G. C. (2013a). MoViA: A mobile video annotation tool. In Proceedings of the 2013 ACM Symposium on Document Engineering, DocEng '13, pages 219-222. ACM.

Cunha, B. C. R., Machado Neto, O. J., e Pimentel, M. d. G. C. (2013b). A heuristic evaluation of a mobile annotation tool. In Proceedings of the 19th Brazilian Symposium on Multimedia and the Web, WebMedia '13, pages 89-92. ACM.

Cunha, B. C. R., Pedrosa, D., Goularte, R., e Pimentel, M. d. G. C. (2012). Video annotation and navigation on mobile devices. In Proceedings of the 18th Brazilian Symposium on Multimedia and the Web, WebMedia '12, pages 261264. ACM.

Davis, J. G., Subrahmanian, E., Konda, S., Granger, H., Collins, M., e Westerberg, A. W. (2001). Creating shared information spaces to support collaborative design work. Information Systems Frontiers, 3(3):377-392.

Davis, M. (1993). Media streams: an iconic visual language for video annotation. In Proceedings of the IEEE Symposium on Visual Languages, pages 196-202.

De Moor, K., Ketyko, I., Joseph, W., Deryckere, T., De Marez, L., Martens, L., e Verleye, G. (2010). Proposed framework for evaluating quality of experience in a mobile, testbed-oriented living lab setting. Mobile Networks and Applications, 15(3):378-391.

DiMicco, J., Millen, D. R., Geyer, W., Dugan, C., Brownholtz, B., e Muller, M. (2008). Motivations for social networking at work. In Proceedings of the 2008 ACM Conference on Computer Supported Cooperative Work, CSCW '08, pages 711-720. ACM.

Ebara, Y. (2013). Tele-immersive environment with tiled display wall for intuitive remote collaborative work. Artificial Life and Robotics, 17(3-4):483-487. 
Evans, D. (2011). The internet of things how the next evolution of the internet is changing everything. CISCO white paper, Cisco Internet Business Solutions Group. Disponivel em: http://postscapes.com/cisco-internet-ofthings-white-paper-how-the-next-evolution-of-the-internet-is-changingeverything/.

Fagá, Jr., R., Motti, V. G., Cattelan, R. G., Teixeira, C. A. C., e Pimentel, M. d. G. C. (2010). A social approach to authoring media annotations. In Proceedings of the 1Oth ACM symposium on Document engineering, DocEng '10, pages 1726. ACM.

Ferretti, S., Mirri, S., Roccetti, M., e Salomoni, P. (2007). Notes for a collaboration: On the design of a wiki-type educational video lecture annotation system. In Semantic Computing, 2007. ICSC 2007. International Conference on, pages 651-656.

Field, A. (2013). Discovering Statistics using IBM SPSS Statistics. SAGE Publications, 4th edition.

Frokjaer, E. e Hornb, K. (2005). Cooperative usability testing: complementing usability tests with user-supported interpretation sessions. In Extended Abstracts on Human factors in Computing Systems, CHI '05, pages 1383-1386. ACM.

Gatica-Perez, D. e Hua, G. (2011). Technical area for requested research contribuitions: Location-based and mobile multimedia. ACM Multimedia 2011.

Georgiev, T. (2012). Investigation of the user's text reading speed on mobile devices. In Proceedings of the 13th International Conference on Computer Systems and Technologies, CompSysTech '12, pages 329-336. ACM.

Geyer, W., Richter, H., e Abowd, G. D. (2005). Towards a smarter meeting recordcapture and access of meetings revisited. Multimedia Tools and Applications, 27(3):393-410.

Giannoukos, I., Lykourentzou, I., Mpardis, G., Nikolopoulos, V., Loumos, V., e Kayafas, E. (2008). Collaborative e-learning environments enhanced by wiki technologies. In Proceedings of the 1st International Conference on PErvasive Technologies Related to Assistive Environments, PETRA '08, pages 59:1-59:5. ACM.

Goadrich, M. H. e Rogers, M. P. (2011). Smart smartphone development: iOS versus Android. In Proceedings of the 42nd ACM Technical Symposium on Computer Science Education, SIGCSE '11, pages 607-612. ACM. 
Goularte, R., Camacho-Guerrero, J. A., Inacio Jr., V. R., Cattelan, R. G., e Pimentel, M. d. G. C. (2004). M4note: A multimodal tool for multimedia annotations. In Proceedings of the WebMedia \& LA-Web 2004 Joint Conference 10th Brazilian Symposium on Multimedia and the Web 2nd Latin American Web Congress, LA-WebMedia '04, pages 142-149. IEEE Computer Society.

Grassi, M., Morbidoni, C., e Nucci, M. (2012). A collaborative video annotation system based on semantic web technologies. Cognitive Computation, 4:497514.

Grunewaldt, L., Moller, K., Morisse, R., e Sempf, T. (2006). Collaborative video annotation environments: Implemented features and a new approach for object detection and recognition. In International Conference on Digital Telecommunications, ICDT '06, page 14.

Guimarães, R. L., Cesar, P., e Bulterman, D. C. (2012). "Let me comment on your video": Supporting personalized end-user comments within third-party online videos. In Proceedings of the 18th Brazilian Symposium on Multimedia and the Web, WebMedia '12, pages 253-260. ACM.

Hosack, B. (2010). VideoANT: extending online video annotation beyond content delivery. TechTrends, 54(3):45-49.

Hürst, W., Welte, M., e Jung, S. (2007). An evaluation of the mobile usage of electure podcasts. In Proceedings of the 4th International Conference on Mobile Technology, Applications, and Systems and the 1st International Symposium on Computer Human Interaction in Mobile Technology, Mobility '07, pages 16-23. ACM.

Huang, T. e Fox, G. (2012). Collaborative annotation of real time streams on Android-enabled devices. In International Conference on Collaboration Technologies and Systems, CTS '12, pages 39-44.

IDC (2013). IDC finds worldwide smartphone shipments on pace to grow nearly 40\% in 2013 while average selling prices decline more than 12\%. Acesso em: 20 de julho de 2014. Disponivel em: http://www.idc.com/ getdoc . jsp? container Id=prUS24461213.

ISO (2002). ISO/IEC 15938-2:2002: Information technology - Multimedia content description interface - Part 2: Description definition language. Technical report, International Organization for Standardization (ISO). 
ISO (2010). ISO 9241-210:2010: Ergonomics of human system interaction Part 210: Human-centred design for interactive systems (formerly known as 13407). Technical report, International Organization for Standardization (ISO).

Jaimes, A. e Sebe, N. (2007). Multimodal human-computer interaction: A survey. Computer Vision and Image Understanding, 108(1-2):116-134.

Kanis, M., Robben, S., Hagen, J., Bimmerman, A., Wagelaar, N., e Kröse, B. (2013). Sensor monitoring in the home: Giving voice to elderly people. In Proceedings of the 7th International Conference on Pervasive Computing Technologies for Healthcare, PervasiveHealth '13, pages 97-100. ICST.

Kopf, S., Wilk, S., e Effelsberg, W. (2012). Bringing videos to social media. In IEEE International Conference on Multimedia and Expo, ICME '12, pages 681686.

Kruskal, J. B. e Wish, M. (1978). Multidimensional Scaling. Quantitative Applications in the Social Sciences (Book 11). SAGE Publications, 1st edition.

Laghari, K. e Connelly, K. (2012). Toward total quality of experience: A qoe model in a communication ecosystem. IEEE Communications Magazine, 50(4):58-65.

Lahti, J., Westermann, U., Palola, M., Peltola, J., e Vildjiounaite, E. (2005). MobiCon: Integrated capture, annotation, and sharing of video clips with mobile phones. In Proceedings of the 13th Annual ACM International Conference on Multimedia, MULTIMEDIA '05, pages 798-799. ACM.

Latulipe, C., Carroll, E. A., e Lottridge, D. (2011). Love, hate, arousal and engagement: Exploring audience responses to performing arts. In Proceedings of the SIGCHI Conference on Human Factors in Computing Systems, CHI '11, pages 1845-1854. ACM.

Law, E., Roto, V., Vermeeren, A. P., Kort, J., e Hassenzahl, M. (2008). Towards a shared definition of user experience. In Extended Abstracts on Human Factors in Computing Systems, CHI '08, pages 2395-2398. ACM.

Law, E. L.-C., Roto, V., Hassenzahl, M., Vermeeren, A. P., e Kort, J. (2009). Understanding, scoping and defining user experience: a survey approach. In Proceedings of the SIGCHI Conference on Human Factors in Computing Systems, CHI '09, pages 719-728. ACM.

Lin, C.-Y., Tseng, B. L., e Smith, J. R. (2003). Videoannex: Ibm mpeg-7 annotation tool for multimedia indexing and concept learning. In Proceedings of the IEEE International Conference on Multimedia and Expo, ICME '03. 
Liu, X., Corner, M., e Shenoy, P. (2009). SEVA: Sensor-enhanced video annotation. ACM Transactions on Multimedia Computing, Communications, and Applications (TOMCCAP), 5(3):24:1-24:26.

Lux, M. e Riegler, M. (2013). Annotation of endoscopic videos on mobile devices: A bottom-up approach. In Proceedings of the 4th ACM Multimedia Systems Conference, MMSys '13, pages 141-145. ACM.

Machado Neto, O. e Pimentel, M. d. G. (2013). Heuristics for the assessment of interfaces of mobile devices. In Proceedings of the 19th Brazilian Symposium on Multimedia and the Web, WebMedia '13, pages 93-96. ACM.

MacKenzie, I. S. (2009). Human-computer Interaction: An Empirical Research Perspective. Morgan Kaufmann.

Martins, D. S. (2014). Models and operators for extension of active multimedia documents via annotations. PhD thesis, Universidade de São Paulo.

Martins, D. S. e Pimentel, M. d. G. C. (2011). End-user ubiquitous multimedia production: Process and case studies. In Proceedings of the 2011 Fourth International Conference on Ubi-Media Computing, U-MEDIA '11, pages 197-202. IEEE Computer Society.

Martins, D. S., Vega-Oliveros, D. A., e Pimentel, M. d. G. C. (2011). Automatic authoring of interactive multimedia documents via media-oriented operators. SIGAPP Applied Computing Review, 11(4):26-37.

Miller, F. P., Vandome, A. F., e McBrewster, J. (2009). Collaborative Software: Computer Supported Cooperative Work, Online Chat, Wiki, Enterprise Bookmarking, Metcalfe's Law, Social Software, Online Dating ... Network, Friendster, Twitter, Facebook. Alpha Press.

Minneman, S., Harrison, S., Janssen, B., Kurtenbach, G., Moran, T., Smith, I., e van Melle, B. (1995). A confederation of tools for capturing and accessing collaborative activity. In Proceedings of the Third ACM International Conference on Multimedia, MULTIMEDIA '95, pages 523-534. ACM.

Mirza-Babaei, P., Nacke, L. E., Gregory, J., Collins, N., e Fitzpatrick, G. (2013). How does it play better?: Exploring user testing and biometric storyboards in games user research. In Proceedings of the SIGCHI Conference on Human Factors in Computing Systems, CHI '13, pages 1499-1508. ACM. 
Moraes, C. R., Arantes, F. L., e Pimentel, M. d. G. C. (2010). DiGaE: um Ambiente para Encontros Distribuídos. In Proceedings of the 16th Brazilian Symposium on Multimedia and the Web, volume 1 of WebMedia'10, pages 139-141.

Morisse, K. e Sempf, T. (2005). An approach for collaboration and annotation in video post-production. In Sunderam, V., Albada, G., Sloot, P., e Dongarra, J., editors, Computational Science - ICCS 2005, volume 3516 of Lecture Notes in Computer Science, pages 375-382. Springer.

Motti, V. G., Fagá, Jr., R., Catellan, R. G., Pimentel, M. d. G. C., e Teixeira, C. A. (2009). Collaborative synchronous video annotation via the watch-andcomment paradigm. In Proceedings of the 17th European Conference on European Interactive Television Conference, EuroITV '09, pages 67-76. ACM.

Naaman, M. e Zancanaro, M. (2011). Technical area for requested research contribuitions: Human, social, and educational aspects of multimedia. ACM Multimedia 2011.

Nielsen, J. (1994). Usability Engineering. Morgan Kaufmann, 2nd edition.

Nielsen, J. e Molich, R. (1990). Heuristic evaluation of user interfaces. In Proceedings of the SIGCHI Conference on Human Factors in Computing Systems, CHI '90, pages 249-256. ACM.

Nielsen Norman Group (2000). Jakob Nielsen's Alertbox: Why you only need to test with 5 users. Acesso em: 22 de julho de 2014. Disponivel em: http: //www.nngroup.com/articles/why-you-only-need-to-test-with-5-users/.

O’Hara, K., Mitchell, A. S., e Vorbau, A. (2007). Consuming video on mobile devices. In Proceedings of the SIGCHI Conference on Human Factors in Computing Systems, CHI '07, pages 857-866. ACM.

Partala, T. e Kallinen, A. (2012). Understanding the most satisfying and unsatisfying user experiences: emotions, psychological needs, and context. Interacting with Computers, 24(1):25-34.

Pimentel, M. d. G. C., Bulterman, D. C. A., Cesar, P. S., e Munson, E. V. (2012). Special issue on multimedia authoring and annotation. Multimedia Tools and Applications.

Pimentel, M. d. G. C., Cattelan, R. G., Melo, E., Freitas, G., e Teixeira, C. (2010). Watch-and-Comment as an approach to collaboratively annotate points of interest in video and interactive-TV programs. In Mobile TV: Customizing Content 
and Experience, Human-Computer Interaction Series, pages 349-368. Springer.

Pimentel, M. d. G. C., Ishiguro, Y., Kerimbaev, B., Abowd, G. D., e Guzdial, M. (2001). Supporting educational activities through dynamic web interfaces. Interacting with Computers, 13(3):353-374.

Pimentel, M. d. G. C., Prazeres, C., Ribas, H., Lobato, D., e Teixeira, C. (2005). Documenting the pen-based interaction. In Proceedings of the 11th Brazilian Symposium on Multimedia and the Web, WebMedia '05, pages 1-8. ACM.

Öquist, G. e Lundin, K. (2007). Eye movement study of reading text on a mobile phone using paging, scrolling, leading, and RSVP. In Proceedings of the 6th International Conference on Mobile and Ubiquitous Multimedia, MUM '07, pages 176-183. ACM.

Sallnäs, E.-L. (2005). Effects of communication mode on social presence, virtual presence, and performance in collaborative virtual environments. Presence: Teleoperators Virtual Environments, 14(4):434-449.

Sama, M., Rosenblum, D. S., Wang, Z., e Elbaum, S. (2008). Model-based fault detection in context-aware adaptive applications. In Proceedings of the 16th ACM SIGSOFT International Symposium on Foundations of Software Engineering, SIGSOFT '08, pages 261-271. ACM.

Sauro, J. e Lewis, J. R. (2008). Guantifying the User Experience: Practical Statistics for User Research. Morgan Kaufmann.

Schildbach, B. e Rukzio, E. (2010). Investigating selection and reading performance on a mobile phone while walking. In Proceedings of the 12th International Conference on Human Computer Interaction with Mobile Devices and Services, MobileHCI '10, pages 93-102. ACM.

Schmidt, K. e Bannon, L. (2013). Constructing CSCW: The first quarter century. Computer-Supported Cooperative Work, 22(4-6):345-372.

Schmitt, M., Gunkel, S., e Cesar, P. (2013a). A quality of experience testbed for video-mediated group communication. In Proceedings of the 2013 IEEE International Symposium on Multimedia, ISM '13, pages 514-515. IEEE Computer Society.

Schmitt, M., Gunkel, S., Cesar, P., e Hughes, P. (2013b). A qoe testbed for socially-aware video-mediated group communication. In Proceedings of the 
2Nd International Workshop on Socially-aware Multimedia, SAM '13, pages 3742. ACM.

Schroeter, R., Hunter, J., Guerin, J., Khan, I., e Henderson, M. (2006). A synchronous multimedia annotation system for secure collaboratories. In IEEE International Conference on e-Science and Grid Computing, e-Science 06, page 41.

Schroeter, R., Hunter, J., e Kosovic, D. (2004). FilmEd - Collaborative video indexing, annotation, and discussion tools over broadband networks. In Proceedings of the 1Oth International Multimedia Modelling Conference, pages 346353.

Singh, V., Latulipe, C., Carroll, E., e Lottridge, D. (2011). The choreographer's notebook: a video annotation system for dancers and choreographers. In Proceedings of the 8th ACM Conference on Creativity and Cognition, C\&C '1 1, pages 197-206. ACM.

Sumaray, A. e Makki, S. K. (2012). A comparison of data serialization formats for optimal efficiency on a mobile platform. In Proceedings of the 6th International Conference on Ubiquitous Information Management and Communication, ICUIMC '12, pages 48:1-48:6. ACM.

Tang, J. C. (1991). Findings from observational studies of collaborative work. International Journal of Man-Machine Studies, 34(2):143-160.

Timmerer, C., Martini, M., e Huusko, J. (2012). Special issue on mobile multimedia delivery.

Truong, K. N., Abowd, G. D., e Brotherton, J. A. (2001). Who, what, when, where, how: Design issues of capture \& access applications. In Proceedings of the 3rd International Conference on Ubiquitous Computing, UbiComp '01, pages 209-224. Springer-Verlag.

Vega-Oliveros, D. A., Martins, D. S., e Pimentel, M. d. G. C. (2011a). Mediaoriented operators for authoring interactive multimedia documents generated from capture sessions. In Proceedings of the 2011 ACM Symposium on Applied Computing, SAC'11, pages 1267-1272. ACM.

Vega-Oliveros, D. A., Oliveira, L. S., Martins, D. S., e Pimentel, M. d. G. C. (2011b). Viewing by interactions: Media-oriented operators for reviewing recorded sessions on tv. In Proceddings of the 9th International Interactive Conference on Interactive Television, EuroITV'11, pages 213-222. ACM. 
Vermeeren, A. P. O. S., Law, E. L.-C., Roto, V., Obrist, M., Hoonhout, J., e Väänänen-Vainio-Mattila, K. (2010). User experience evaluation methods: current state and development needs. In Proceedings of the 6th Nordic Conference on Human-Computer Interaction: Extending Boundaries, NordiCHI '10, pages 521-530. ACM.

Weher, K. e Poon, A. (1994). Marquee: A tool for real-time video logging. In Proceedings of the SIGCHI Conference on Human Factors in Computing Systems, CHI '94, pages 58-64. ACM.

Weiser, M. (1991). The computer for the 21st century. Scientific American, 265(3):66-75.

Weiser, M. (1993). Hot topics-ubiquitous computing. Computer, 26(10):71-72.

Welch, B. L. (1947). The generalization of "student's"problem when several different population variances are involved. Biometrika, 34(1-2):28-35.

Wong, W. Y. e Reimann, P. (2009). Web based educational video teaching and learning platform with collaborative annotation. In Ninth IEEE International Conference on Advanced Learning Technologies, ICALT '09, pages 696-700.

Zhai, G., Fox, G., Pierce, M., Wu, W., e Bulut, H. (2005). eSports: Collaborative and synchronous video annotation system in grid computing environment. In Seventh IEEE International Symposium on Multimedia, page 9.

Zhang, J.-K., Ma, C.-X., Liu, Y.-J., Fu, Q.-F., e Fu, X.-L. (2013). Collaborative interaction for videos on mobile devices based on sketch gestures. Journal of Computer Science and Technology, 28(5):810-817. 
REFERÊNCIAS BIBLIOGRÁFICAS 


\section{Apêndice}

\section{Estágio de Pesquisa no Exterior: Avaliação das Experiências do Usuário Compartilhadas}

Durante o mestrado foi realizado um estágio de pesquisa no exterior por meio do programa de Bolsa Estágio Pesquisa no Exterior (BEPE), programa da FAPESP. O estágio, cuja proposta foi estudar a avaliação de experiência do usuário em sistemas colaborativos e sociais, foi realizado no instituto CWI (Centrum Wiskunde \& Informatica), em Amsterdã, dentro do Grupo de Sistemas Interativos e Distribuídos (DIS). O objetivo principal do estágio foi investigar métodos de avaliação de experiência do usuário, através do estudo, adaptação e aplicação de métodos de avaliação. Durante o estágio a aluna teve a oportunidade de trabalhar em dois projetos distintos. Um dos projetos envolveu a análise de dados de um experimento realizado com uma turma de alunos de computação da Universidad Autónoma de Madrid. Neste experimento, o objetivo era investigar o relacionamento entre medidas fisiológicas e o estado emocional dos alunos. Para isto, os alunos utilizaram sensores fisiológicos enquanto assistiam a vídeos sobre o tema de Banco de Dados e responderam questionários sobre seu estado emocional no início e no final do experimento. Este trabalho exigiu estudos sobre métodos estatísticos para análise, compreessão e apresentação dos dados. O segundo estudo envolveu auxiliar no planejamento de experimentos em videoconferências em grupo. Este trabalho exigiu um estudo extenso em métodos de avaliação de experiência do usuário e a participação ativa no planejamento de experimentos, principalmente nas tarefas de aprimoramento de questões e hipóteses de pesquisa e o desenvolvimento de questionários de experiência de 
usuário.

A Seção A.1 introduz conceitos importantes relacionados exclusivamente ao desenvolvimento dos trabalhos do estágio. As Seções A.2 e A.3 descrevem resumidamente as principais atividades e os resultados obtidos durante o estágio. A Seção A.4 apresenta as considerações finais sobre os trabalhos desenvolvidos no estágio.

\section{A. 1 Conceitos Relacionados}

A seguir são apresentados os dois principais conceitos relacionados aos trabalhos realizados durante o estágio: medidas fisiológicas e qualidade de experiência. A interpretação de medidas fisiológicas foi o tema do trabalho que envolveu a análise de dados de sensores em um contexto educacional. Já o tema de pesquisa do trabalho em videoconferências em grupo investigou o impacto de atrasos na qualidade da experiência dos usuários.

\section{A.1.1 Medidas Fisiológicas}

Medidas Fisiológicas, também chamadas biométricas, estão expandindo fronteiras na área de Interação Humano-Computador no que pode ser definido como Computação Fisiológica [ACM TOCHI, 2014]. A utilização de dados fisiológicos capturados através de sensores ampliou as pesquisas da área de interação humano-computador. Suas aplicações vão desde o design e a criação de aplicativos que utilizam estes dados como entrada [Kanis et al., 2013] até o uso dos mesmos na avaliação da experiência do usuário [Mirza-Babaei et al., 2013].

Mudanças fisiológicas estão diretamente associadas à resposta emocional, porém a ligação entre as medidas e os eventos ainda não é clara. A possibilidade de se utilizar medidas objetivas obtidas através de sensores é de grande importância na área de avaliação de experiência de usuário, deste modo a interpretação de medidas fisiológicas para o entendimento do estado afetivo do usuário torna-se necessária [Alexandros e Michalis, 2013; Latulipe et al., 2011]. Pressão sanguínea, respiração, resposta galvânica da pele (GSR) e batimentos cardíacos são exemplos de medidas que podem ser utilizadas para medir emoções de forma implícita. Uma medida comum utilizada em trabalhos de interação usuário-computador é a resposta galvânica da pele, medida que acredita-se medir excitação e esforço mental. Historicamente utilizada em detectores de mentira, esta biométrica mede a secreção de suor pelas glândulas endócrinas, o que está diretamente associado a reação do sistema nervoso autônomo como resposta a estímulos [Latulipe et al., 2011]. 


\section{A.1.2 Gualidade de Experiência}

Quality of Experience (QoE), ou qualidade de experiência, é um tópico ainda mais recente que o de experiência do usuário e ainda não existe um consenso sobre sua definição. Porém neste trabalho é adotada a definição bem aceita proposta por De Moor et al. [2010], que sugere que @oE deve ser vista como um conceito multidimensional, englobando a qualidade de serviço (QoS), a experiência do usuário e o contexto do sistema como um todo. A Figura A.1 representa este conceito. A experiência do usuário está relacionada a experiência subjetiva, podendo ser medida através de métodos subjetivos (e.g., questionários, entrevistas) ou objetivos (neste caso, medidas fisiológicas) [Laghari e Connelly, 2012]. O contexto é considerado por muitos autores como parte da experiência, porém pode ser apresentado separadamente. Já o foco da qualidade de serviço está na medida de desempenho da rede e do sistema através da investigação de parâmetros como banda, atraso e perda de pacotes, podendo ser avaliada de forma objetiva ou envolvendo a opinião subjetiva do usuário (e.g., $\mathrm{MOS}^{1}$ ) [De Moor et al., 2010].

\section{Quality of Experience}

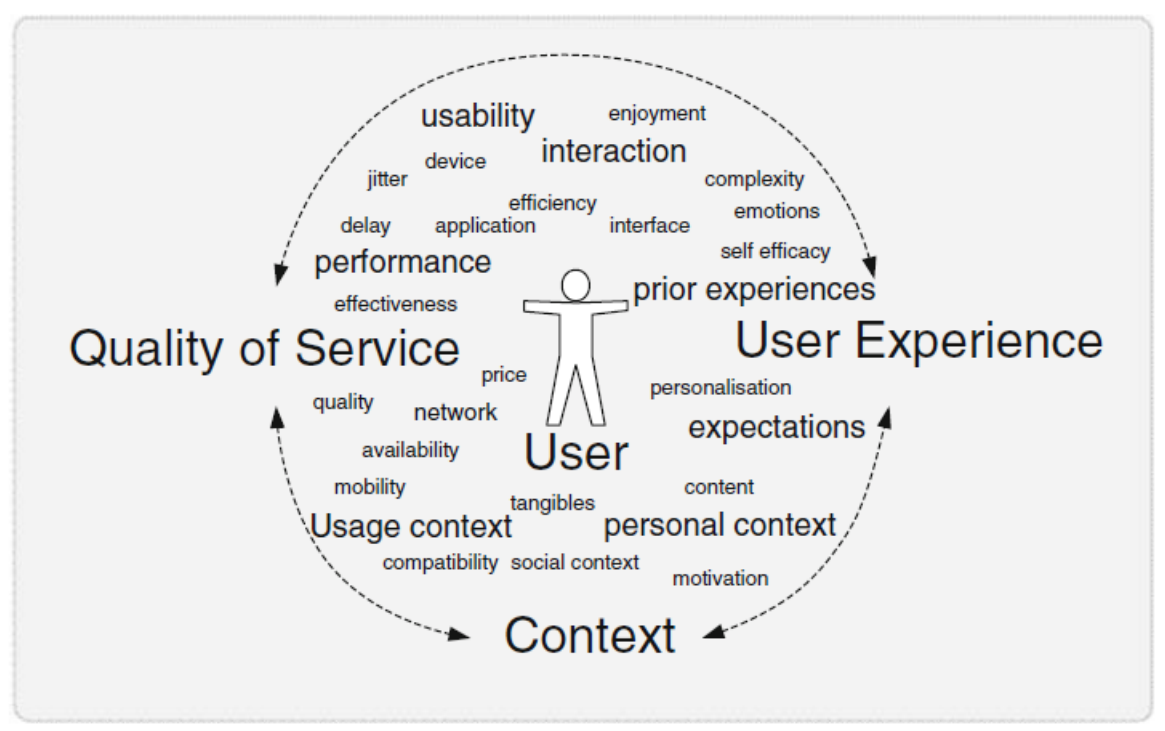

Figura A.1: O conceito de Qualidade de Experiência [De Moor et al., 2010].

\section{A.2 Interpretação de Dados Fisiológicos em um Contexto Edu- cacional}

Um dos trabalhos desenvolvidos no CWI pesquisa o significado de medidas fisiológicas capturadas por sensores para melhor compreensão do estado afetivo de indivíduos humanos em diferentes situações, como em aulas, apresentações de

\footnotetext{
${ }^{1}$ http://en.wikipedia.org/wiki/Mean_opinion_score
} 
teatros ou até vídeos comerciais. O entendimento destas medidas, e posterior tradução das mesmas para um formato visual compreensivel para diferentes tipos de usuários, pode permitir com que eventos a distância, ou seja, aqueles em que não é possível a observação direta do público, sejam enriquecidos através do fornecimento de um feedback da experiência do público aos responsáveis pela sua apresentação ou criação. Professores poderiam acompanhar a atenção e interesse dos alunos, artistas e diretores poderiam perceber a resposta do público: o impacto da distância pode ser diminuído. Com este objetivo, experimentos envolvendo a captura de dados fisiológicos através de sensores têm sido conduzidos pelo CWI e colaboradores. Como forma de obter conhecimento sobre a área e, ao mesmo tempo, contribuir com o trabalho dos pesquisadores, a aluna trabalhou na análise de dados de um dos experimentos realizados com sensores.

$\mathrm{O}$ experimento analisado durante o estágio foi realizado na Universidad $\mathrm{Au}$ tónoma de Madrid com a colaboração de pesquisadores do local. O cenário do experimento foi uma aula de graduação da turma de Ciências da Computação em que alunos assistiram a vídeos sobre o tema de Banco de Dados, mais especificamente, sobre programação com linguagem SQL. Um total de 34 alunos foram reunidos em uma sala de aula onde assistiram os vídeos juntos. Três diferentes estilos de vídeos foram exibidos. O primeiro vídeo tratava-se de um conjunto de slides acompanhado pelo vídeo de uma professora explicando seu conteúdo, de forma bastante similar a uma aula presencial. O segundo vídeo era uma conversa entre a professora e dois alunos sobre o tema em questão. O terceiro era um vídeo tutorial em que a tela do computador foi gravada juntamente com a voz do professor explicando os procedimentos. Os alunos mantiveram sensores de resposta galvânica da pele (GSR) conectados em suas mãos durante todo o experimento. Dois questionários foram aplicados: um questionário inicial, aplicado antes do experimento, e um questionário final, aplicado após a exposição dos vídeos. O questionário final foi composto de perguntas relacionadas ao humor, atenção, ânimo e preferencias dos participantes com relação aos vídeos apresentados.

\section{A.2.1 Desenvolvimento}

O trabalho do estágio consistiu em analisar e comparar os dados dos sensores e resultados dos questionários coletados durante o experimento através de métodos estatísticos adequados. Fizeram parte da análise dados coletados de 24 participantes. A análise foi composta por duas etapas. Na primeira etapa foi feita a análise de escala multidimensional (MDS) para identificar similaridades e dissimilaridades entre os dados dos sensores e associar o resultado aos possíveis estados emocionais dos participantes através da comparação com os dados 
coletados por questionários. Já na segunda fase foram geradas médias para os valores dos sensores nos três intervalos de tempo correspondentes aos vídeos exibidos. Em seguida as médias foram comparadas através da análise de variância (ANOVA) para verificar a existência de diferenças significativas entre os dados dos sensores e questionários para os três vídeos.

Para realizar a primeira parte da análise foram calculados os coeficientes de correlação de Pearson para os valores dos sensores. A partir destes valores foi aplicado o método MDS utilizando uma escala de duas dimensões. O valor de estresse de Kruskal foi de 0.13, abaixo do limiar de 0.15, portanto, aceitável. No entanto, um valor diferente de zero indica alguma distorção dos dados de entrada, de modo que a análise deve ser feita com cuidado. Depois de gerado, o gráfico resultante foi analisado de forma a encontrar padrões emocionais entre os resultados de sensores e questionários.

A Figura A.2 apresenta o gráfico MDS obtido classificado pelos conceitos de atenção e energia e codificado por cores. Os pontos que se encontram a esquerda são declarados como distraídos, enquanto os da direta estão atentos. A área em vermelho possui participantes que declararam alta concentração de energia. A área laranja apresenta usuários atentos, porém seus níveis de energia declarados, apesar de positivos, não são tão altos como os encontrados no grupo vermelho. A área destacada em amarelo contém usuários que responderam estarem cansados, mas ao mesmo tempo atentos e com um bom rendimento em termos de entendimento. O sensor de rótulo $\mathrm{m} 5$, apesar de ter resultados do questionário similares, aparece distanciado do grupo. O grupo destacado em azul não apresentou um padrão em termos de atenção ou energia, porém foi observado que todos declararam algum aspecto negativo com intensidade, podendo ser distração, falta de interesse, dificuldade de entendimento, cansaço ou tristeza. Os pontos $\mathrm{m} 3$ e $\mathrm{k} 4$ revelaram respostas com valores muito negativos nos questionários para todos os itens. Por fim, não foi possível encontrar um padrão para k6.

A segunda parte da análise consistiu na análise de variância dos valores obtidos por meio dos sensores e questionários. O experimento realizado teve apenas uma variável independente, neste caso o vídeo, e os mesmos indivíduos participaram em todas as condições, configurando um design experimental do tipo um fator intra-sujeitos (one-way within-subjects). Devido a esta configuração, foi aplicado o método de análise de variância para medidas repetidas, também conhecido como rANOVA.

Antes da análise dos dados de sensores, foram realizados testes para garantir que as exigências de normalidade e esfericidade foram satisfeitas e um valor discrepante (outlier) foi excluído. Os resultados da análise de variância para 


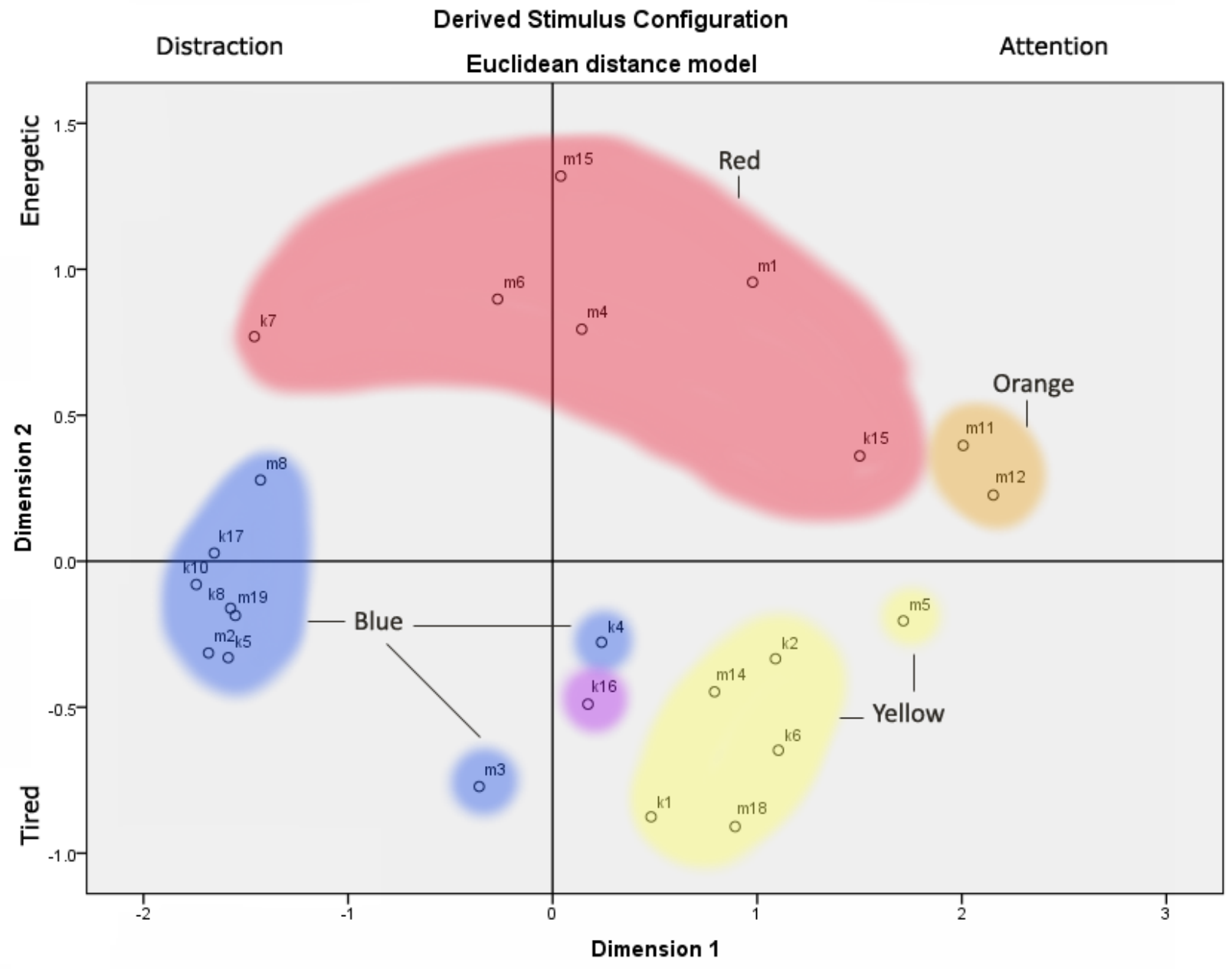

Figura A.2: Gráfico MDS para dados coletados de sensores. 
dados de sensores resultaram na não rejeição da hipótese nula de que as médias são iguais $(\mathrm{p}=.78)$. Assim concluímos que não houve diferença significativa entre as médias dos sensores para os três vídeos.

Para os dados de questionários foram testadas as dimensões de eficácia e satisfação, medidas utilizadas pelos participantes para qualificar os vídeos. Para a satisfação, o teste rANOVA revelou que existe diferença significativa entre as médias e a comparação em pares mostrou que o existe diferença significativa entre o segundo vídeo quando comparado com o primeiro e terceiro vídeo $(\mathrm{p}=.01$ e $\mathrm{p}=.044$, respectivamente), sendo que os alunos consideraram o segundo vídeo menos satisfatório. Para a medida de eficiência, os dados não apresentaram uma distribuição normal, por este motivo foi aplicado o método ANOVA de Friedman, que, por ser um teste não paramétrico, possui suposições mais flexíveis com relação aos dados. Novamente, o teste apontou diferenças significativas entre as notas dadas aos vídeos, sendo que os alunos consideraram o segundo vídeo menos efetivo que o primeiro $(\mathrm{p}=.033)$ e terceiro $(\mathrm{p}=.004)$ vídeo. Observa-se que, neste experimento, apesar dos alunos avaliarem os vídeos diferentemente, os mesmos resultados não puderam ser observados na análise dos dados de sensores.

\section{A.2.2 Discussão}

Apesar de serem encontradas similaridades nas respostas dos questionários e resultados de sensores que se apresentam próximos no gráfico MDS, não podemos fazer afirmações generalizadas. Porém, tais similaridades podem ser um indicativo de que os dados podem ser interpretados em termos de envolvimento, atenção e energia, estimulando investigações adicionais. No caso da análise de variância, os dados coletados pelos sensores não apresentaram diferenças significativas, apesar das respostas aos questionários mostrarem diferenças.

A dificuldade de encontrar um padrão entre os dados capturados por sensores pode ser explicada por problemas que ocorreram durante a coleta de dados, o que levou a necessidade de limpeza e aproximação dos valores. Outra dificuldade na interpretação dos resultados foram respostas inconsistentes encontradas nos questionários, por exemplo, um participante afirmou não ter energia e ao mesmo tempo indiciou não estar cansado, medidas consideradas antagônicas. Em um experimento em sala de aula, um aluno pode se sentir desconfortável em responder que está distraído ou desinteressado, deste modo é importante esclarecer que os dados serão utilizados apenas para o experimento científico e a sua privacidade será respeitada. Além disso, medidas realizadas através de respostas subjetivas estão propensas a erros causados por problemas de interpretação ou até mesmo dificuldade de compreensão do próprio estado afetivo. A opinião 
subjetiva do participante, seja através de questionários ou entrevistas, ainda é a principal fonte de informação para compreensão de dados de sensores, o que deve implicar em um esforço maior por parte dos pesquisadores para que estes dados sejam coletados com maior fidelidade.

Os problemas identificados servem como lições para experimento futuros: é importante um planejamento minucioso e extremo cuidado na condução de experimentos com usuários, principalmente quando envolvem coleta de dados de sensores fisiológicos, pois este instrumento adiciona uma complexidade a mais no processo de avaliação.

\section{A.3 Qualidade de Experiência em Videoconferências em Grupo}

Graças às melhorias na infraestrutura de rede e nas tecnologias de transmissão de vídeo e comunicação, videoconferências têm se tornado um meio popular de comunicação em ambientes de trabalho, universidades e, mais recentemente, em computadores pessoais, conectando familiares e amigos. Inicialmente, videoconferências conectavam apenas duas localizações, porém, atualmente, o cenário com múltiplos pontos de comunicação é cada vez mais comum. Esta configuração traz novos desafios para a área de comunicação por vídeo. Variações em parâmetros, como sincronização, atraso, qualidade do vídeo, entre outros, claramente prejudicam a qualidade de experiência do usuário. No entanto, em um cenário com várias localizações o impacto dessas variações é ainda maior. Em um grupo, a naturalidade e a dinâmica da conversação, entre outros fatores, dependem fortemente da percepção dos usuários com relação à conversa e aos outros participantes. Neste cenário, a compreensão dos parâmetros que influenciam a conversa e o impacto que cada um possui sobre uma videoconferência em grupo, pode possibilitar que sistemas se configurem dinamicamente e provenham, de forma otimizada, características mínimas para garantir uma qualidade de experiência adequada.

Com o objetivo de propiciar um ambiente em que parâmetros de rede podem ser configurados de forma controlada e dinâmica, e assim testar diferentes condições em videoconferências em grupo, pesquisadores do grupo de Sistemas Interativos e Distribuídos do CWI desenvolveram um testbed que permite manipular os parâmetros de qualidade de serviço e, ao mesmo tempo, adquirir informações sobre experimentos através de observação e questionários.

O sistema foi modelado a partir de uma lista de oito requisitos [Schmitt et al., 2013a,b]:

- R1: Manipulação em tempo real de parâmetros de GoS na camada de aplicação. 
- R2: Monitoramento dos parâmetros de GoS.

- R3: Manipulação dos parâmetros de GoS individualmente para cada participante.

- R4: Gravação da sessão nas diferentes perspectivas de cada participante.

- R5: Monitoramento ao vivo e possibilidade de interação discreta (invisível) para o condutor do experimento.

- R6: Controle do progresso do experimento.

- R7: Capacidade de integração de novas atividades.

- R8: Integração com questionários de avaliação.

Os parâmetros de qualidade de serviço que a ferramenta permite manipular são: distorção, atraso, jitter, sincronização entre fluxos e sincronização entre participantes. A Figura A.3 mostra uma tela do sistema como vista pelos usuários. Os trabalhos de Schmitt et al. [2013a,b] descrevem em detalhes o testbed implementado.

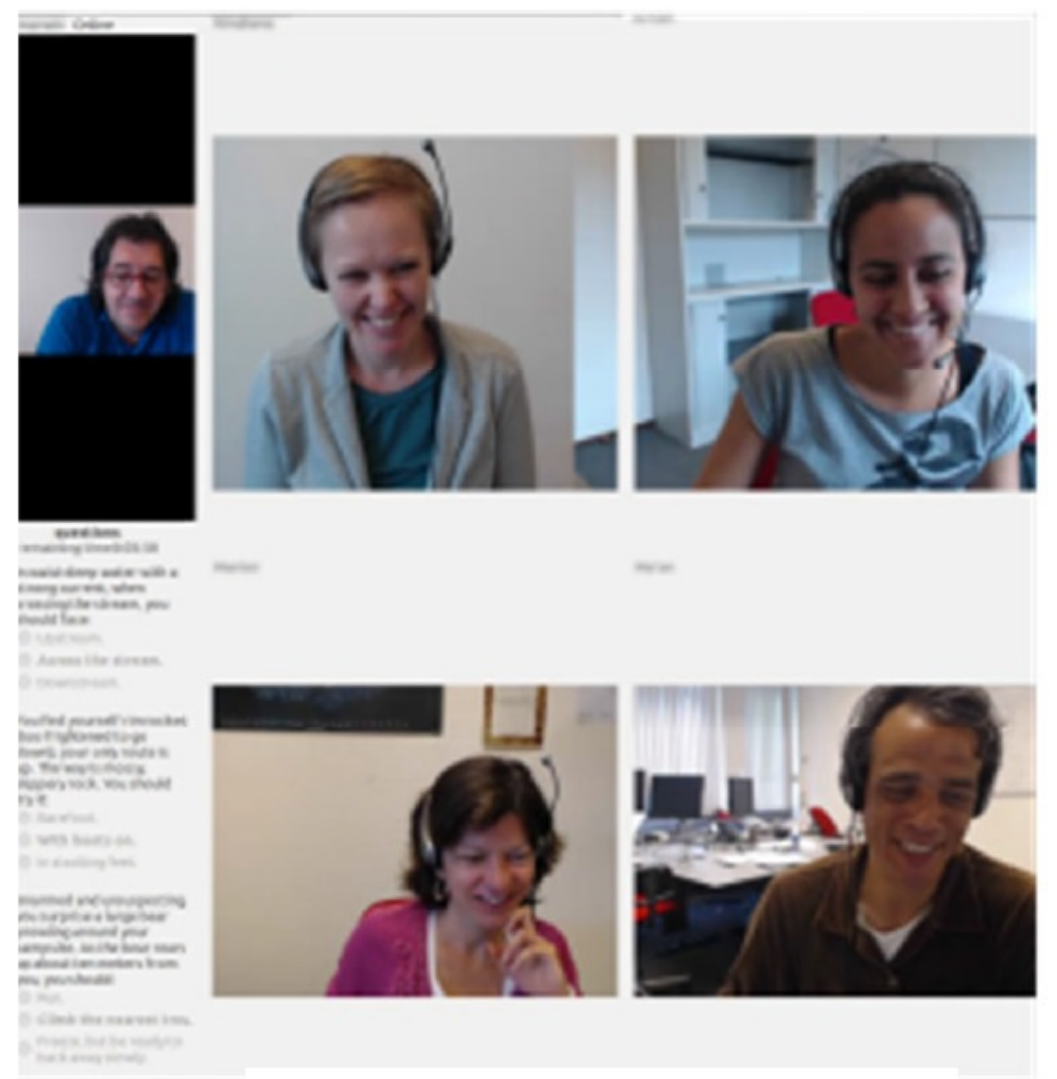

Figura A.3: Tela do testbed de videoconferências como vista pelos usuários [Schmitt et al., 2013a].

\section{A.3.1 Desenvolvimento}

As principais atividades deste trabalho foram fundamentadas no estudo de trabalhos relacionados e consistiram, principalmente, em auxiliar no planejamento de um experimento cujo objetivo era avaliar o impacto do atraso na qualidade de 
experiência dos participantes de uma videoconferência em grupo. Deste modo, as atividades consistiram em propor novos questionários, baseando sua construção na revisão da literatura, melhorar a interface de questionários do testbed e auxiliar na definição de um novo cenário de teste. Para este fim, foi necessário estudar um experimento anterior, já realizado pelos pesquisadores do DIS, e auxiliar na melhoria do planejamento e métodos de captura de dados do próximo experimento.

No experimento anterior, os pesquisadores envolvidos utilizaram o testbed para analisar o impacto do atraso aplicado em todos os participantes de uma videoconferência em grupo. Cada sessão do experimento contou com cinco pessoas participando de uma videoconferência. A tarefa dos participantes foi responder um conjunto de questões sobre sobrevivência. No início da sessão uma pessoa era selecionada, aleatoriamente, para realizar o papel de moderador, responsável por selecionar as respostas das questões de sobrevivência e moderar a conversa, caso necessário. Uma sessão era dividida em quatro partes. No início de cada parte os participantes respondiam as questões de sobrevivência individualmente. Em seguida os participantes discutiam as questões entre o grupo e decidiam juntos a respostas para as questões. Em cada parte o atraso era variado, aleatoriamente, entre as condições: sem atraso, $500 \mathrm{~ms}, 1000 \mathrm{~ms}, 2000 \mathrm{~ms}$. No final de cada parte os participantes respondiam um questionário individual sobre a qualidade de experiência da sessão de discussão em grupo.

Considerando o planejamento do experimento anterior, em uma primeira etapa, foram aprimoradas as questões e hipóteses de pesquisa e os conceitos relacionados a aspectos emocionais. A Tabela A.1 sumariza estas informações.

O próximo passo consistiu em criar três questionários, sendo um questionário para avaliação dos conhecimentos em computação e experiência com videoconferências, um novo questionário de questões de sobrevivência, utilizado para a tarefa de discussão, e um questionário para avaliação da qualidade de experiência, a ser aplicado várias vezes durante o experimento.

O questionário de proficiência em computação e dados sobre a experiência anterior do usuário com videoconferências teve sua primeira parte baseada principalmente no trabalho de Boot et al. [2013] que propõe um questionário validado para medir o grau de instrução de idosos em computação. O questionário foi modificado e algumas questões foram removidas e novas adicionadas para se adequar a um público geral. A segunda parte foi desenvolvida após uma pesquisa sobre sistemas de videoconferência. As questões investigaram os tipos de tecnologias de videoconferência utilizadas (computador pessoal, dispositivos móveis ou sistemas dedicados), os locais (e.g., casa, trabalho, escola) e a quantidade de localizações (i.e., quantidade de clientes em uma sessão). 
Tabela A.1: Questões de pesquisa, hipóteses e conceitos para o experimento de videoconferência planejado.

\begin{tabular}{|l|l|}
\hline Conceitos & Qualidade percebida (qualidade geral e atrasos percebidos) \\
& Dinâmica da conversação (interrupções, pausas, naturalidade) \\
& Envolvimento (preseça social, concentração, diversão) \\
& Performance percebida (satisfação com desempenho e resultados) \\
& Desempenho real (pontuação, tempo) \\
& Esforço
\end{tabular}

O questionário com questões de sobrevivência foi a base da tarefa que os participantes realizaram. O questionário foi composto por quinze questões no total, de forma que o experimento pudesse ser dividido em cinco parte com três questões cada. As questões foram baseadas em testes de diversos sites especializados nos temas de natureza, meio ambiente e aventura. Foram selecionadas questões que pudessem gerar discussões entre os participantes, de modo que cada um pudesse explicar sua linha de raciocínio para chegar na resposta escolhida.

O questionário utilizado para medir a qualidade de experiência foi criado com base na nova lista de conceitos, questões e hipóteses de pesquisa (Tabela X). Para sua criação, foi realizada uma extensiva revisão da literatura sobre métodos de avaliação de experiência do usuário e qualidade de experiência, questionários e trabalhos práticos com avaliação em videoconferências. A partir disso foi criada uma lista de questões relacionadas aos conceitos definidos no planejamento. As questões consideradas mais adequadas foram selecionadas com base em discussões entre os pesquisadores envolvidos. Por fim, todas as questões foram modificadas para terem um tom positivo, dada as vantagens apontadas por Sauro e Lewis [2008]. 
Além das atividades relacionadas ao planejamento, foram feitas melhorias no módulo de questionários do testbed. A interface foi modificada para melhor apresentação das questões aos usuários, melhorando sua leitura e usabilidade. O formato do arquivo de entrada de questionários também foi modificado. Para geração das telas de questionários o sistema recebia um arquivo do tipo texto que deveria conter diversas palavras chaves e simbolos específicos para ser interpretado corretamente. Este formato não era intuitivo e causava muitos erros por parte dos desenvolvedores. O sistema foi modificado para receber um arquivo do tipo XML, com uma estrutura mais intuitiva e com validação através do respectivo arquivo XSD, desde modo a criação de questionários para o testbed foi facilitada.

A configuração do experimento foi definida para ser o mais similar possível com o experimento anterior. Deste modo seria possível fazer algumas comparações entre os resultados. Diferentemente do experimento anterior, foi definido como objetivo investigar qual o impacto do atraso na qualidade da experiência quando aplicado em um único indivíduo específico. Foi definido que o atraso seria aplicado no participante com papel de moderador, selecionado no início da sessão de forma aleatória, e em outro participante aleatório, alternadamente. O experimento foi dividido em cinco partes e, assim como o experimento anterior, em cada parte os participantes respondem três questões de sobrevivência individualmente e em seguida discutem e respondem as questões em grupo. Após a discussão, cada participante responde individualmente um questionário sobre a experiência que acabou de ter. As condições de atraso definidas para cada parte da sessão foram: sem atraso, 500ms de atraso para o moderador, 500ms de atraso para o participante aleatório, 1000ms de atraso para o moderador, 1000ms de atraso para o participante aleatório. O atraso aplicado é de duas vias, sendo que o indivíduo recebe o vídeo dos outros participantes com atraso e o grupo recebe o vídeo do indivíduo também com atraso. No final do experimento os participantes respondem o questionário sobre sua experiência em informática e videoconferências e participam de um grupo foco com os pesquisadores.

Durante o estágio foram realizados dois testes pilotos e um experimento formal. Os testes pilotos foram realizados com pesquisadores do grupo e seus resultados auxiliaram na correção de problemas do sistema e questionários. O experimento formal contou com a participação de cinco pessoas, todos estudantes, recrutados pelo pessoal de recursos humanos da instituição. Experimentos ainda estão sendo conduzidos, deste modo ainda não é possivel fazer afirmações sobre o impacto do atraso. Contudo, os primeiros resultados indicam que o atraso aplicado no indivíduo com papel de moderador, ou seja, um papel de liderança, possui um impacto maior do que o atraso em um participante aleatório. 


\section{A.3.2 Discussão}

Os resultados obtidos encorajam a continuação dos experimentos para verificar a questão do impacto do atraso aplicado em diferentes participantes. O entendimento de diferentes situações pode apoiar o desenvolvimento de técnicas que manipulem parâmetros de qualidade de serviço de forma individual, de acordo com o padrão de comportamento de cada participante em uma videoconferência, e assim alcançar a qualidade de experiência desejada. Mais experimentos serão conduzidos pelos pesquisadores do grupo de modo a produzir resultados estatísticos relevantes.

\section{A.4 Considerações Finais}

Os estudos realizados contribuíram não só para os trabalhos desenvolvidos no CWI de uma forma geral, mas também para ampliar os conhecimentos da aluna nas áreas de experiência de usuário, análise de dados de sensores, planejamento de experimentos e análise estatística de resultados. O trabalho realizado para interpretação de dados fisiológicos contribuiu para um grande aprendizado da aluna em métodos de análise estatística de dados de sensores e questionários. A realização da análise também exigiu a compreensão de design de experimentos com usuários. Já a participação no projeto que envolveu a investigação do impacto da variação de parâmetros de qualidade de serviço na qualidade da experiência do usuário foi de grande utilidade para o aprendizado de métodos de avaliação, criação de questionários e planejamento de experimentos. Os conhecimentos adquiridos foram de grande ajuda para colaboração em outro experimento (Seção 3.2.2) e serão de grande importância em trabalhos futuros (Seção 5.3). 